\title{
Predicting Deer Hunting Participation Using Theory of Planned Behavior and Constraint Integrated Theory of Planned Behavior Models: A Study of Oregon Big Game Hunters
}

\author{
Suresh Kumar Shrestha \\ West Virginia University
}

Follow this and additional works at: https://researchrepository.wvu.edu/etd

\section{Recommended Citation}

Shrestha, Suresh Kumar, "Predicting Deer Hunting Participation Using Theory of Planned Behavior and Constraint Integrated Theory of Planned Behavior Models: A Study of Oregon Big Game Hunters" (2013). Graduate Theses, Dissertations, and Problem Reports. 5002.

https://researchrepository.wvu.edu/etd/5002

This Dissertation is protected by copyright and/or related rights. It has been brought to you by the The Research Repository @ WVU with permission from the rights-holder(s). You are free to use this Dissertation in any way that is permitted by the copyright and related rights legislation that applies to your use. For other uses you must obtain permission from the rights-holder(s) directly, unless additional rights are indicated by a Creative Commons license in the record and/ or on the work itself. This Dissertation has been accepted for inclusion in WVU Graduate Theses, Dissertations, and Problem Reports collection by an authorized administrator of The Research Repository @ WVU.

For more information, please contact researchrepository@mail.wvu.edu. 


\title{
Predicting Deer Hunting Participation Using Theory of Planned Behavior and Constraint Integrated Theory of Planned Behavior Models: A Study of Oregon Big Game Hunters
}

\author{
Suresh Kumar Shrestha \\ at West Virginia University \\ in partial fulfillment of the requirements for the degree of \\ Doctor of Philosophy \\ in \\ Forest Resources Science \\ Committee \\ Robert C. Burns, Ph.D., Chair \\ Steven W. Selin, Ph.D. \\ Chad D. Pierskalla, Ph.D. \\ Jinyang Deng, Ph.D. \\ John Confer, Ph.D.

\begin{abstract}
Division of Forestry and Natural Resources
Recreation, Parks and Tourism Resources Program
\end{abstract} \\ Morgantown, West Virginia \\ 2013
}

Dissertation submitted to the Davis College of Agriculture, Natural Resources and Design

Keywords: Hunting Participation, Theory of Planned Behavior, Leisure Constraints, Constraint Integrated Theory of Planned Behavior

Copyright 2013 Suresh K. Shrestha 


\begin{abstract}
Predicting Deer Hunting Participation Using Theory of Planned Behavior and Constraint Integrated Theory of Planned Behavior Models: A Study of Oregon Big Game Hunters

Suresh Kumar Shrestha
\end{abstract}

Studies have established that the theory of planned behavior (TPB) is a simple but effective model for providing theoretical explanation as to why people participate in a given recreation activity, including general hunting activity. Understanding leisure constraints is another popular approach in leisure research, which is considered more useful from the practitioners' point of view. Literature suggested that significant relationships exist between constraint dimensions and constructs of theory of planned behavior. It was assumed that integrating constraints to TPB might not only enhance the predicting power of the TPB but might also provide a practical dimension to it. The aims of this research were: (1) determine whether TPB can explain specific hunting activity (deer hunting), and (2) determine if the predictors of the TPB mediate the effects of different constraints dimensions on deer hunting intensions, and (3) determine if constraint integrated TPB can better explain deer hunting behavior than the original TPB. The data were collected from a two-staged mail back surveys of the hunters from Oregon in 2009 and 2010. The response rate was 20\% and 67\% in the 2009 and 2010 survey, respectively. Mediation analysis was conducted using Kenny's Criteria. Model assessments were performed using structural equation modeling (SEM). Model comparison was done by comparing Chi-square ratio and $\mathrm{AIC}$ and BIC.

The findings of the research are presented in the form of three articles for peer reviewed journals, two of which have already published. The first two articles were based on the 360 responses received in 2009 mail back survey. The third paper was based on the responses of 242 respondents who participated in both 2009 and 2010 surveys.

Building on the exiting knowledge of application of TPB, the first article verified that TPB can successfully explain specific hunting intentions (deer hunting intentions) and unlike general hunting activity, specific hunting activity is less under volitional control. The second article expanded our knowledge regarding the roles of TPB constructs in mediating the effects of constraint dimensions on deer hunting intentions. It demonstrated that constraint dimensions are negatively related with the TPB constructs and TPB constructs mediated the effects of constraint 
dimensions on deer hunting intentions, directly and indirectly. The third article demonstrated that TPB can successfully describe deer hunting behavior and three constraint dimensions integrated TPB models could successfully explain more variance in reported hunting participation. It also provided opportunities of future research for leisure constraint researchers by providing the evidences of constraint negotiating roles of the TPB predictors.

Recommendations are made to use more comprehensive measures of attitudes, subjective norms and PBC as well as specific measures of constraints for better understanding of the entire phenomenon especially the specific roles of attitudes and subjective norms in the original and extended TPB model. Practitioners are advised to develop programs for enhancing PBC and for reducing internal and external constraints through skill development and providing more satisfying hunting opportunities by enhancing quality and quality of game population. 


\section{DEDICATION}

I dedicate this work to my late parents and loving Sister Puspa Shrestha whose encouragement and persuasion inspired me to achieve this highest academic degree. 


\section{ACKNOWLEDGEMENT}

Completing this Doctoral Dissertation would not have been possible without the direct and indirect help and support of a number of kind people around me, to only some of whom it is possible to give particular mention here.

First of all, I would like to express my deep appreciation and gratitude to my Committee Chair, Associate Professor Robert C. Burns, for the inspiring guidance and mentorship he has provided since day one of my enrollment in the Doctoral program at the West Virginia University. I would also greatly appreciate his relentless/continual contributions of time, ideas, and funding to make my Ph.D. experience both productive and stimulating.

In the same way, I would like to extend my sincerest gratitude and appreciation to my respective Committee Members Professor Steven Selin, Associate Professor Chad Pierskalla, and Associate Professor Jinyang Deng from West Virginia University as well as Associate Professor John Confer from California University of Pennsylvania. Their continuous scholarly advice and guidance helped me to streamline my research and focus on quality output. Each of my Committee Members contributed to my intellectual growth while studying at West Virginia University as a research advisor and class instructor.

Associate Professor Jinyang Deng from West Virginia University and Professor Jerry Vaske from Colorado State University deserve my special recognition for their valuable suggestions and aid in data analysis, especially using Structural Equation Modeling.

I am also grateful to the Oregon State Department of Fisheries and Wildlife staff for granting permission to conduct my research and for providing me an extensive list of big game hunters. The Oregon big game hunters also deserve my special acknowledgement for their support in providing essential information needed for my research by participating in the study.

I would like to express my sincere thanks to WVU and Charles "Chuck" Frayer, of Region 6, US Forest Service for their generous funding support for the study and research through Dr. Robert Burns.

My time at the WVU and Morgantown was productive, memorable and enjoyable by many officials, and friends and groups. All of them equally deserve my special appreciation. In this respect, I am grateful to the Division Director Dr. Joseph McNeel and his staff for their understanding and providing all administrative assistance, especially Chief Administrative 
Officer Donna DeWitt. In the similar note, I am also grateful to West Virginia University, Office of International Students and Scholars officers Karen Bird, Kelly Rice and Kharibhat Narayan for providing their support and time to ensure that the status of my family and myself was up-todate. Likewise, I am also thankful to my colleagues at Recreation Research Lab, namely Teri, Jen, Chris, Rachel, Sarah Woodruff and Sarah D'Agostino who always provided a very comfortable and friendly working environment.

Nepali communities at WVU always created a "home away from the home" environment by organizing many Nepali cultural and sporting events. It made me feel as if I was in my own home country. In this respect, I would like to express special thanks to all Nepalis in Morgantown, especially Iswor and Sudhikchha, Bishesh and Sumi, and Rajendra and Vandana for being a lively family friends during our entire period of stay in Morgantown.

Lastly, but most importantly, it would be a remiss if I didn't acknowledge the innumerable sacrifices made by my wife, Bindu. She carried far more responsibility in parenting our two sons, Shrey and Samartha, as well as household burdens while I pursued this final degree. My brothers and sisters and my in-laws have given me their unequivocal support throughout this period as well. My mere expressions of gratitude to them do not suffice.

I would like end this note of acknowledgment by thanking several other people who extended their helps at different times for completing this documents but I am unable to mention their names here due to space limitation. Thank you all! 


\section{TABLE OF CONTENTS}

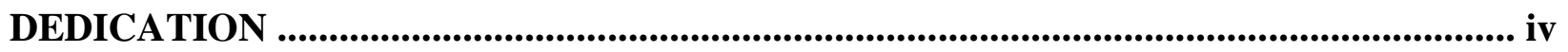

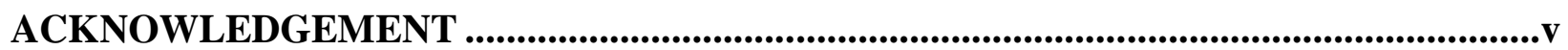

TABLE OF CONTENTS …........................................................................................ vii

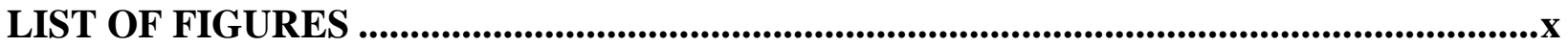

CHAPTER 1: Introduction....................................................................................................................1

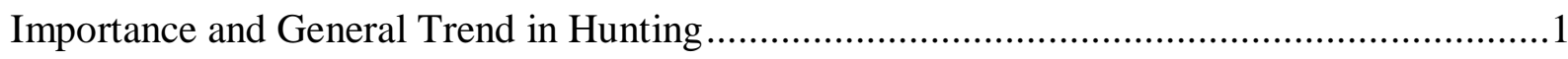

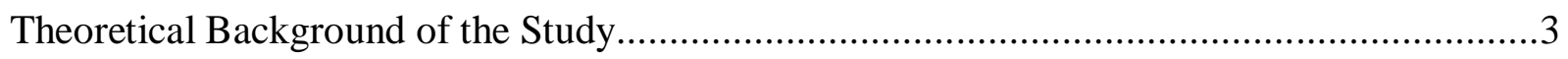

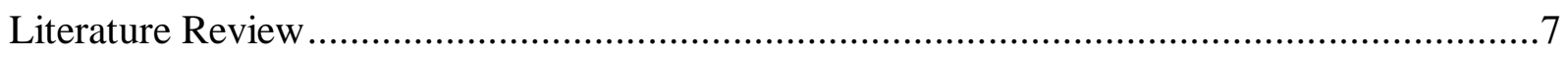

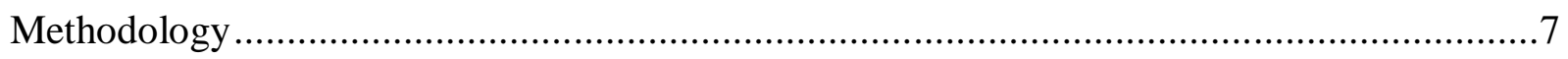

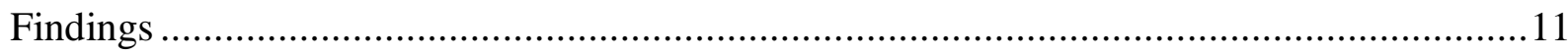

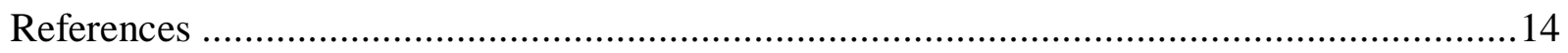

CHAPTER 2: Article 1 .............................................................................................................22

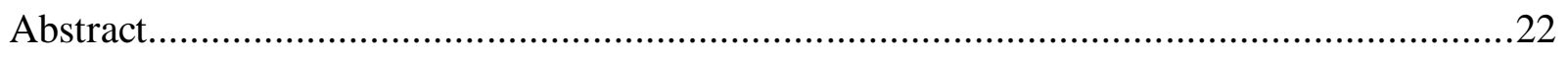

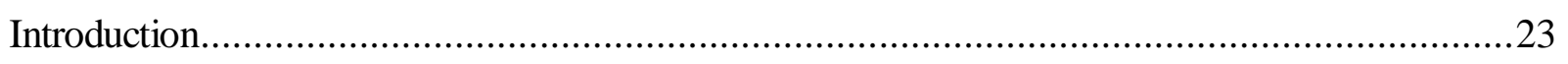

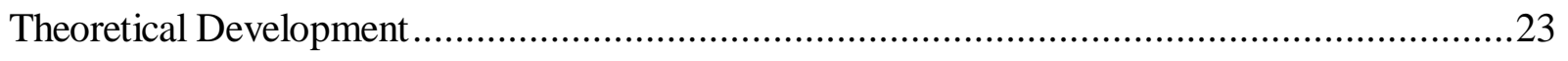

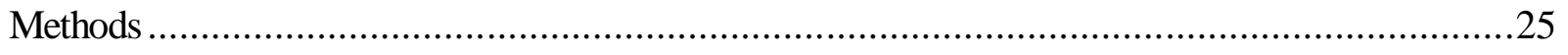

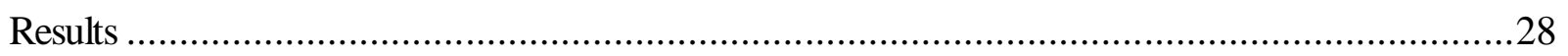

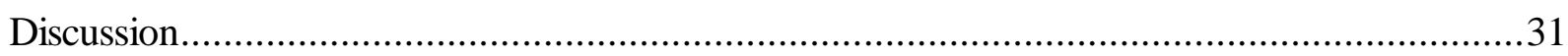

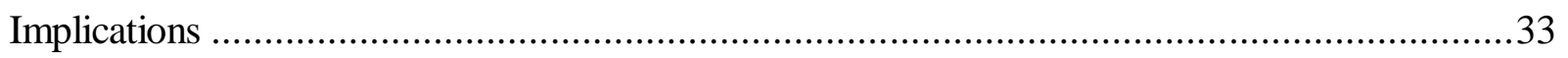

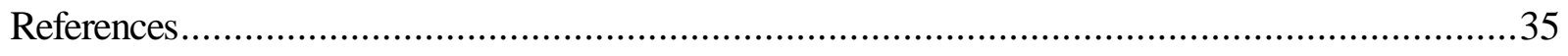

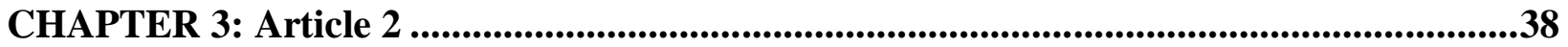

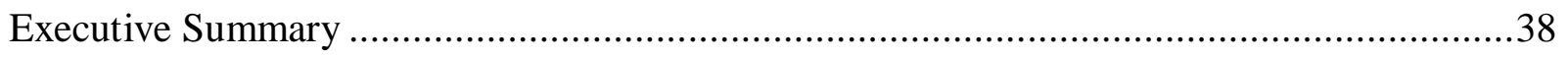

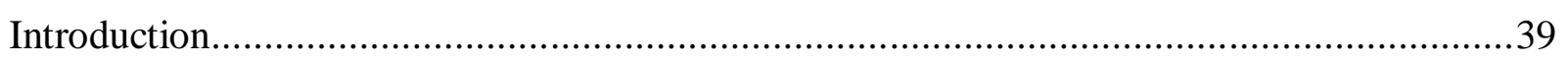

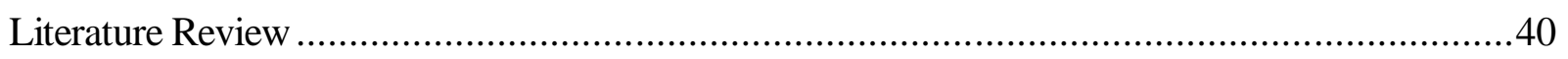

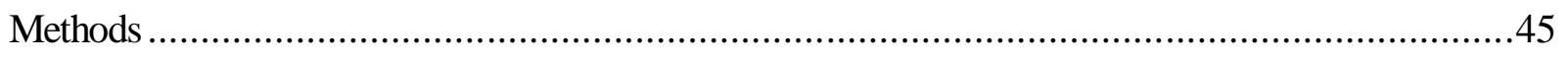

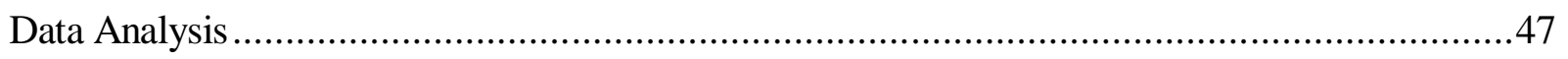

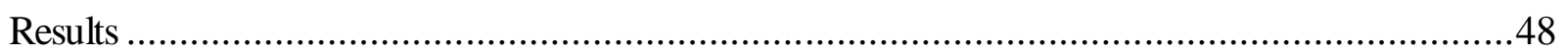

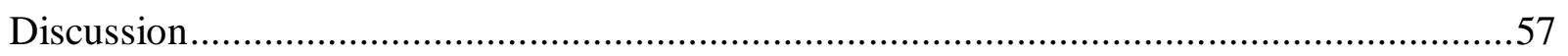

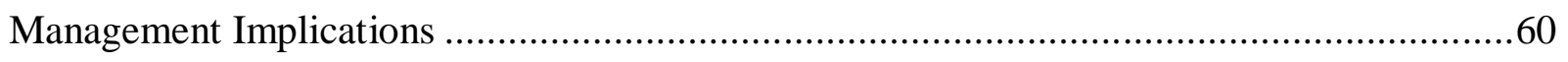

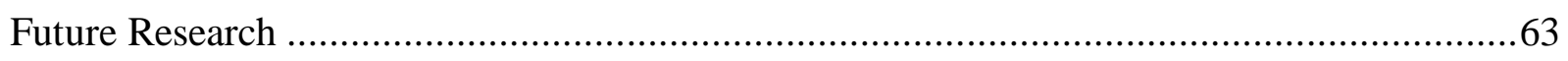

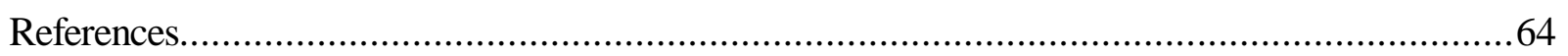


CHAPTER 4: Article 3 .......................................................................................................70

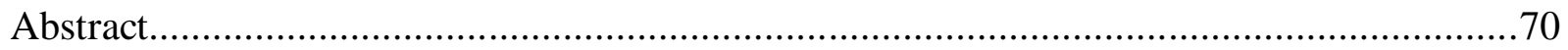

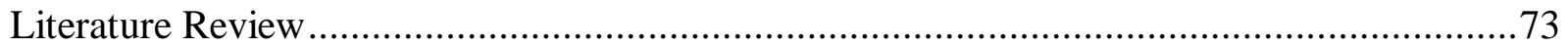

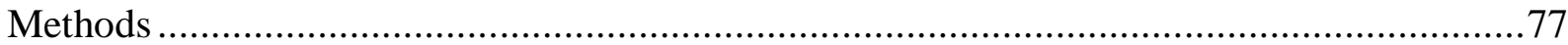

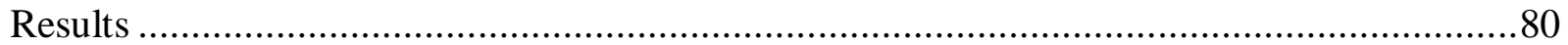

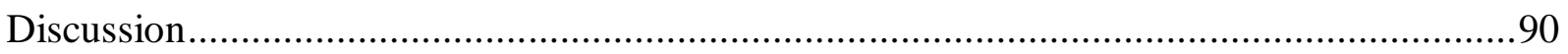

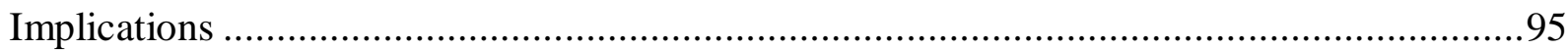

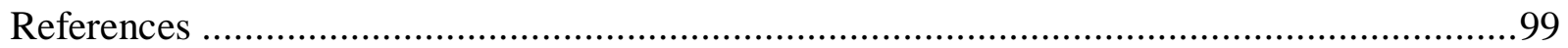

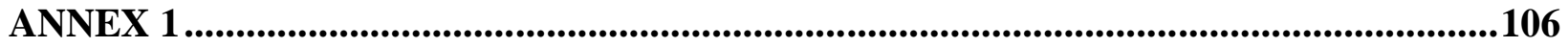

ANNEX 2 . .

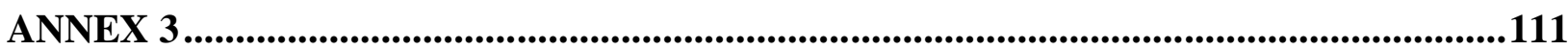




\section{LIST OF TABLES}

\section{CHAPTER 2: Article 1.}

Table 1: Means of hunting attitudes, subjective norms, PBC, and intentions and measurement model statistics $(n=360)$

Table 2: Structural equation model assessment statistics $(n=360)$ 31

\section{CHAPTER 2: Article 2.}

Table 1: Sampling and response rate 46

Table 2: Means and factor loading of items on constraint dimensions and reliability of scales $(n=359)$ 51

Table 3: Means and factor loading of items on constraint dimensions and reliability of scales $(n=359)$ 52

Table 4: Correlations among TPB predictors and four constraint dimensions $(n=$ 359).

Table 5: Assessment of Third and Fourth criteria of mediation effect of attitudes on constraints-intentions relationship $(n=359)$.

Table 6: Assessment of Third and Fourth criteria of mediation effect of subjective norms on constraints-intentions relationships $(n=359)$. 56

Table 7: Assessment of Third and Fourth criteria of mediation effect of PBC on constraints -intentions relationships $(n=359)$ 56

\section{CHAPTER 4:}

Table 1: Mean attitudes, subjective norms, PBC and intentions to participate in deer hunting in 2009 in Oregon and reliability of the items used to measure the TPB constructs $(n=242)$ 82

Table 2: Mean for constraint items, factor loading of items on constraints dimensions and reliability of items measuring the constructs $(n=242)$.

Table 3: Correlation of overall means of constraint dimensions with overall means of TPB components $(n=242)$.

Table 4: Model assessment statistics for original and constraint integrated TPB models $(n=242)$. 


\section{LIST OF FIGURES}

\section{CHAPTER 1: Introduction}

Figure 1: Theory of planned behavior model (Ajzen \& Driver, 1999) ............................... 4

\section{CHAPTER 2: Article 1}

Figure 1: The relationships of the items with TPB constructs and effects of attitudes, subjective norms and PBC on deer hunting intentions $(n=360)$. 30

\section{CHAPTER 4: Article 3}

Figure 1: Original TPB model showing relationships among latent variables and

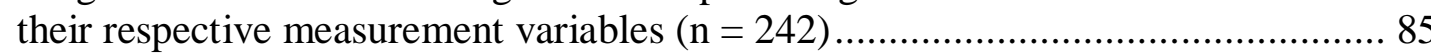

Figure 2: Constraint integrated TPB models showing relationships among model variables $(n=242)$ 88 


\section{CHAPTER 1: Introduction}

This chapter discusses the importance and trend of hunting in the USA and Oregon, and problem statement, outlines of methodology, general findings and implications. The specific methods used to address the research questions specific to the three articles are described in the respective articles in Chapter Two, Chapter Three, and Chapter Four.

\section{Importance and General Trend in Hunting}

Hunting has been playing a multifaceted role in the American way of life both as subsistence and pastime activity (Brown et al., 2000a). It was a common practice of livelihood for the indigenous Indians and European immigrants until the nineteenth century (Gregg, 2001). Brown, et al. (1995) reported the existence of numerous hunting-related traditions throughout the United States. The concept of sport hunting was introduced in the United States in the mid nineteenth century by Henry William Herbert (Mighetto, 1991; Herbert, 1849). In the aftermath of civil war, with accelerated wealth and increased leisure time, sport hunting accelerated rapidly in United States (Riess, 1995) and become a pastime activity and way of life for many. At the same time, growing demand of food and fibers due to the population increase and urbanization also triggered commercial hunting (Geist, 1995). Hunting is currently regarded as an activity of great social, economic, and environmental significances and approved by the majority of Americans (Responsive Management, 2006a; Responsive Management, 2006b). Studies conducted during the last three decades indicated that sport hunting extended opportunities to realize a variety of health, psychological, emotional, social, political, economic and environmental benefits (NSSF/Southwick Associates, 2008; Southwick Associates, 2007; RM/NSSF, 2008; USDI/USFWS/US Census, 2006; Holsman, 2000; Hautaluoma \& Brown, 1979; Kellert, 1978; Hendee, 1974; More, 1973; Potter, Hendee \& Clark, 1973; Stankey, Lucas $\&$ Ream, 1973). From the management perspective too, regulated hunting is a primary mechanism to manage deer and other wildlife population (Brown et al., 2000a \& 2000b) and fund wildlife conservation programs through the sales of hunting license (Floyd \& Lee, 2002; Anderson et al., 1985).

Because of the socio-cultural, economic, environmental and management significance of hunting, one of the prime objectives of wildlife managers is to retain the existing hunters and 
recruit new hunters. The trend data, however, indicate people's participation in hunting is declining (Mozumder et al., 2007; Floyd \& Lee, 2002; Cordell \& Super, 2000; Bissell, Duda, \& Young, 1998; Duda, Bissell \& Young, 1998). There are three sources of information that provide trends of hunting participation in United States; i.e., national survey of hunters and anglers, hunting permits issued by individual states, and annual registration to hunters' education course. Each of these sources indicates that hunting participation is decreasing throughout the USA since last two decades. According to the 2006 National Survey of Hunters and Anglers conducted by USDI/FWS/UADC/US Census Bureau (2006), hunters' population has steadily increased since 1955 from 11.8 million to its peak to 17.1 million in 1975 representing about $10 \%$ of the total US population. But after that there has been a constant decline in hunters' population and reached to its second lowest level in 2006 (12.5 million hunters representing only 5\% of the total US population) since 1955. Similar trend has been noted in the number of days spent in general hunting and big game hunting. The same survey indicated that the hunters' expenditures declined by $14 \%$ from the year 1996 to the year 2006 .

Considering the dependency of the wildlife managers on regulated hunting to manage the size of the game and other wildlife species including control of pest wildlife species (Brown et al., 2000), such decline in hunters' number will have tremendous direct and indirect managerial, social, economic and environmental implications. Since hunting license sales are a major source of revenue for the state conservation agencies (Anderson et al., 1985; Floyd \& Lee, 2002), the wildlife agencies can experience revenue loss due to the drop in hunting license sales (Sun, Van Kooten \& Voss, 2005; Anderson, et al., 1985). This, in turn, will diminish their operating budgets affecting wildlife conservation programs adversely. Likewise, decrease in hunting activities can lead to overpopulation of game and other pest animals, which might increase human-wildlife conflicts due to increased wildlife-vehicle collisions, crop damage, ornamental plant damage, interference with forest regeneration, and Lyme disease (Lauber \& Brown, 2000).

The position of the Pacific West including the State of Oregon is even worse with respect to hunting trends. According to 2006 National Survey, in the year 1955, about 1.12 million people representing $8.2 \%$ of the total population participated in hunting in South Pacific. By 1991, although the number of hunters remained almost the same, it represented only $4 \%$ of the population of the region, which was also much lower than the national average of $7 \%$ 
representation for that year. By the year 2006, the number of hunters in this region declined to 0.789 million representing just $2 \%$ of the total population

(USDI/FWS/UADC/US Census Bureau, 2006). Since fishing and hunting activities contribute \$2.8 billion in Oregon (Dean Runyan Associates, 2009), any decline in the hunters' population might negatively affect the state's wildlife conservation programs. According to the Responsive Management (2008), the number of hunting license holders in Oregon declined by $33 \%$ between the years 1981 to 2005 and decreased by $18 \%$ between the years 1999 to 2005 . In such a situation, the wildlife managers need a comprehensive management plan not only to keep hold of the existing hunters but also to recruit new hunters specially the younger generations and gain a wider level of support from the people and society (Lauber \& Brown, 2000).

\section{Theoretical Background of the Study}

One of the pre-requisites of developing a comprehensive management plan is to understand the hunters and their interrelationships with the game animals (Brown, 2009). More specifically it requires understanding why people participate in hunting and what factors affect people's participation in hunting including various types of constraints and facilitators affecting their participation in hunting (Grilliot \& Armstrong, 2005; Lauber \& Brown, 2000; Enck, Decker, \& Brown. 2000; Enck \& Decker, 1991; Hautaluoma \& Brown, 1979; Hendee, 1974). Scholars have emphasized the need of a sound theoretical framework for understanding why people participate in hunting (Hammitt, McDonald, \& Patterson, 1990; Manfredo \& Larson, 1993; Manfredo, Vaske, \& Decker, 1995a). Such a framework would be helpful in building a cumulative body of knowledge regarding hunting behavior by integrating diverse research findings, testing the reliability of constructs and examining the predictive validity of hunting behavior models. Manfredo, Vaske, and Decker (1995b) suggested that research is needed to identify the factors, such as behavioral norms and beliefs that describe people's behavior towards wildlife oriented activities (cognitive approach).

Studies have showed that researchers' explanation of behavior (public theory) not necessarily fit with the practitioners' language (personal theories) (Parr, 1996; Hemingway \& Parr, 2000). Following this, several leisure scientists have advocated for integrating practitioners' 
personal theories for making the research information more useful for the planning and management of leisure services (Henderson, Presley \& Bialeschki, 2004; Henderson, 2010).

Over the decades a variety of theories and models have been applied in leisure researches for identifying the factors that can predict participation in leisure and recreation (Henderson, Presley \& Bialeschki, 2004; Holden, 2003; Kyle et al., 2003). Among these models, the Theory of planned behavior (TPB) model by Ajzen (1991) and various forms of constraints models by Crawford and Godbey (1987), Crawford, Jackson and Godbey (1991) and Jackson, Crawford, and Godbey (1993) are quite frequently used for explaining leisure and recreation participation.

Basically, TPB is an attitudinal model, extended from the theory of reasoned action (Fishbein \& Ajzen, 1975; Ajzen \& Fishbein, 1980). According to the TPB, a human behavior is a function of an individual's intention to perform a behavior in question. Intention, in turn, is determined by a combination of attitude, subjective norms, and perceived behavioral control (PBC) related to that specific behavior (Figure 1).

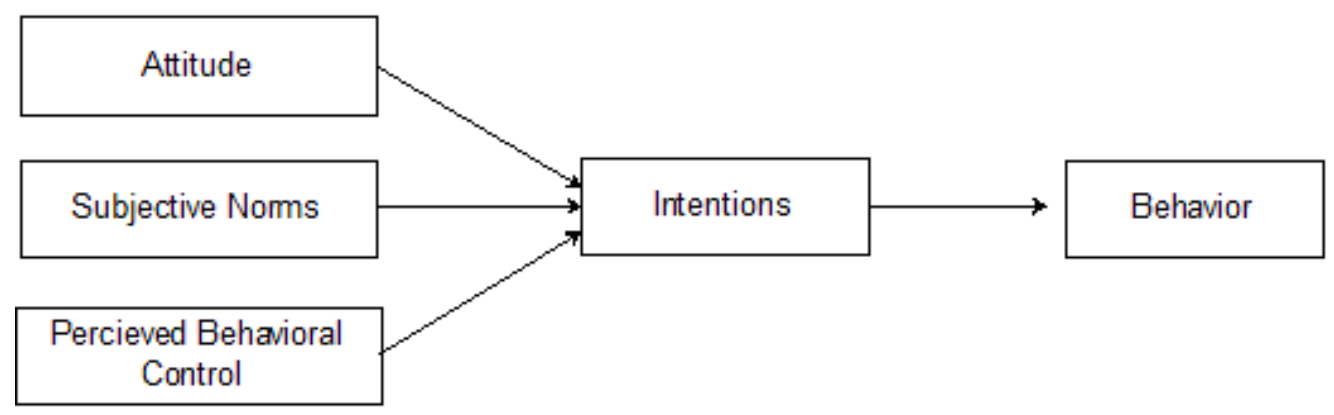

Figure 1: Theory of planned behavior model (Ajzen \& Driver, 1999)

The TPB theory has been already used to explain intentions and participation in a number of recreation behaviors. For example, canoeing/kayaking, orienteering and archery (Kouthouris \& Spontis, 2008), boating, biking, climbing, jugging and beach activities (Ajzen \& Driver, 1992 $\&$ 1991), physical activities participation (Blanchard et al., 2008), and exercise (Blanchard et al., 2003) and swimming (Eves, Hoppe \& McLaren, 2003; Mummery \& Wankel, 1999).

The studies used TPB for explaining general hunting intentions or behavior (Hrubes, Ajzen \& Daigle, 2001; Rossi \& Armstrong, 1999). Ajzen (1991) suggested that the model is more effective for describing specific activity at specific time and place. Therefore, the first 
objective of this study was to assess the effectiveness of the TPB in explaining specific hunting intentions and behavior (deer hunting). The TPB model, being a public theory, mostly constitutes psychological variables such as attitudes, subjective norms, PBC and intentions, which do not provide a clear cut direction to the practitioners for addressing a field problem.

Another framework called, constraints approach to leisure research, recognizes that participation in a leisure activity depends on presence or absence of constraints (Jackson 1991). Constraint approach provides straightforward information to the practitioners about which factors constrain participation and help them decide on actions for reducing the effect of the identified constraints. Many scholars supported the view that constraints approach is useful for practitioner for decision making (e.g. White \& Bustam, 2010; Walker \& Virden, 2005; Jackson, 1998). Constraints research although has been of limited success in providing explanation for recreation participation because people participated in recreation activities even in the presence of constraints (Son et al, 2008; Burns \& Graefe, 2007; Walker, Jackson \& Deng, 2007; Carroll \& Alexandris, 1997; Scott \& Jackson, 1996; Hubbard \& Mannell, 2001).

Considering the efficiency of the TPB in understanding why people participate in an activity and prospect of the leisure constraint research to the practitioners, it would be a productive exercise to extend the TPB model by integrating constraints dimensions. There are sufficient theoretical and empirical backings for trying out such an exercise. For example, the proponent of the TPB model (Ajzen, 1991) described the model as open to further elaboration if further important proximal determinants are identified: "The theory of planned behavior is, in principle, open to the inclusion of additional predictors if it can be shown that they capture a significant proportion of the variance in intention or behavior after the theory's current variables have been taken into account" (P. 199). He further contended that the effects of any variable that is not included in the TPB model are mediated by its predicators. At the same time constraint-TPB studies suggested that the TPB predictors have significant negative correlations with constraints dimensions (Alexandris, Barkoukis, Tsormpatsoudis \& Grouios, 2003; Alexandris \& Stodolska, 2004). More recent studies have indicated that the TPB predictors partially or fully mediate the effects of constraints on behavioral intensions (e.g., Alexandris, Barkoukis \& Tsormpatsoudis, 2007; Alexandris \& Stodolska, 2004; Alexandris, Barkoukis, Tsormpatsoudis \& Grouios, 2003). If this is true, the inclusion of constraints in the TPB model 
should help enhancing the predictive capability of the TPB, while proving a practical dimension to it. Despite these indications no research has so far made any attempt to extend the TPB by combining constraints. Therefore, the second objective of this research was to examine whether the effect of constraints on deer hunting intentions is mediated by the TPB predictors, and the third objective was to assess the efficiency of the constraint integrated TPB model in predicting deer hunting intentions and behavior in comparison to the original TPB.

\section{Objectives}

1. To assess the effectiveness the TPB model in predicting deer hunting intentions (Chapter 2, Article 1) and behaviors (Chapter 4, Article 3) of Oregon big game hunters.

2. To examine the role of the predictors of the TPB in mediating the relationships of constraints with deer hunting intentions (Chapter 3, Article 2).

3. To assess the effectiveness of the constraint integrated TPB models in predicting deer hunting participation in comparison to the original TPB model (Chapter 4, Article 3).

Several hypotheses related to these objectives were tested. These hypotheses were:

Hypothesis 1: Attitude, subjective norms and PBC of the big game hunters are positively associated with deer hunting intentions.

Hypothesis 2: Deer hunting intentions of big game hunters are positively associated with reported deer hunting participation.

Hypothesis 3: PBC of big game hunters has a direct positive effect on reported deer hunting participation.

Hypothesis 4: Attitude, subjective norms, and PBC of the big game hunters mediated the effects of constraint dimensions on deer hunting intensions.

Hypothesis 5: The original TPB model testing hypothesis was: The deer hunting intentions and participation data are consistent with the TPB model. In other words, "how likely it is that the values of independent variables (attitude, subjective norms and PBC) can successfully predict values of intermediate variable (hunting intentions) and dependent variables (reported deer hunting participation) for the Oregon big game hunters." 
Hypothesis 6: The constraints integrated TPB model testing hypothesis was: The deer hunting intentions and participation data are consistent with the constraint integrated TPB model. In other words, "how likely it is that the values of independent variables (constraint dimension) and intermediate variables ((attitude, subjective norms and PBC and intentions) can successfully predict dependent variables (reported deer hunting participation) for the Oregon big game hunters."

\section{Literature Review}

The literatures, specific to the research questions, are discussed in respective articles. These reviews covered the theory of planned behavior and its application in recreation research, constraint approach to leisure research and their limitations, theoretical and empirical evidences of relationships between constraint dimensions and TPB components including mediating effects of attitude, subjective norms and PBC on relationships between constraint dimensions and intentions.

\section{Methodology}

Questionnaire Survey: The data needed for the study were collected using two-staged self-administered mail back survey mail back survey. The first mail back survey was conducted in August-September 2009. The main purpose of this survey was to ask respondents' intentions of participation in deer hunting intensions in Oregon in 2009 hunting season and indentifying perceived constraints to general hunting. The sample included 2,000 Oregon hunters who had purchased a big game (deer/elk/bear) hunting license/tags for the 2008 hunting season. The sample was randomly selected from a database $(N=161,693)$ of names and addresses of Oregon big game hunters, provided by the Oregon Department of Fish and Wildlife (ODFW). A prestudy post card was sent to each selected respondent one week before mailing the survey instrument. The pre-study post card alerted the prospective respondents about the impending survey and its importance (ANNEX 1). The surveys were mailed from West Virginia University mail center with no reference to ODFW.

The survey packet included a cover letter, the survey instrument, and a self-addressed, stamped envelope (ANNEX 2). Two post survey reminder requests were mailed to nonrespondents after the first wave. The first reminder was mailed without a replacement 
questionnaire and the second reminder was mailed with a replacement questionnaire. A total of 2,000 surveys were mailed to the randomly selected license holders, of which 193 surveys were returned because of incorrect addresses. The final sample size included 1,807 hunters. Of the 1,807 hunters who received the survey, 360 completed and returned the survey (response rate $=$ 20\%). This response rate might be attributed to the fact that only two reminder requests were mailed in a 15 days period. Dillman (2000) suggested incentives and an additional contact with the non-respondents via certified mail or its alternative. These steps might have had improved the response rate, however, it was not feasible in this case. First, because the hunting season had already started in Oregon which made asking hunting intention questions irrelevant as some of the respondents might have already begun hunting. Second, providing incentives for completing and returning surveys was not permitted.

The second mail back survey was conducted in January 2010 with 360 hunters who completed the first survey in 2009. The purpose of second survey was to ask, whether they participated in deer hunting in 2009 in Oregon (ANNEX 3). The response rate for the second survey was $67 \%$. The analysis was conducted with 242 responses as they consisted of both intentions and participation responses.

Although funding prohibited a formal non-response bias check, the profiles of the respondents (sample) was compared with the population. There was little difference in the representation of hunters of different groups between the sample and the population, in terms of indicator variables including sex and age. For example, the mean age of the population was 52 years and sample mean was 51 years, while the male-female ratio was 86:14 in the population and 82:18 in the sample. In addition, an extrapolation approach (Armstrong \& Overton, 1977; Israel, 2011) was used to compare the profiles of the hunters who responded before the second follow up survey $(n=236)$ and hunters who responded after second follow up survey $(n=124)$. There were no significant differences between groups in these respects. Finally, the sample's deer harvesting success rate $(35 \%)$ was within the forecasted deer harvesting success rate range of 26-37\% for the years 1992 to 2003 (ODFW, 2011). The harvesting success rate survey was not conducted after 2003. These results suggested there were little or no differences between respondents and non-respondents. 
Measurement and Scales: Researchers focusing on TPB have measured attitude as a product of evaluative outcomes and behavioral beliefs. Likewise, subjective norms were measured as product of subjective norms and normative beliefs and PBC was measured as product of PBC and control beliefs (Ajzen \& Driver, 1992). Ajzen (2002), however, suggested that attitude, subjective norm, $\mathrm{PBC}$, and intention could be assessed directly but cautioned that the measures must be directly compatible with the behavior in terms of action, target, context, and time elements. Accordingly, the multi-item standard direct measures of attitudes, subjective norms, PBC and intentions, suggested by Ajzen (2002) and applied by Ajzen and Driver (1992) in their study were used. The questions were rephrased for deer hunting context (ANNEX 2, Question 8 - 11).

Attitude was treated as a person's evaluation of the benefits (affective such as good or bad, pleasant or unpleasant, interesting or uninteresting and instrumental such as health, social and economic benefits) of participation in deer hunting. It was measured with six items using seven-point semantic differential scale ranging from 1 (highly negative evaluation) to 7 (highly positive evaluation). The items used were: "For me deer hunting in Oregon in 2009 would be 1) "Unpleasant - Pleasant;" 2) "Boring - Interesting;" 3) "Unenjoyable - Enjoyable;" 4) "Harmful - Useful (socially);" 5) "Harmful - Useful (health-wise);" and 6) Harmful - Useful (economically)."

Intentions, subjective norms and PBC were assessed through the use of a seven-point scale that ranged from 1 (strongly disagree) to 7 (strongly agree). Subjective norms represented respondent's perception about what other people important to him/her think about his/her participation in deer hunting in Oregon during the 2009 hunting season. The four items that assessed subjective-norms were: (a) "People important to me think I should hunt deer in 09"; (b) "People who I value think I should hunt deer in 09"; (c) "People important to me support my deer hunting 09"; and (d) "People important to me will go deer hunting in 09." The PBC characterized a person's perceived level of confidence to participate in deer hunting in Oregon in 2009 hunting season, taking account of skills and resources including past experience. The three items used to assess PBC were: (a) "I am confident that I can go deer hunting in OR in 09"; (b) "If I want to go deer hunting in 09, I can go easily go"; and (c) "The factors that influence my decision to go deer hunting in OR in 09, are in my total control." Intentions were treated as 
respondents' conscious plan or decision to participate in deer hunting in Oregon during the 2009 hunting season. The three items used for measuring the intentions were: (a) "I intend to participate in deer hunting in Oregon in 2009 hunting season"; (b) "I will try to participate in deer hunting in Oregon in 2009 hunting season"; and (c) "I am determined to participate in deer hunting in Oregon in 2009 hunting season."

Perceived constraints to hunting were measured by asking the perceived frequency of encountering 25 constraints for participation in hunting in Oregon (ANNEX 2, Question 12). The constraint items were derived from Shinew, Floyd and Parry (2004) and Burns and Graefe (2007) and were rephrased for hunting. A 5-point scale developed by Shinew, et al. ranging from 1 (never/not at all) to 5 (always/a lot) was used to measure the hunting constraints.

Reliability of the items and scales used for measuring the TPB concepts were examined by calculating of Cronbach's alpha. The mediation analysis was performed following Baron and Kenny's Criteria (Baron and Kenny, 1986). Structural equation modeling (SEM) was used to assess the fit of the model with the data in Analysis of Moment of Structures (AMOS), which included measurement modeling and structural modeling. Measurement modeling included confirmatory factor analysis (CFA) which assessed the observed-latent variables relationships. Structural modeling was performed by calculating path coefficients (regression weights) using maximum likelihood estimates (MLE). The fit of the measurement model and structural model was assessed using Chi-square fit index. However, because of the high sensitivity of the Chisquare to sample size (Garson, 2011), at least five other popular goodness of fit measures were applied (Arbuckle 2006; Jaccard \& Wan 1996; Kline 1998). These measures included CMIN/DF ratio, baseline comparisons like Comparative Fit Index (CFI), Normed Fit Index (NFI), Tucker Lewis index (TLI) and the Standardized Root Mean Square Residuals (SRMR) and Root Mean Square Error of Approximation (RMSEA).

According to Kline (1998), a CMIN/DF ratio of three or less is acceptable, and less than one indicative of over-fit. However, other scholars suggest values as high as five are acceptable (Schumacker \& Lomax, 2004). Likewise, SRMR and RMSEA below .08 is considered as an adequate fit and both CFI, NFI and TLI should be equal to or greater than 90 to accept the model (Garson, 2011). Path coefficients and their critical ratios (CRs - an equivalent of $t$-value 
for regression weights) were used for testing hypothesis at $p<.05$. A critical ratio of 1.96 indicates that the path coefficient is significant at $p<.05$.

\section{Findings}

The findings of the study are presented in the form of three peer reviewed articles in Chapter two, Chapter three and Chapter four, respectively.

Chapter Two (Article 1) describes big game hunters' profiles and assesses the applicability of the theory of planned behavior (TPB) in predicting deer hunting intentions based on responses received from first mail back survey (n 360). The findings suggested that hunters possessed very positive intentions to participate in deer hunting in Oregon. They also held very positive attitude towards participating in deer hunting, and perceived that people close to them were supportive to their participation in deer hunting. They also believed to have necessary skills and resources to participate in deer hunting. The SEM established that the TPB model successfully predicted deer hunting intentions. It demonstrated that that behavioral control (PBC) was the strongest predictor of hunting intentions, followed by subjective norms, while the effect of attitudes was not significant. These findings implied that TPB could be useful for understanding why people participate in deer hunting and deer hunting is not under complete volitional control. Resource managers may want to consider initiating viable programs and strategies to enhance hunting success rate and quality of experiences by enhancing control beliefs through enhancing opportunities and skills.

Chapter Three (Article 2) explores the degree to which the antecedents of the TPB, i.e., attitude, subjective norms and PBC mediated the relationship of hunting constraints with deer hunting intention from the responses received from first mail back survey of 2009. Since one respondent did not fill out responses to constraint items, the sample size (n) for this paper was 359. The mediation analysis was performed following Baron and Kenny's Criteria. It demonstrated that the TPB elements have moderate to strong negative correlations with the four constraints dimensions (site and management, partner and health, skill and lack of confidence, and time, distance and money), except for the correlation between subjective norms and partner and health. It established that all antecedents of the TPB fully or partially mediated the relationships of the four constraint dimensions with deer hunting intentions, except for the 
relationship between intention and partner and health constraint dimension. Attitude fully mediated the relationships of intention with partner and health constraint dimension while partially mediated with rest three constraint dimensions. Excluding the partner and health constraint dimension, subjective norms partially mediated the relationships of intention with other three constraint dimensions. PBC fully mediated the relationships of intention with site and management constraint dimensions and partially mediated with rest two constraint dimensions. These findings demonstrated that constraints affect deer hunting intention directly and indirectly through mediated effects of the antecedents of the TPB variables. This implied that future efforts on extending TPB may consider integrating constraints to offer a more practical dimension to the TPB. Conversely, constraint research may examine the role of attitude, subjective norms and $\mathrm{PBC}$ on constraint negotiation. The stronger influence of PBC on constraints - intention relationship implied that consultation, education, psychological support, design, and delivery of appropriate programs are among the strategies that should be applied to reduce the influence of perceived behavioral control. Descriptive findings implied that managers may want to enhance the quality of experience by increasing harvesting success through habitat improvement and predator control, as well as extending hunting opportunities in public and private lands.

Chapter Four (Article 3) addresses two research questions, based on 242 responses of participants of 2009 and 2010 surveys. First, can the theory of planned behavior (TPB) successfully predict deer hunting behavior? Second, can integration of constraints dimensions in the TPB model improve the prediction of deer hunting intention and behavior? The data were collected from a two-staged mail back surveys of the hunters from Oregon in 2009 and 2010. The response rate was $20 \%$ and $67 \%$ in the first and second survey, respectively. Models were assessed using structural equation modeling (SEM). The results showed that the original TPB model successfully predicted $51 \%$ variance in the intentions and $21 \%$ variance in the reported participation in deer hunting. Among the six constraints integrated TPB models, fear integrated, time, money and distance integrated and total constraint integrated model showed good fit with the data, and explained $2 \%$ to $4 \%$ more variance in reported hunting participation. Both original and extended models showed that attitude and subjective norms had no significant role in the model while PBC was a significant factor for predicting deer hunting participation directly as well as indirectly through intentions. Evidences were found regarding constraint negotiation roles of the TPB predictors on deer hunting participation. Recommendations are made to use 
more comprehensive measures of attitudes, subjective norms and PBC as well as specific measures of constraints for better understanding of the entire phenomenon. Practitioners are advised to develop programs for enhancing $\mathrm{PBC}$ and reducing internal and external constraints through skill development and providing more satisfying hunting opportunities by enhancing quality and quality of game population. 


\section{References}

Ajzen, I. (1991). The theory of planned behavior. Organizational Behavior and Human Decision Processes, 50, 179-211.

Ajzen, I. \& Fishbein, M. (1980). Understanding attitude and predicting social behavior. Englewood Cliffs, NJ: Prentice-Hall.

Ajzen, I. \& Driver, B. (1991). Prediction of leisure participation from behavioral, normative and control beliefs: an application of theory of planned behavior. Leisure Sciences, 13, 185204.

Ajzen, I. \& Driver, B. (1992). Application of theory of planned behavior to leisure choice. Journal of Leisure Research, 24(3), 207-224.

Ajzen, I. (2002). Constructing a TPB questionnaire: Conceptual and Methodological Considerations. Revised in 2006. Retrieved from http://socgeo.ruhosting.nl/html/files/spatbeh/tpb.measurement.pDF, August, 2009.

Alexandris, K., Barkoukis, V., \& Tsormpatzoudis, C. (2007). Does theory of planned behavior elements mediate the relationship between perceived constraints and intention to participate in physical activities? A study among older individuals. European Review of Aging and Physical Activity, 4(1), 39-48.

Alexandris, K., Barkoukis V., Tsorbatzoudis, C., \& Grouios, H. (2003). A study of perceived constraints on a community based physical activity program for the elderly in Greece. Journal of Aging and Physical Activity, 11, 305-318.

Alexandris K. \& Stodolska, M. (2004). The influence of perceived constraints on the attitudes towards recreational sport participation. Leisure and Society, 27, 197-217.

Anderson, M., Reiling, S., \& Criner, G. (1985). Consumer demand theory and wildlife agency revenue structure. Wildlife Society Bulletin, 13, 375-384.

Arbuckle, J. (2006). Amos 7.0 User's Guide. Amos Development Corporation. PA: Spring House.

Armstrong, J. \& Overton, T. (1977). Estimating nonresponse bias in mail surveys. Journal of Marketing Research, 14, 396-402. 
Baron M. \& Kenny, A. (1986). The moderator-mediator variable distinction in socialpsychological research: conceptual, strategies and statistical considerations. Journal of Pers Social Psychology, 51, 1173-1182.

Bissell, S., Duda, M., \& Young, K. (1998). Recent studies in hunting and fishing participation in the United States. Human Dimensions of Wildlife, 3(1), 75-80.

Blanchard, C., Rhodes, R., Nehl, E., Fisher, J., Sparling, P., \& Courneya, K. (2003). Ethnicity and the theory of planned behavior in the exercise domain. American Journal of Health Behavior, 27(6), 579-591.

Blanchard, C., Fisher, J. Sparling, P., Nehl, E., Rhodes, R., Courneya, K., \& Baker, F. (2008). Understanding physical activity behavior in African American and Caucasian college students: An application of the theory of planned behavior. Journal of American College Health, 56(4), 341-347.

Brown, P. (2009). Introduction: Perspectives on the past and Future of Human Dimension of Fish and Wildlife. In M. J. Manfredo, J. Vaske, P. J. Brown, D. J. Decker and E. A. Duke (Eds.), Wildlife and Society: The Science of Human Dimension (pp. 1-6). Wasington DC: Island Press

Brown, T., Decker, D., Riley, S., Enck, J., Lauber, T., Curtis, P., \& Mattfeld, G. (2000b). The future of hunting as a mechanism to control white-tailed deer populations. Wildlife Society Bulletin, 28(4), 797-807.

Brown, T., Decker, D., \& Enck , J. (1995). Preliminary insights about the socio-cultural importance of hunting and trapping. Human Dimensions Research Unit Series Report, 95-2. Ithaca, NY: Cornell University.

Brown, T., Decker, D., Siemer, W., \& Enck, J. (2000a). Trends in hunting participation and implications for management of game. In W.C. Gartner \& D.W. Lime (Eds.), Trends in Outdoor Recreation, Leisure and Tourism (pp. 780-787). New York, NY: CABI Publishing.

Burns, R. \& Graefe, A. (2007). Constraints to outdoor recreation: Exploring the Effects of Disabilities on Perceptions and Participation. Journal of Leisure Research, 39, 156-181. 
Carroll, B. \& Alexandris, K. (1997). Perception of constraints and strength of motivation: their relation to recreational sport participation. Journal of Leisure Research, 29, 279-299.

Cordell, H. \& Super, G. (2000). Trends in American's Outdoor Recreation. In W. C. Gartner \& D. W. Lime (Eds.), Trends In Outdoor Recreation, Leisure And Tourism, (pp. 133-144). New York: CABI.

Crawford, D., Jackson, E., \& Godbey, G. (1991). A hierarchical model of leisure constraints. Leisure Sciences, 13(4), 309 - 320.

Crawford, D. \& Godbey, G. (1987). Reconceptualizing barriers to family leisure. Leisure Sciences, 9, 119-127.

Dean Runyan Associates. (2009). Fishing, hunting, wildlife viewing, and shellfishing in Oregon 2008: State and County Expenditure Estimates. Report Prepared for Oregon Department Of Fish and Wildlife. Portland, Oregon.

Dillman, D. (2000). Mail and internet surveys: the tailored design method. New York, NY: John Wiley \& Sons, Inc.

Duda, M., Bissell, S., \& Young, K. (1998). Wildlife and the American mind: public opinion and attitudes toward fish and wildlife management. Harrisonburg, VA: Responsive Management.

Enck, J. \& Decker, D. (1991). Hunters' perspectives on satisfying and dissatisfying aspects of the deer-hunting experience in New York. Human Dimensions Research Unit Series Report, 91-4 (pp. 83). Ithaca, NY. Cornell University.

Eves, F., Hoppe, R., \& McLaren, L. (2003). Prediction of specific types of physical activity using the theory of planned behavior. Journal of Applied Biobehavioral Research, 8(2), 77-95.

Fishbein, M. \& Ajzen, I. (1975). Belief, attitude intention and behavior: an introduction to theory and research. Reading, MA: Addison-Wesley.

Floyd, M. \& Lee, I. (2002). Who buys fishing and hunting licenses in Texas? Results from a statewide household survey. Human Dimensions of Wildlife, 7, 91-106. 
Garson, G. (2011). Structural equation modeling. Statnotes: Topics in Multivariate Analysis. Retrieved from http://faculty.chass.ncsu.edu/garson/pa765/statnote.htm

Geist, V. (1995). North American policies of wildlife conservation. In V. Geist \& I. MctaggertCowen (Eds.), Wildlife Conservation Policy (pp. 77-129). Calgary, Alberta, Canada: Detseling Enterprises Ltd.

Gregg, R. (2001). Hunting. In G. W. McDonogh, Robert Gregg, \& Cindy H. Wong (Eds.), Encyclopedia of Contemporary American Culture (pp. 571-572). New York, NY: Rutledge.

Grilliot, A. L. \& Armstrong, J. B. (2005). A comparison of deer hunters with disabilities and nondisabled hunters in Alabama: motivations and satisfactions in deer hunting. Wildlife Society Bulletin, 33(1), 243-250. Retrieved from http://www.jstor.org/stable/3784861.

Hammitt, W., McDonald, C., \& Patterson, M. (1990). Determinants of multiple satisfaction for deer hunting. Wildlife Society Bulletin, 18, 331-337.

Hautaluoma, J. \& Brown, P. (1979). Attributes of the deer hunting experience: a cluster analytic study. Journal of Leisure Research, 10, 271-287.

Hemingway, J. \& Parr, M. (2000). Leisure research and leisure practice: Three perspectives on constructing the research-practice relation. Leisure Sciences, 22, 139-162.

Hendee, J. (1974). A multiple satisfaction approach to game management. Wildlife Society Bulletin, 2, 104-113.

Henderson, K. (2010). Leisure Studies in the 21st Century: The Sky is Falling? Leisure Sciences, $32,391-400$.

Henderson, K., Presley, J., \& Bialeschki, M. (2004). Theory in recreation and leisure research: reflection from the editors. Leisure Sciences, 26, 411-425.

Herbert, H. (1849). Frank Forester's field sports of the United States and British Provinces of North America. New York, NY: Stringer and Townsed.

Holden, A. (2003). Investigating trekkers' attitudes to the environment of Annapurna, Nepal. Tourism Management, 24: 341-344. 
Holsman, R. (2000). Goodwill hunting? Exploring the role of hunters as ecosystem stewards. Wildlife Society Bulletin, 28(4), 808-816.

Hrubes, D., Ajzen, I., \& Daigle, J. (2001). Predicting hunting intentions and behavior: an application of the theory of planned behavior. Leisure Sciences, 23, 165-178.

Hubbard, J. \& Mannell, R. (2001). Testing competing models of the leisure constraint and negotiation process in a corporate employee recreation setting. Leisure Sciences, 23, 145163.

Israel, G. D. (2011). Sampling issues: Nonresponse. PEOD9. Gainesville, FL: Agricultural Education and Communication Department, University of Florida. Retrieved from http://edis.ifas.ufl.edu/pd008.

Jaccard, J. \& Wan, C. (1996). LISREL approaches to interaction effects in multiple regression. Thousand Oaks, CA: Sage Publications.

Jackson, E. L. (1988). Leisure constraints: a survey of past research. Leisure Sciences, 10, 203215.

Jackson E. L. (1991). leisure constraints /constrained leisure: special issue introduction. Journal of Leisure Research, 23, 279-285.

Jackson, E., Crawford, D., \& Godbey, G. (993) Negotiation of leisure constraints. Leisure Sciences, 15(1), 1-11.

Kellert, S. (1978). Attitudes and characteristics of hunters and antihunters. Transactions of the North American Wildlife and Natural Resources Conference, 43, 412-423.

Kline, R. B. (1998). Principles and practices of structural equation modeling. NY: Guilford Press.

Kouthouris, C. \& Spontis, A. (2008). Outdoor recreation participation: an application of the theory of the planned behavior. The Sport Journal, 11(2).

Kyle, G., Graffe, A., Manning, R., \& Bacon, J. (2003). An examination of the relationship between leisure activity involvement and place attachment among hikers along the Appalachian Trail. Journal of Leisure Research, 35, 249-273. 
Lauber, T. \& Brown, T. (2000). Deer hunting and deer hunting trends in New York State. HDRU Series No 00-1. Human Dimensions Research Unit, Department Of Natural Resources. Ithaca, NY: Cornell University.

Manfredo, M. \& Larson, R. (1993). Managing for wildlife viewing recreation experiences: An application in Colorado. Wildlife Society Bulletin, 21, 226-236.

Manfredo, M., Vaske, J., \& Decker, D. (1995a). Human dimension of wildlife management: Basic concepts. In R. L. Knight \& K. J. Gutzwiller (Eds.), Human dimension in wildlife programs (pp. 62-71). Washington, DC: Mercury Press.

Manfredo, M., Vaske, J., \& Decker, D. (1995b). Human dimension of wildlife management: Basic concepts. In R. L. Knight \& K. J. Gutzwiller (Eds.), Wildlife and recreationists: Coexistence through management and research (pp. 17-31). Washington, DC: Mercury Press.

Mighetto, L. (1991). Wild animals and American environmental ethics. Tucson, Arizona: University of Arizona Press.

More, T. A. (1973). Attitudes of Massachusetts hunters: Transactions of the North American Wildlife and Natural Resource Conference, 3, 230.

Mozumder, P., Starbuck, C., Berrens R., \& Alexander, S. (2007). Lease and fee hunting on private lands in the U.S.: a review of the economic and legal issues. Human Dimensions of wildlife, 12, 1-14.

Mummery, W. \&_Wankel, L. (1999). Training adherence in adolescent competitive swimmers: An application of the theory of planned behavior. Journal of Sport \& Exercise Psychology, 21(4), 313-328.

NSSF/Southwick Associates. (2008). Lifetime value from newly recruited hunters and target shooters. Fernandina Beach, FL: NSSF.

Parr, M. (1996). The relation between leisure theory and recreation practice. Leisure Sciences, $18,315-332$. 
Potter, D., Hendee, J., \& Clark, R. (1973). Hunting satisfaction: game, guns, or nature. In J. C. Hendee \& C. Schoenfeld (Eds.), Human Dimensions in Wildlife Programs (pp. 62-71). Washington, DC: Mercury Press.

Responsive Management. (2006a). Sportsmen's Attitudes. Unpublished Survey about Various Hunting and Fishing Issues. Harrisonburg, VA: Responsive Management.

Responsive Management. (2006b). The Public's attitudes toward and participation in the shooting sports. Harrisonburg, VA: Responsive Management.

Responsive Management. (2008). Increasing hunting participation by investigating factors related to hunting license sales increases in 1992, 1999, and 2004 against 13 other years of hunting license sales decline between 1990 - 2005. Harrisonburg, VA: Responsive Management.

Riess, S. A. (1995). Sports in Industrial America, 1850-1920. Wheeling, Illinois: Harlan Davidson.

RM/NSSF. (2008). The future of hunting and the shooting sports: research-based recruitment and retention strategies. Final Report. Produced for U.S. Fish And Wildlife Service. Harrisonburg, Virginia: Responsive Management/National Shooting Sport Foundation.

Rossi, A. \& Armstrong, J. (1999). Theory of reasoned action vs. theory of planned behavior: Testing the suitability and sufficiency of a popular behavior model using hunting intentions. Human Dimensions of Wildlife, 4, 40-56.

Schumacker, R. \& Lomax, R. (2004). A beginner's guide to structural equation modeling, second edition. Mahwah, NJ: Lawrence Erlbaum Associates.

Scott, D., \& Jackson, E. (1996). Factors that limit and strategies that might encourage people's use of public parks. Journal of Park and Recreation Administration, 14(1), 1-11.

Southwick Associates. (2007). Hunting in America: An Economic Engine and Conservation Powerhouse. Washington, DC: Southwick Associates/Association of Fish and Wildlife Agencies.

Son, J., Kerstetter, D., \& Mowen, A. (2008). Do age and gender matter in the constraint negotiation of physically active leisure? Journal of Leisure Research, 40(2), 267-289 
Stankey, G., Lucas, R., \& Ream, R. (1973). Relationship between hunting success and satisfaction. Transactions of the North American Wildlife and Natural Resource Conference. 38, 235-245.

Shinew, K. J., Floyd, M. F., \& Parry, D. (2004). Understanding the relationship between race and leisure activities and constraints: exploring an alternative framework. Leisure Science, 26, 181-199.

Sun, L., Van Kooten, G., \& Voss, G. (2005). Demand for wildlife hunting in British Columbia.Canadian Journal of Agricultural Economics, 53, 25-46.

USDI/FWS/UADC/US Census Bureau. (2006). 2006 national survey of fishing, hunting, and wildlife-associated recreation. Washington DC: U.S. Department of the Interior, Fish and Wildlife Service, and U.S. Department of Commerce, U.S. Census Bureau.

Walker, G., Jackson, E., \& Deng, J. (2007). Culture and Leisure Constraints: A Comparison of Canadian and Mainland Chinese. Journal of Leisure Research, 39(4), 567-590.

Walker, G., \& Virden, R. (2005). Constraints on outdoor recreation. In E.L. Jackson (Ed.), Constraintsto Leisure (pp. 201-219). State College, Penna.: Venture Publishing.

White, H. \& Bustam, T. (2010). Using leisure constraints research to inform outdoor recreation research and natural resource management decisions. Parkbreak Perspective. Hancock, MI: George Wright Society, Retrieved from http://www.georgewright.org/pbp005_white.pdf. 


\title{
CHAPTER 2: Article 1
}

Predicting Deer Hunting Intentions Using the Theory of Planned Behavior: A Survey of Oregon Big Game Hunters

\author{
Suresh K. Shrestha \\ Robert C. Burns \\ Chad D. Pierskalla, \\ Steve Selin
}

(This articles was published in Human Dimensions of Wildlife: An International Journal in Volume 17, 2012)

\begin{abstract}
This article describes deer hunters' profiles and assesses the applicability of the theory of planned behavior (TPB) in predicting deer hunting intentions. Model assessment was performed using structural equation modeling (SEM). The TPB model success- fully predicted hunting intentions. Perceived behavioral control (PBC) emerged as the strongest predictor of hunting intentions, followed by subjective norms, while the effect of attitudes was not significant. These findings imply that TPB could be useful for under- standing why people participate in deer hunting and deer hunting is not under complete volitional control. The findings suggest that hunters fully intended to participate in deer hunting. Resource managers may want to consider initiating viable programs and strategies to enhance hunting success rate and quality of experiences by enhancing control beliefs through enhancing opportunities and skills.
\end{abstract}

Keywords: Theory of Planned Behavior, Deer Hunting Intention, Structural Equation Modeling 


\section{Introduction}

Trend data indicate that participation in hunting has been declining in the United States over the past two decades. According to National Survey of Fishing, Hunting, and WildlifeAssociated Recreation, hunting participation has declined in both in the numbers of hunters as well as hunting licenses sold (Aiken \& Harris, 2011). Hunting participation has declined from over 14.1 million to 12.5 million between the years 1991 to 2006 and the number of licenses sold has declined from 16.5 million to 14.6 million between the same periods of time (Responsive Management, 2008a). The number of hunting license holders in Oregon has declined by 33\% between the years 1981 and 2005 (Responsive Management, 2008b). Fishing and hunting activities typically contribute $\$ 2.8$ billion to Oregon's economy annually (Dean Runyan Associates, 2009). Declines in the hunting population might negatively affect the state's wildlife conservation programs.

\section{Theoretical Development}

Researchers have emphasized the need for a sound theoretical framework to build a cumulative body of knowledge regarding hunting behavior (Hammitt, McDonald, \& Patterson, 1990; Manfredo \& Larson, 1993; Manfredo, Vaske, \& Decker, 1995a). Such a framework would be helpful in integrating diverse research findings, testing the reliability of constructs and examining the predictive validity of hunting behavior models. Manfredo, Vaske, and Decker (1995b) suggested that research is needed to identify the factors, such as behavioral norms and beliefs that describe people's behavior towards wildlife oriented activities (cognitive approach). In line with this, other researchers have applied Ajzen's (1991) theory of planned behavior (TPB) and Ajzen and Fishbien's (1980) theory of reasoned actions (TRA) for describing hunting intentions and participation (Hrubes, Ajzen, \& Daigle, 2001; Rossi \& Armstrong, 1999).

According to the TRA, intentions are central for describing an individual's behavior. Intentions, in turn, depend on attitude towards the behavior and subjective norms for the behavior. Intentions are assumed to capture one's motivations for participation and reflect how much of an effort an individual will exert to perform the behavior (Ajzen \& Driver, 1992). Because behaviors are not always under volitional control, however, it is useful to consider effects of perceived behavioral control (PBC) on prediction of the behavior directly as well as 
indirectly through intentions (Ajzen, 1991). In the TPB model, behavior is a function of an individual's intentions to perform a behavior; intentions, in turn, depend on attitudes, subjective norms and perceived behavioral control for performing the behavior. $\mathrm{PBC}$ is posited to directly and indirectly affect behavior.

Attitude toward a behavior refers to the degree to which the person has a favorable or unfavorable evaluation of the behavior in question (Ajzen \& Driver, 1992). Subjective norms refer to the perceived social pressure to perform or not to perform the behavior. PBC represents perceived ease or difficulty of performing the behavior. The more favorable the attitudes, subjective norms and $\mathrm{PBC}$ are, the stronger the person's intentions to perform the behavior. The importance of these predictors is expected to vary across behaviors and populations.

The TPB has been used extensively to model the determinants of outdoor recreation behavior. Examples include studies focusing on boating, biking, climbing, jogging, and beach activities (Ajzen \& Driver, 1991, 1992). The results have been mixed. Meta-analytic reviews of TPB studies (Armitage \& Conner, 1999, 2001; Conner \& Armitage, 1998; Downs \& Hausenblas, 2005; Godin \& Kok, 1996) indicate that intentions are a reliable predictor of actual or reported behavior; and PBC is a reliable predictor of both intentions and behavior. The role of attitudes and subjective norms in explaining intention and behavior depended on the type of behavior and strength of measure of normative components. Downs, Graham, and Yang (2006) found that attitude, subjective norms and $\mathrm{PBC}$ predicted 55\% of the variance in intentions. Intentions and $\mathrm{PBC}$ explained 51\% variance in past exercise behavior. Armitage and Conner (2001) noted that TPB accounted for 39\% variance in intentions and $27 \%$ of variance in behavior when behavior measures were self-reported.

The findings of Hrubes et al. (2001) and Rossi and Armstrong (1999) supported the predictive utility of the TPB for describing hunting intentions. Both studies found that attitudes and subjective norms were more important predictors of hunting intentions than the PBC, suggesting that hunting behavior is under volitional control. These studies, however, were designed to better understand general hunting intentions and behavior rather than deer hunting activity at a specific time and place. In addition, there was a large discrepancy in the amount of variations explained in hunting intentions between these studies. Rossi and Armstrong found that 
TPB explained $38 \%$ of the variance in hunting intentions, while Hrubes et al. reported that TPB explained $86 \%$ variations in intentions.

As earlier research works have showed that intentions serve as a valid predictor of actual and reported behavior, this article assessed whether the TPB model can predict deer hunting intentions. A secondary goal was to examine which components of the TPB account for variation in hunting intentions. Our model assessment hypothesis was that the TPB model can describe deer hunting intention. The specific hypothesis were: (a) deer hunting attitudes are positively associated with deer hunting intentions; (b) subjective norms for deer hunting are positively associated with deer hunting intentions; (c) PBC for deer hunting is positively associated with deer hunting intentions.

\section{Methods}

A self-administered mail back survey was conducted in August-September 2009. The sample included 2,000 Oregon hunters who had purchased a big game (deer/elk/bear) hunting license/tags for the 2008 hunting season. The sample was randomly selected from a database $(N=$ 161,693) of names and addresses of Oregon big game hunters, provided by the Oregon Department of Fish and Wildlife (ODFW). A pre-study post card was sent to each selected respondent one week before mailing the survey instrument. The pre-study post card alerted the prospective respondents about the impending survey and its importance. The surveys were mailed from a major research university mail center with no reference to ODFW.

The survey packet included a cover letter, the survey instrument, and a self-addressed, stamped envelope. Two post survey reminder requests were mailed to non-respondents after the first wave. The first reminder was mailed without a replacement questionnaire and a second mailed with a replacement questionnaire. A total of 2,000 surveys were mailed to the randomly selected license holders, of which 193 surveys were returned because of incorrect addresses. The final sample size included 1,807 hunters. Of the 1,807 hunters who received the survey, 360 completed and returned the survey (response rate $=20 \%$ ). This response rate might be attributed to the fact that only two reminder requests were mailed in a 15 days period. The short window of time was necessary because the annual hunting season had already started in Oregon when approval to mail the surveys was received. 


\section{Measurement and Scales}

Researchers focusing on TPB have measured attitude as a product of evaluative outcomes and behavioral beliefs. Likewise, subjective norms were measured as product of subjective norms and normative beliefs and PBC was measured as product of PBC and control beliefs (Ajzen \& Driver, 1992). Ajzen (2002), however, suggested that attitude, subjective norm, PBC, and intention could be assessed directly but cautioned that the measures must be directly compatible with the behavior in terms of action, target, context, and time elements. Accordingly, the multiitem standard direct measures of attitudes, subjective norms, $\mathrm{PBC}$ and intentions, suggested by Ajzen (2006) and applied by Ajzen and Driver (1992) in their study were used. The questions were rephrased for deer hunting context.

Attitude was treated as a person's evaluation of the benefits (affective such as good or bad, pleasant or unpleasant, interesting or uninteresting and instrumental such as health, social and economic benefits) of participation in deer hunting. It was measured with six items using sevenpoint semantic differential scale ranging from 1 (highly negative evaluation) to 7 (highly positive evaluation). The items used were: "For me deer hunting in Oregon in 2009 would be 1) "Unpleasant - Pleasant;" 2) "Boring - Interesting;" 3) "Unenjoyable - Enjoyable;" 4) "Harmful Useful (socially);" 5) "Harmful - Useful (health-wise);" and 6) Harmful - Useful (economically)."

Intentions, subjective norms and PBC were assessed through the use of a seven-point scale that ranged from 1 (strongly disagree) to 7 (strongly agree). Subjective norms represented respondent's perception about what other people important to him/her think about his/her participation in deer hunting in Oregon during the 2009 hunting season. The four items that assessed subjective-norms were: (a) "People important to me think I should hunt deer in 09"; (b) "People who I value think I should hunt deer in 09"; (c) "People important to me support my deer hunting 09"; and (d) "People important to me will go deer hunting in 09." The PBC characterized a person's perceived level of confidence to participate in deer hunting in Oregon in 2009 hunting season, taking account of skills and resources including past experience. The three items used to assess PBC were: (a) "I am confident that I can go deer hunting in OR in 09"; (b) "If I want to go deer hunting in 09, I can easily go"; and (c) "The factors that influence my decision to go deer hunting in OR in 09, are in my control." Intentions were treated as respondents' conscious plan or decision to participate in deer hunting in Oregon during the 2009 hunting season. The three items 
used for measuring the intentions were: (a) "I intend to participate in deer hunting in Oregon in 09 hunting season"; (b) "I will try to participate in deer hunting in Oregon in 09 hunting sea- son"; and (c) "I am determined to participate in deer hunting in Oregon in 09 hunting season."

For easier interpretation of the means, the scales of each item were recoded into -3 to +3 . A positive mean value indicated "agreement" with the statement or a "favorable" attitude, and a negative value indicated "disagreement" with the statement or an "unfavorable" attitude.

Although funding prohibited a formal non-response bias check, we compared our sample to the hunting population. We found little difference in the representation of sex and age between the sample and the population. For example, the mean age of the population was 52 years and sample mean was 51 years, while the male-female ratio was 86:14 in the population and 82:18 in the sample. In addition, an extrapolation approach (Armstrong \& Overton, 1977; Israel, 2011) was used to compare the profiles of the hunters who responded before the second follow up survey $(n=$ $236)$ with the hunters who responded after second follow up survey $(n=124)$. There were no significant differences in the profiles of the two groups. Finally, our sample's harvesting success rate $(35 \%)$ was within the forecasted deer harvesting success rate range of 26-37\% for the years 1992 to 2003 (ODFW, 2011). After 2003, harvesting success rate survey was not conducted. These results suggested there were little or no differences between respondents and non-respondents.

Reliability of the items and scales used for measuring the TPB concepts were examined by calculating of Cronbach's alpha. Structural equation modeling (SEM) was used to assess the fit of the model with the data in Analysis of Moment of Structures (AMOS). Confirmatory factor analysis (CFA) was used to assess the observed-latent variables relationships. A structural model assessment was performed by calculating path coefficients (regression weights) using maximum likelihood estimates (MLE). The fit of the measurement model and structural model was assessed using Chi-square fit index. However, because of the high sensitivity of the Chi-square to sample size (Garson, 2011), five other popular goodness of fit measures were applied (Arbuckle 2006; Jaccard \& Wan 1996; Kline 1998). These measures included CMIN/DF ratio, baseline comparisons like Comparative Fit Index (CFI), Normed Fit Index (NFI), and the Standardized Root Mean Square Residuals (SRMR) and Root Mean Square Error of Approximation (RMSEA). 
According to Kline (1998), a CMIN/DF ratio of three or less is acceptable, and less than one indicative of over-fit. However, other scholars suggest values as high as five are acceptable (Schumacker \& Lomax, 2004). Likewise, SRMR and RMSEA below .08 is considered as an adequate fit and both CFI and NFI should be equal to or greater than .90 to accept the model (Garson, 2011). Path coefficients and their critical ratios (CRs - an equivalent of $t$-value for regression weights) were used for testing hypothesis at $p<.05$. A critical ratio of 1.96 indicated that the path coefficient was significant at $p<.05$.

\section{Results}

\section{Profile of the Respondents}

The respondents were predominantly male $(82 \%)$ and more than half of the respondents $(55 \%)$ were 51 years of age or older. On average, the respondents had been hunting in Oregon for nearly 27 years and had participated in hunting for more than 29 years. The number of days per year spent deer hunting has declined at least by one day during the period of 2004 to 2008 (from 11.4 days to 10.1 days). About one-third (35\%) reported harvesting one or more bucks or does during 2008. Harvesting deer for meat and trophy was the most important motivation of hunting participation (45\%), followed by enjoying nature/open space (25\%), spending time with family and friends (18\%), and challenge of hunt (11\%). The quality of experience (6-point scale: "1" = "worst" and "6" = "excel-lent") indicated that the quality of hunting experience in Oregon during the year 2008 was between fair to good (mean 2.9). Some respondents (8\%) who hunted deer in 2007 did not participate in deer hunting in 2008. We noted a significant difference in the number of respondents who hunted deer during the years 2007 and $2008\left(\chi^{2}=59.100, p=.001\right)$. Also, $45 \%$ of the 2007 deer hunters hunted other big game (elk and/or bear) in 2008, in addition to deer. These dynamics suggest lower expectations may be related to the low hunting success rate, low deer population, reduced access to hunting areas that were previously open for hunting, and too many hunters were the main reasons for the lower quality of experience.

\section{Model Assessment}

Cronbach's alpha calculated for intentions, attitudes, subjective norms, and PBC were $.95, .91, .82$, and .90 , respectively. These reliability scores were well over Nunnally and Bernstein's (1994) recommendation of minimum value of .7 for the reliability of items used for 
measuring a multi-item construct (Table 1). Table 1 also shows the item means, factor means, and observed latent variable relationships (regression weights). The overall mean for each of the four TPB constructs were positive and cluster closely around two, suggesting hunters expressed a highly positive attitude toward participating in deer hunting in 2009. Likewise, the subjective norms of the hunters were also positive; indicating that hunters perceived most people important to them would support their participation in deer hunting in 2009. Positive means for PBC and intentions suggested that the hunters also believed that they had sufficient control over participation in deer hunting in the 2009 hunting season, and they were very positive regarding their intentions to hunt in Oregon in 2009.

Table 1: Means of hunting attitudes, subjective norms, PBC, and intentions and measurement model statistics $(n=360)$

\begin{tabular}{|c|c|c|c|c|c|c|}
\hline Factors & Items used for measuring TPB constructs & Mean & $\begin{array}{c}\text { Beta } \\
(\beta)\end{array}$ & $\begin{array}{l}\text { Critical } \\
\text { ratio }\end{array}$ & $\alpha$ & $\begin{array}{l}\text { Overall } \\
\text { mean }\end{array}$ \\
\hline \multirow{3}{*}{ Intention } & I intend to participate in deer hunting in OR in 09 & 2.29 & .935 & $1.00^{*}$ & \multirow{3}{*}{.953} & \multirow{3}{*}{$\begin{array}{l}2.15 \\
(1.45)\end{array}$} \\
\hline & I will try to participate in deer hunting in OR in 09 & 2.08 & .907 & $29.96^{* *}$ & & \\
\hline & I am planning to participate in deer hunting in 09 & 2.08 & .943 & $33.66^{* *}$ & & \\
\hline \multirow{6}{*}{ Attitude } & $\begin{array}{c}\text { Hunting deer in OR in } 09 \text { would be: } \\
\text { Unpleasant - Pleasant }\end{array}$ & 1.99 & .678 & $10.86^{* *}$ & \multirow{6}{*}{.913} & \multirow{6}{*}{$\begin{array}{l}1.64 \\
(1.37)\end{array}$} \\
\hline & $\begin{array}{l}\text { Hunting deer in OR in } 09 \text { would be: } \\
\text { Boring - Interesting }\end{array}$ & 1.62 & .855 & $12.83^{* *}$ & & \\
\hline & $\begin{array}{c}\text { Hunting deer in OR in } 09 \text { would be: } \\
\text { Unenjoyable - Enjoyable }\end{array}$ & 1.99 & .388 & $6.78^{* *}$ & & \\
\hline & $\begin{array}{l}\text { Hunting deer in OR in } 09 \text { would be: } \\
\text { Harmful - Useful (socially) }\end{array}$ & 1.54 & .908 & $13.32^{* *}$ & & \\
\hline & $\begin{array}{l}\text { Hunting deer in OR in } 09 \text { would be: } \\
\text { Harmful - Useful (healthwise) }\end{array}$ & 1.78 & .928 & $13.32^{* *}$ & & \\
\hline & $\begin{array}{l}\text { Hunting in OR in } 09 \text { would be: } \\
\text { Harmful - Useful (financially) }\end{array}$ & 0.86 & .613 & $1.00^{*}$ & & \\
\hline \multirow{4}{*}{$\begin{array}{l}\text { Subjective } \\
\text { norms }\end{array}$} & People important to me think I should hunt deer in 09 & 1.77 & .751 & $1.00^{*}$ & \multirow{4}{*}{.823} & \multirow{4}{*}{$\begin{array}{l}1.83 \\
(1.06)\end{array}$} \\
\hline & People who I value think I should hunt deer in 09 & 2.14 & .947 & $18.58^{* *}$ & & \\
\hline & People important to me support my deer hunting in 09 & 2.27 & .894 & $17.88^{* *}$ & & \\
\hline & People important to me will go deer hunting in 09 & 1.14 & .475 & $8.93^{* *}$ & & \\
\hline \multirow{3}{*}{ PBC } & I am confident that I can go deer hunting in OR in 09 & 2.05 & .892 & $1.00^{*}$ & \multirow{3}{*}{.899} & \multirow{3}{*}{$\begin{array}{l}1.81 \\
(1.43)\end{array}$} \\
\hline & If I want to go deer hunting in 09, I can go easily & 1.89 & .911 & $23.87^{* *}$ & & \\
\hline & $\begin{array}{l}\text { Factors that influence my decision to go deer hunting } \\
\text { in OR in } 09 \text {, are in my total control }\end{array}$ & 1.51 & .793 & $19.11^{* *}$ & & \\
\hline
\end{tabular}

Notes:

1. ${ }^{* *}$ Significant at the alpha level of .01 and ${ }^{*}$ significant at alpha level of .05 . 
The CFA results showed that the loading of items on their respective latent variable (attitude, subjective norms, PBC and intentions) was close to .8 or above. The critical ratio indicated that each of these observed-latent relationships was significant at $p<.05$ ( $C R$ value > 1.96). Each latent variable described a considerable amount of variation in their observed variables (Figure 1). These findings suggested the latent TPB constructs and the observed variables could be successfully used in model testing.

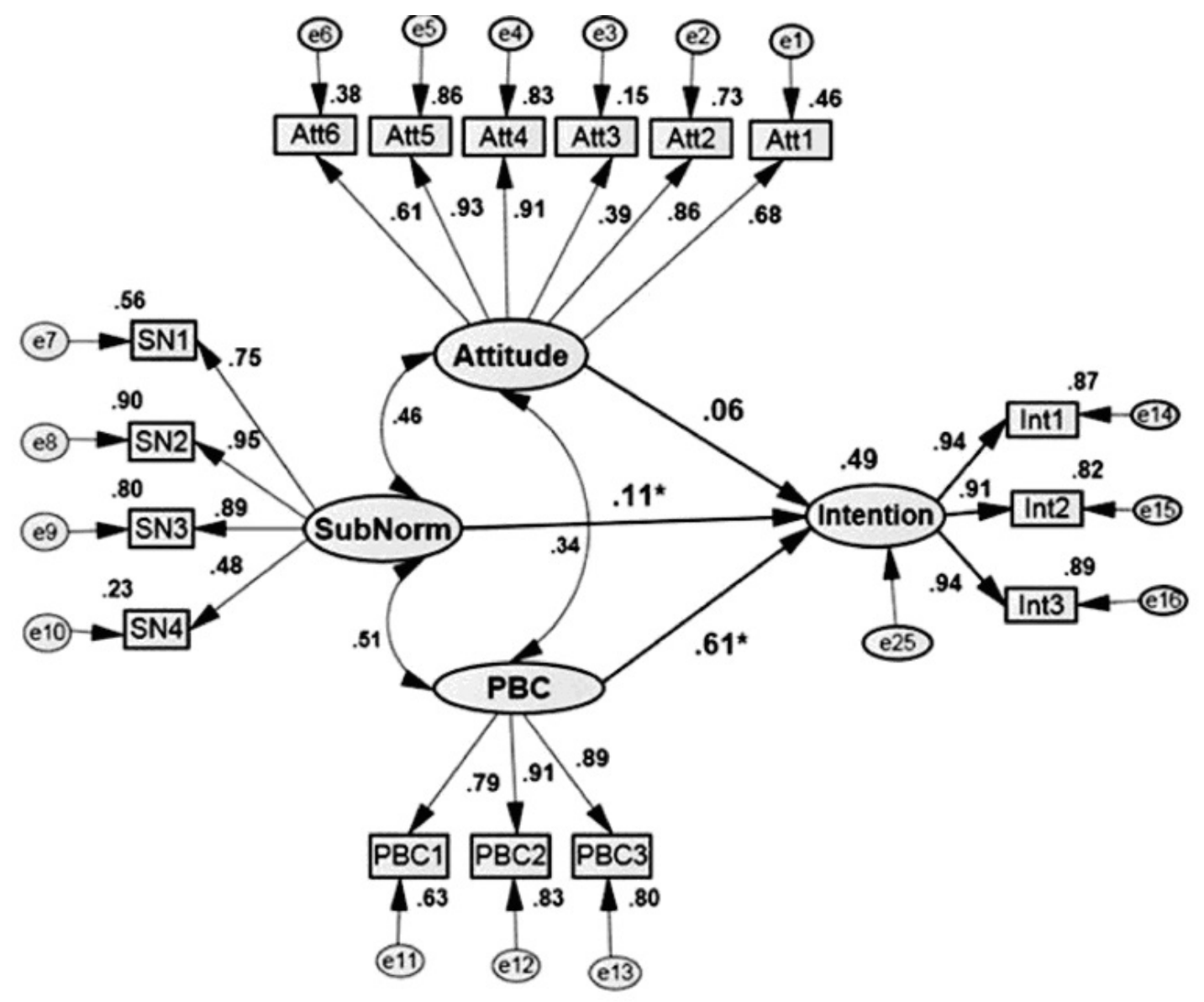

Figure 1: The relationships of the items with TPB constructs and effects of attitudes, subjective norms and $\mathrm{PBC}$ on deer hunting intentions $(n=360)$

Assessment of the Structural Model (TPB): The model assessment statistics such as CMIN/DF ratio (3.61), CFI (.94), NFI (.93), SRMR (.05), and RMSEA (.08) indicated the data 
provided a good fit to the model (Table 2). Accordingly, the hypothesis that the deer hunting intentions data fit well with the TPB model was accepted.

Table 2 also shows that the model explained $49 \%$ of deer hunting intentions. Subjective norms $(\beta=.11)$ and $\operatorname{PBC}(\beta=.61)$ had positive and significant effect on deer hunting intentions (Figure 1). These results supported the second and third hypotheses. The more peer support or encouragement the hunters received to participate in hunting and the stronger the hunters' believed that they had control over participation in hunting, the more likely they were report intentions to participate in deer hunting. The first hypothesis, that hunting attitudes were positively associated with hunting intentions, was rejected $(\beta=.059, C R=1.201, p=.230)$.

Table 2: Structural equation model assessment statistics $(n=360)$

\begin{tabular}{lllllllll}
\hline$R^{2}$ & $\chi^{2}$ (CMIN) & $d f$ & CMIN/DF & CFI & NFI & RMSEA & SRMR & Hypothesis \\
\hline .489 & 378.592 & 98 & 3.861 & .937 & .917 & .080 & .0507 & Accepted \\
\hline
\end{tabular}

\section{Discussion}

The article examined whether TPB can effectively describe specific big game hunting intentions. We found that the deer hunting intentions data fit well with the TPB model, and that the model explained $49 \%$ of variation in deer hunting intentions. This result is consistent with previous research that has shown the usefulness of the model in explaining various outdoor recreation behaviors, including general hunting (Hrubes et al., 2001) and other recreation activities (Ajzen \& Driver, 1991, 1992; Armitage \& Conner, 1999, 2001; Downs \& Hausenblas, 2005; Godin \& Kok, 1996). Armitage and Conner (1999, 2001) noted the amount of variance explained by the TPB in describing the behavioral intentions for different exercise and outdoor recreation activities ranged between 22\% and 50\%. Rossi and Armstrong (1999) also found similar results in their Alabama hunters' study, which found that attitude, subjective norms, and PBC could describe $38 \%$ of the variance in hunting intentions. This is, however, much lower than what Hrubes et al. (2001) found in their Vermont general hunters' survey. This group found that TPB model could explain $86 \%$ variance in general hunting intentions. Although, they did not discuss what could have resulted in such a large amount of variance being explained. One possible reason might be that Hrubes et al. did not focus on specific hunting activity in terms of species, place and time. Since TPB is considered to be more efficient for describing intentions and 
behaviors for specific activity; in their case, the lack of specificity might have provided the hunters the freedom to consider many game species during expressing their attitudes, subjective norms, PBC and intentions. This, in turn, might have led them to express more positive attitudes, subjective norms, $\mathrm{PBC}$, and hunting intentions based on the species they intend to hunt at any place and time; which might have inflated the amount of variance explained.

In contrast to the findings of Hrubes et al. (2001), which showed that attitudes, subjective norms, and $\mathrm{PBC}$ each had a significant effect on hunting intentions, this study found that only subjective norms and PBC had a positive and significant effect on hunters' intentions to participate in deer hunting. The nature of specificity in our study may have affected behavioral intentions. Unlike general hunting activity, which does not specify species to hunt at a specific time and place, specific hunting behavior may be not under total volitional control. "The relative importance of attitude, subjective norm, and perceived behavioral control in the prediction of intention is expected to vary across behaviors and situations ..." (Ajzen, 1991, p. 188). In situations where attitudes are strong, or where normative influences are powerful, PBC may be less predictive of intentions and vice versa. The magnitude of the PBC-intention relationship is dependent on the type of behavior and the context.

An alternative explanation might be found in the expectancy-value model (Fishbein \& Ajzen, 1975), where an individual's overall attitude, which determines intentions and behavior, depends on subjective values of the outcomes associated with the behavior and the strength of these associations. Specifically, the evaluation of each outcome contributes to the attitude in direct proportion to the person's subjective probability that the behavior produces the outcome in question. Daigle, Hrubes, and Ajzen (2002) examined the most likely outcomes of hunting and concluded that preferred activities were perceived as producing more desirable outcomes than less preferred activities, and they were associated with more favorable attitudes, subjective norms, and perceptions of control. Accordingly, our findings may indicate hunters are aware that not all of their behavioral beliefs, such as successful harvesting of deer for meat, could be met by participating in deer hunting in the upcoming year. This may explain why intentions were not adequately explained by attitudes in this study. Hini, Gendall, and Kearns (1995) suggested such relationships might be associated with the amount and quality of opportunity to perform the behaviors. People may have strong positive attitudes and beliefs, but, knowing that there are 
limited and less quality opportunities available in the specific place for specific activity, an individual's intentions might not be truly reflected by his/her attitudes and beliefs. The findings of the descriptive analyses in our study also provided some evidences to support this view. The sample respondents reported the lack of access and poor quality of game as the primary reasons for the lower quality of experience. As a second alternative explanation, deer hunting may be a social or familial related behavior in which people are interested to participate in, despite knowing that most of their beliefs will not be fulfilled. Finally, it might be also related to the measure that was used for identifying attitudes. We replicated the measures of attitudes from exercise and other outdoor recreation studies, and these measures may not truly reflect deer hunting attitudes.

\section{Implications}

The findings of this study are relevant to both researchers and managers. For researchers, the findings demonstrate that the theory of planned behavior offers considerable power in predicting and explaining participation in hunting intentions. This TPB model provides a method of understanding why people participate in deer hunting in different places and situations. This study did not incorporate actual or reported behavior. The effectiveness of the model in predicting these latter constructs in future studies is encouraged. Unlike general hunting behavior, deer hunting may not be completely volitional. Subjective norms and perceived behavioral control play important roles in determining deer hunting intentions. We used a direct measure of attitude, subjective norms and PBC replicated from other outdoor studies. Future research may consider using more comprehensive measures that involve measuring attitude as a product of behavioral beliefs and outcomes evaluation, subjective norms as a product of normative beliefs and motivation to comply, and PBC as a product of control beliefs and control belief strength. Use of such a comprehensive measure might provide further insights to this phenomenon, including the role of attitudes.

For resource managers, the positive intentions of respondents to participate in hunting during the upcoming hunting season may be encouraging, as intentions have been well recognized as indicators of future participation. The challenge for resource managers is to recognize potential hunters' positive intentions and initiate programs and strategies that may enhance the PBC of hunters. This may be achieved by addressing internal resources issues (e.g., skill 
development) and external resources (e.g., enhancing hunting opportunities, game population, and abundance of game). Initiatives in these areas could help to motivate hunters who have positive intentions to participate in hunting in future seasons. Significant positive effects of PBC on deer hunting intention also convey similar meanings to resource managers. This is particularly germane because hunting site related limitations and/or constraints are not under volitional control of the hunters. It is the resource managers who have control of these external resources, although long standing budgetary constraints may limit success in this area. 


\section{References}

Aiken, R., \& Harris, A. (2011). Deer hunting in the United States: Demographics and trends. Addendum to the 2006 national survey of fishing, hunting, and wildlife-associated recreation. Report 2006-10. Retrieved from http://library.fws.gov/Pubs/deerhunting_natsurvey06.pdf

Ajzen, I. (2002). TPB questionnaire construction: constructing a theory of planned behavior questionnaire. Revised in 2006. Retrieved from http://www.people.umass.edu/aizen/pdf/tpb.measurement.pdf

Ajzen, I. (1991). The theory of planned behavior. Organizational Behavior and Human Decision Processes, 50, 179-211.

Ajzen, I., \& Driver, B. (1991). Prediction of leisure participation from behavioral, normative and control beliefs: An application of theory of planned behavior. Leisure Sciences, 13, 185204.

Ajzen, I., \& Driver, B. (1992). Application of theory of planned behavior to leisure choice. Journal of Leisure Research, 24(3), 207-224.

Ajzen, I., \& Fishbein, M. (1980). Understanding attitude and predicting social behavior. Englewood Cliffs, NJ: Prentice-Hall.

Arbuckle, J. (2006). Amos 7.0 User's Guide. Amos Development Corporation. PA: Spring House.

Armitage, C. J., \& Conner, M. (1999). The theory of planned behaviour: Assessment of predictive validity and perceived control. British Journal of Social Psychology, 38, 35-54.

Armitage, C. J., \& Conner, M. (2001). Efficacy of the theory of planned behaviour: A metaanalytic review. British Journal of Social Psychology, 40, 471-499.

Armstrong, J. S., \& Overton, T. S. (1977). Estimating nonresponse bias in mail surveys. Journal of Marketing Research, 14, 396-402.

Conner, M., \& Armitage, C. J. (1998). Extending the theory of planned behavior: A review for further research. Journal of Applied Social Psychology, 28(15), 1429-1464. 
Daigle, J., Hrubes, D., \& Ajzen, I. (2002). A comparative study of beliefs, attitudes, and values among hunters, wildlife viewers, and other outdoor recreationists. Human Dimensions of Wildlife, 7, 1-19.

Dean Runyan Associates. (2009). Fishing, hunting, wildlife viewing, and shellfishing in Oregon 2008: State and county expenditure estimates. Report Prepared for Oregon Department of Fish and Wildlife. Portland, Oregon.

Downs, D. S., Graham, G. M., \& Yang, S. P. (2006). Youth exercise intention and past exercise behavior: Examining the moderating influences of sex and meeting exercise recommendations. Research Quarterly for Exercise and Sport, 77(1), 91-99.

Downs, D. S., \& Hausenblas, H. A. (2005). Applying the theories of reasoned action and planned behavior to exercise: A meta-analytic update. Journal of Physical Activity and Health, 2, 76-97.

Fishbein, M., \& Ajzen, I. (1975). Belief, attitude, intention, and behavior: An introduction to theory and research. Reading, MA: Addison-Wesley.

Garson, G. D. (2011). Structural equation modeling. Statnotes: Topics in Multivariate Analysis. Retrieved from http://faculty.chass.ncsu.edu/garson/pa765/statnote.htm.

Godin, G., \& Kok, G. (1996). The theory of planned behavior: A review of its applications in health-related behaviors. American Journal of Health Promotion, 11, 87-98.

Hammitt, W. E., McDonald, C. D., \& Patterson, M. E. (1990). Determinants of multiple satisfaction for deer hunting. Wildlife Society Bulletin, 18, 331-337.

Hini, D., Gendall, P., \& Kearns, Z. (1995). The link between environmental attitudes and behavior. Marketing Bulletin, 6, 22-31.

Hrubes, D., Ajzen, I., \& Daigle, J. (2001). Predicting hunting intentions and behavior: An application of the theory of planned behavior. Leisure Sciences, 23, 165-178.

Israel, G. D. (2011). Sampling issues: Nonresponse. PEOD9. Gainesville, FL: Agricultural Education and Communication Department, University of Florida. Retrieved from http://edis.ifas.ufl.edu/pd008 .

Jaccard, J., \& Wan, C. K. (1996). LISREL approaches to interaction effects in multiple regression. Thousand Oaks, CA: Sage Publications. 
Kline, R. B. (1998). Principles and practices of structural equation modeling. New York, NY: Guilford Press.

Manfredo, M. J., \& Larson, R. A. (1993). Managing for wildlife viewing recreation experiences: An application in Colorado. Wildlife Society Bulletin, 21, 226-236.

Manfredo, M. J., Vaske, J. J., \& Decker, D. J. (1995a). Human dimension of wildlife management: Basic concepts. In R. L. Knight \& K. J. Gutzwiller (Eds.), Human dimension in wildlife programs (pp. 62-71). Washington, DC: Mercury Press.

Manfredo, M. J., Vaske, J. J., \& Decker, D. J. (1995b). Human dimension of wildlife management: Basic concepts. In R. L. Knight \& K. J. Gutzwiller (Eds.), Wildlife and recreationists: Coexistence through management and research (pp. 17-31). Washington, DC: Mercury Press.

Nunnally, J., \& Bernstein, I. (1994). Psychometric theory. New York, NY: McGraw-Hill.

ODFW. (2011). 2010 Big game statistics. Salem, OR: Oregon Department of Fish and Wildlife. Retrieved from http://www.dfw.state.or.us/resources/hunting/big_game/controlled_hunts/docs/hunt_stati stics/10/2010_big_game_statistics.pdf.

Responsive Management. (2008a). The future of hunting and the shooting sports: Researchbased recruitment and retention strategies. Harrisonburg, VA: Responsive Management/NSSF.

Responsive Management (2008b). Increasing hunting participation by investigating factors related to hunting license sales increases in 1992, 1999, and 2004 against 13 other years of hunting license sales decline between 1990-2005. Harrisonburg, VA: Responsive Management.

Rossi, A. N., \& Armstrong, J. B. (1999). Theory of reasoned action vs. theory of planned behavior: Testing the suitability and sufficiency of a popular behavior model using hunting intentions. Human Dimensions of Wildlife, 4, 40-56.

Schumacker, R. E., \& Lomax, R. G. (2004). A beginner's guide to structural equation modeling, second edition. Mahwah, NJ: Lawrence Erlbaum Associates. 


\title{
CHAPTER 3: Article 2
}

The Role of Elements of Theory of Planned Behavior in Mediating the Effects of Constraints on Intentions: A Study of Oregon Big Game Hunters

\author{
Suresh K. Shrestha \\ Robert C. Burns \\ Jinyang Deng \\ John Confer \\ Alan R. Graefe \\ Elizabeth A. Covelli
}

(This Article was published in Journal of Park and Recreation Administration in Volume 30, Number 2, Summer 2012)

\section{Executive Summary}

This study aimed to explore the degree to which the antecedents of the theory of planned behavior (TPB) (i.e., attitude, subjective norms, and perceived behavioral control [PBC]) mediated the relationship of hunting constraints with deer hunting intention. The data were collected using a mail back survey in 2009. The sample consisted of 359 hunters randomly selected from the list of the hunters who had purchased an Oregon big game (deer, elk, and/or bear) hunting license in 2008. The TPB elements exhibited moderate to strong negative correlations with the four constraint dimensions (site and management; partner and health; skill and confidence; and time, distance, and money), except for the correlation between subjective norms and partner and health. The mediation analysis showed that constraints affected deer hunting intention directly and indirectly through the elements of the TPB, especially the PBC. Management implications suggested in the manuscript include the possibility of reducing the impacts of constraints on hunting intention, by enhancing level of confidence (PBC) of the hunters through methods such as skill enhancement training, increasing harvesting success through game population management, and extending hunting opportunities in public and private lands. We also suggest the development of promotional programs targeting women and minorities. Future research might focus on extending the TPB by integrating constraints to offer a more practical dimension to the TPB. Conversely, constraint research may examine the role of attitude, subjective norms, and PBC on constraint negotiation.

Keywords: Theory of Planned Behavior, Deer Hunting, Constraints, Hunting Participation, Mediation Effects 


\section{Introduction}

The TPB model, proposed by Ajzen (1991), states that an individual's participation in a behavior depends on the intention of the person to participate in that behavior, and the intentions themselves depend on attitudes, subjective norms, and perceived behavioral control (PBC) the person is believed to have on the behavior (Ajzen, 1991). The constraints negotiation model (Jackson et al., 1993), on the other hand, proposes a person's eventual leisure behavior depends upon the successful negotiation of the constraints, which are organized in a sequential manner.

Mannell and Kleiber (1997) suggested that the attitudes, subjective norms, and PBC could affect the formation of leisure preference (the immediate descriptor of participation in the constraints theory). Similarly, Wigfield and Eccles (2000) also suggested that choice, preference, and performance of the individuals can be explained by their beliefs (e.g., attitudes, subjective norms, and PBC) about how well they succeed in that activity and the extent to which they value the activity. These arguments indicate that the TPB elements (attitude, subjective norms, and $\mathrm{PBC}$ ) have relationships with constraints that determine preference and participation. On the other hand, Ajzen (1988) claimed that the effects of non-TPB variables on behavioral intention are likely to be mediated by the antecedents of the intention (i.e., attitudes, subjective norms, and $\mathrm{PBC})$. If the above suggestions are true, the relationship of constraints with behavior intentions might be also mediated by TPB elements. However, there have been very limited attempts to investigate the relationships of the constraints with the variables related to the attitudinal models describing participation (Hubbard \& Mannell, 2001), including the intention and its predictors (attitudes, subjective norms, and PBC) of the TPB (Walker, Jackson, \& Deng, 2007).

An attempt made by Alexandris and Stodolska (2004) to establish the relationships between constraints and TPB predictors showed that the attitudes, subjective norms, and PBC have negative relationships with the perceived leisure constraints. Another study by Alexandris, Barkoukis, and Tsormpatzoudis (2007) found these attitudinal variables mediated the relationships of different constraint dimensions with behavioral intention to participate in physical exercise. How these relationships hold true for outdoor recreational activities, including hunting, has been not yet tested. Accordingly, the aim of the present study was to test the degree to which the elements of the theory of planned behavior act as mediators of the relationship between constraints and intention to participate in deer hunting. More specifically, we examined 
the mediating role of the elements of the theory of planned behavior on the relationships of four different constraint dimensions (site and management; health and partner; confidence and skill; and time, distance, and money) with deer hunting intention. The hypotheses we examined were (a) each of the four constraint dimensions have significant negative relationships with deer hunting attitudes, subjective norms, PBC, and intention; (b) attitudes mediate the effects of four constraint dimensions on deer hunting intention; (c) subjective norms mediate the effects of four constraint dimensions on deer hunting intention; and (d) PBC mediates the effects of four constraint dimensions on deer hunting intention.

\section{Literature Review}

\section{Theory of Planned Behavior}

The theory of planned behavior (Ajzen, 1991) is an extension of the theory of reasoned action (Ajzen \& Fishbein, 1980). The theory states that an individual's participation in a specific behavior depends on the intention of the person to engage in that behavior. Intention, in turn, could be determined by (a) the individual's attitudes toward the behavior, (b) the influence of subjective norms (perceived social norms) toward the behavior, and (c) the influence of perceived level of control (PBC) on the behavior. According to Ajzen (1991), attitudes are the affective and instrumental evaluations of performing a behavior by an individual, based on his/her behavioral beliefs concerning the consequences of engaging in the behavior. Subjective norms are the perceived social pressures on the individual to perform or not to perform a particular behavior. The PBC reflects an individual's perceptions about her/his capability of successfully engaging in the behavior (Ajzen, 1985) and is represented by the perceptions of whether the behavior can be performed both in terms of self-efficacy (easy or difficult) and controllability (perceived extent of control: a little or a lot) taking into account the individual's perception of skills, resources, and opportunities needed to perform a behavior (Ajzen, 1991). The PBC component was introduced to address the criticism that not all human behaviors are under the degree of volitional control (Ajzen, 1985, 1988; Ajzen \& Madden, 1986).

The TPB has been applied to a variety of behavior studies and has received widespread support in recent years. A variety of meta-analytic reviews (Armitage \& Conner, 1999, 2001; Conner \& Armitage, 1998; Downs \& Hausenblas, 2005a, 2005b; Godin \& Kok, 1996) across 
health, leisure, and recreation behaviors have provided strong evidence on the ability of the theory in predicting behavioral intention and participation. These reviews showed that the TPB model has been widely used in the field of leisure and outdoor research. The same manuscripts showed that intention was a strong and reliable predictor of recreation activity participation. This body of work further showed that the TPB model described $39 \%$ to $55 \%$ of the variation in behavioral intention and $27 \%$ to $51 \%$ of variations in the reported or observed participation in a variety of recreation activities. Downs, Graham, and Yang (2006) found that attitude, subjective norms, and $\mathrm{PBC}$ could predict $55 \%$ of the variance in intentions, and intention and $\mathrm{PBC}$ could explain 51\% variance in past exercise behavior. Armitage and Conner (2001) noted that TPB accounted for $39 \%$ variance in intentions and $27 \%$ of variance in behavior when behavior measures were self-reported.

These studies also showed that attitudes, subjective norms, and PBC were positively related to intention and reported or observed behaviors. Among the three predictors, PBC was a consistent and strong predictor of both behavioral intention and participation. The role of the attitudes and subjective norms depended on the type of behavior and strength of measure of normative components.

Two studies also used the TPB model to describe hunting behavior (Hrubes, Ajzen, \& Daigle, 2001; Rossi \& Armstrong, 1999). The study conducted by Hrubes et al. (2001) found that attitudes, subjective norms, and PBC contributed $93 \%$ in explaining behavioral intention of hunting, while intention described $62 \%$ variations in hunting participation. The study of Rossi and Armstrong (1999), however, found that the TPB model could explain 38\% of the variance in hunting intention. However, neither of the hunting studies examined the claim of Ajzen (1988) that the effects of non-TPB variables (such as constraints) on intention are mediated by the TPB predictors.

\section{Constraints Model}

Constraints models are often found in the leisure participation literature, where constraints have been defined as "the factors that are assumed by researchers and perceived by individuals to inhibit or prohibit participation and enjoyment in leisure" (Jackson, 2000, p. 62). The term constraints includes not only the physical and external-to-the-individual constraints 
such as facility problems, but it also includes social constraints such as the lack of partner and psychological constraints such as confidence, fear, and perceived skills (Jackson \& Scott, 1999). It has been argued that the social and psychological constraints have a direct influence on an individual's preference for a specific activity (Crawford, Jackson, \& Godbey, 1991).

Crawford and Godbey (1987) categorized constraints into intrapersonal, interpersonal, and structural constraints. Intrapersonal constraints are "internal" to an individual and are mainly related to the psychological states and attributes, such as lack of skills and perceived health problems. Interpersonal constraints are related to an individual's inability to find partners with whom to participate. Structural constraints are "external to an individual" and include factors related to lack of resources, facility, and financial problems. Crawford et al. (1991) proposed that these constraints are encountered hierarchically. Jackson, Crawford, and Godbey (1993) proposed that the constraints do not always lead to nonparticipation, rather the final outcomes (participation, nonparticipation, modified participation), in a large degree, depend upon the negotiation of these constraints with the development of appropriate strategies. The review of constraint research by Godbey, Crawford, and Shen (2010) and Jackson (2000) has found evidence in support of negotiation of leisure constraints and showed many individuals were participating in leisure activities (modified participation) even in the presence of constraints (e.g., Burns \& Graefe, 2007; Carroll \& Alexandris, 1997; Hubbard \& Mannell, 2001; Scott \& Jackson, 1996; Son, Kerstetter, \& Mowen, 2008; Walker et al., 2007).

The efforts of works by Godbey et al. (2010) and Jackson (2000) also identified several dimensionality and measurement issues with constraint research, including the low internal reliability of the constraints dimensions. This was related to the differing nature of physical activities, the various characteristics of the study population (age, gender, physical or mental ability, family lifecycle, ethnicity, cultural practices, etc.), and the different stages of participation (starting a new leisure activity, pursuing higher or desired levels of specialization or quality of experience, etc.).

Like the TPB, constraints research also recognizes that leisure behaviors are not always under a degree of volitional control (Jackson \& Scott, 1999; Smith \& Biddle, 1999). In other words, if the activity is more strenuous, demands more time and resources, and requires special 
training and skills, volitional control will be reduced, and the individual may perceive constraints.

\section{Constraints and TPB Components Relationships}

There seems to be relationships between the three constructs of TPB and three types of constraints. For example, the attitudes concept seems related to the intrapersonal constraints in the sense that both represent an internal dimension of an individual. Likewise, subjective norms seem related to the interpersonal constraints. This occurs because both factors address the social interaction. In addition, PBC may be related to the structural constraints, as both factors are related to perception about resources and skill. The possible conceptual relationships among these variables have been suggested by many scholars (Hubbard \& Mannell, 2001; Vallerand \& Losier, 1999; Walker et al., 2007; Wigfield \& Eccles, 2000). For example, Mannell and Kleiber (1997) suggested that the attitudes, subjective norms, and PBC could affect the formation of leisure preference, which depends on intra- and interpersonal constraints. Wigfield and Eccles (2000) and Eccles et al. (1983) suggested that choice, preference, and performance of individuals can be explained by their beliefs (e.g., attitudes, subjective norms, and PBC). Walker et al. (2007) expressed concern over isolating intrapersonal constraints from other psychological factors such as attitude, subjective norms, and PBC. If the above suggestions are true, leisure constraints (especially intrapersonal constraints) should be a construct similar to attitudes, subjective norms, and PBC and should help to explain intention.

Furthermore, many authors have empirically verified and explained the constraints negotiation strategies and explored the influence of motivation on negotiation and perceived constraints (Alexandris, Tsormpatzoudis, \& Grouios, 2002; Carroll \& Alexandris, 1997; Hubbard \& Mannell, 2001; Koca, Henderson, Asci, \& Bulgu, 2009; Livenwood \& Stodolska, 2004; Walker et al., 2007). Vallerand and Losier (1999) suggested that social factors and psychological mediators, including attitudes, values, and beliefs, serve as a force for intrinsic and extrinsic motivations whose influence on constraint negotiation has already been established. Parallel to this view, Hubbard and Mannell (2001) and Jackson and Rucks (1995) argued that personal control factor, a construct similar to $\mathrm{PBC}$, may play a role in constraints negotiation. This would mean that the TPB predictors also might explain constraint negotiation through motivations. 
Despite these suggestions, there have been very limited attempts to investigate the relationship between constraints and variables related to attitudinal models describing participation (Hubbard \& Mannell, 2001; Walker et al., 2007). Dawson, Gyurcsik, Culos- Reed, and Brawley (2001) made one of the first attempts to examine the relationship between PBC and constraints. They found that the power of PBC in the TPB is related to the perceived resources (e.g., time, money, skills, and cooperation of other people) that an individual possesses, the existence or absence of perceived constraints, and perceived ability to overcome those constraints. This result supported Ajzen and Driver's (1991) view that the perceptions of presence and strength of internal and external constraints decrease the intensity of the PBC. Alexandris, Barkoukis, Tsormpatzoudis, and Grouios (2003) provided evidence of the negative impact of constraints on intention to participate in physical activities. A similar study by Alexandris and Stodolska (2004) found negative relationships between the attitudinal variables included in the TPB with the perceived leisure constraints, but they did not clarify if the elements of the TPB mediated the constraints- intention relationship. Recently, Alexandris et al. (2007) found that the predictors of the TPB mediated the relationships of different constraints dimensions with behavioral intention. However, their findings are still far from conclusive, primarily because there are few other studies about outdoor recreation activities such as hunting to verify these relationships.

\section{Mediation Effect Analysis}

In statistics, mediation is a method used by researchers to explain the process or mechanism by which one variable affects another (MacKinnon, Fairchild, \& Fritz, 2007). Psychologists often conduct research to establish whether and to what extent one variable affects another. However, the discovery that two variables are related to each other is only one small aim of psychology. Deeper understanding is gained when we comprehend the process that produces the effect (Preacher \& Hayes, 2004). For example, it might be useful to know whether a training program leads to an increase in employee satisfaction by affecting employee attitudes toward job and/or by changing behavioral habits. In this example, attitudes and habits are potential mediators of the relationship between the training program and employee satisfaction. Mediation in its simplest form represents the addition of a third variable called mediator (M) between an independent variable (X) and dependent variable (Y), and the relationship is shown 
as $\mathrm{X} \rightarrow \mathrm{M} \rightarrow \mathrm{Y}$. However, in addition to the $\mathrm{X} \rightarrow \mathrm{M} \rightarrow \mathrm{Y}$ mediation relationship, an incomplete mediation may also include a direct line between $\mathrm{X}$ and $\mathrm{Y}$.

A mediating variable is different from a confounding variable $(Z)$ in the sense that a confounding variable affects both $\mathrm{X}$ and $\mathrm{Y}$, and ignoring $\mathrm{Z}$ leads to incorrect inference about the relation of $\mathrm{X}$ and $\mathrm{Y}$. In one situation, $\mathrm{Z}$ may be related to $\mathrm{X}$ and/or $\mathrm{Y}$, so that information about $\mathrm{Z}$ improves prediction of $\mathrm{Y}$ by $\mathrm{X}$, but does not substantially alter the relation of $\mathrm{X}$ to $\mathrm{Y}$. This is an example of a covariate. In another situation, $\mathrm{Z}$ may also modify the relation of $\mathrm{X}$ to $\mathrm{Y}$ such that the relation of $\mathrm{X}$ to $\mathrm{Y}$ differs at different values of $\mathrm{Z}$. This is an example of a moderating or interaction effect. The distinction between moderating and mediating variables has been an ongoing topic of research (Baron \& Kenny, 1986; Kraemer, Stice, Kazdin, Offord, \& Kupfer, 2001). A mediator is a variable that is in a causal sequence between two variables, whereas a moderator is not part of a causal sequence between the two variables. More detailed definitions of these variables in a three-variable system may be found in Robins and Greenland (1992).

\section{Methods}

\section{Survey and Instruments}

A self-administered mail back survey was conducted in August and September 2009 with 2,000 Oregon big game (deer, elk, and bear) hunters using Dillman's (2000) Tailored Design Method. A sample of names and addresses was randomly selected from an extensive database $(N=$ 250,000) provided by the Oregon Department of Fish and Wildlife (ODFW). The database included the names and addresses of hunters who purchased the big game hunting license for the 2008 hunting season. A pre-study postcard was sent to each selected respondent. The surveys (containing a cover letter, a survey instrument, and a self-addressed stamped envelope) were mailed from a major research university mail center, with no reference to ODFW included on the envelope. Post-survey cards were mailed to non-respondents requesting that they respond. The response rate was 20\% (Table 1). The relatively low response rate in this case might be attributed to the fact that only two reminder requests were mailed (one without replacement questionnaire and a second one with replacement questionnaire) in a 15-day period. Dillman (2000) suggested incentives and one additional contact with non-respondents via certified mail or its alternative. These steps may have had a substantial effect on response rate. 
Table 1: Sampling and response rate

\begin{tabular}{ccccc}
\hline $\begin{array}{l}\text { Number of surveys } \\
\text { mailed }\end{array}$ & $\begin{array}{l}\text { Number of surveys } \\
\text { returned due to incorrect } \\
\text { addresses }\end{array}$ & $\begin{array}{l}\text { Number of } \\
\text { respondents } \\
\text { received survey }\end{array}$ & $\begin{array}{l}\text { Number of } \\
\text { completed surveys }\end{array}$ & $\begin{array}{l}\text { Response } \\
\text { rate }\end{array}$ \\
\hline 2000 & 193 & 1807 & 359 & $20 \%$ \\
\hline
\end{tabular}

The survey questions were related to the characteristics of the respondents, values, motivations of participation in hunting, quality of experience, and concepts related to the TPB model and hunting constraints. The TPB constructs were measured with multiple items and a 7point semantic differential scale developed by Ajzen and Driver (1992), ranging from 1 (strong disagreement/negative feeling) to 7 (agreement/positive feeling). Following the suggestion of Ajzen (2002), the items were rephrased to represent participation in deer hunting in Oregon in the 2009 hunting season. Hunting intention (measured with three items) was treated as respondents' conscious plan or decision to participate in deer hunting in Oregon during the 2009 hunting season. Attitude toward hunting (measured with six items) reflected a person's evaluation of the benefits (affective and instrumental) of participation in deer hunting in Oregon in 2009. Subjective norms (measured with four items) represented respondents' perceptions about what other people important to him/ her think about his/her participation in deer hunting in Oregon during the 2009 hunting season. The PBC (measured with three items) characterized a person's perceived level of confidence to participate in deer hunting in Oregon in the 2009 hunting season, taking account of all non-volitional forces, including resources and skills.

Hunting constraints were measured by asking the perceived frequency for 25 constraints items that they may face regarding hunting in Oregon. A 5-point scale, developed by Shinew, Floyd, and Parry (2004), ranging from 1 (never/not at all) to 5 (always/a lot) was used to measure the hunting constraints. Twenty-two of the constraint items were adopted from Shinew et al. (2004) and Burns and Graefe (2007), and three were added from hunting literature (Woods \& Kerr, 2010).

Due to the absence of population data for comparing TPB and constraint items, nonresponse bias was examined using an extrapolation method as suggested by Armstrong and Overton (1977). This method assumes that subjects who respond less readily are similar to nonrespondents. Less readily has been defined as answering later or requiring more probing. The 
most common type of extrapolation is carried out over successive waves of a questionnaire survey, which refers to the response generated after follow-up postcards. Accordingly, we used Pearson's Chi-square and independent sample t-tests, as appropriate, to compare the profiles, number of years hunting, quality of experience, and means for dependent and independent variables between the hunters who responded before the second follow-up survey $(n=236)$ and hunters who responded after the second follow-up survey $(n=124)$. There were no significant differences between groups in the profiles and means of responses to TPB-related questions. In addition, we also compared representation of sex and age in the sample with the population and found no significant difference. For example, the mean age of the population was 52 years, the sample mean was 51 years, and the male-female ratio was $86: 14$ in the population and 82:18 in the sample. These results suggested little or no differences between respondents and nonrespondents. Accordingly, no adjustments were made to the data to address the issue.

\section{Data Analysis}

IBM SPSS, Version 19 was used for descriptive and inferential analysis of the data. Principal component analysis (PCA) method of factor analysis using varimax rotation was applied to identify constraint dimensions. It was followed by a reliability test of the measurement scales by calculating Cronbach's $\alpha$. The PCA of the 25 constraint items produced an awkward combination of items grouped around seven dimensions that explained about 57\% variance of the construct. Later, we adopted the communalities criteria, and each item having communalities extraction values below 3 were excluded. The five removed items were "like to do other things for recreation," "don't like to do things in outdoor," "sites are closed," "feeling of unwelcome by ranger/staff," and "racial conflicts among users." After removing the five items, PCA was rerun, producing four constraints dimensions.

A series of correlation and multivariate regression analyses were conducted to examine the mediating role of the TPB predictors. For this purpose, indexes were calculated for each construct by summing total item score for the respective construct and dividing it by the number of items for that construct. For example, to create the intention index, the scores for three intention items were summed and divided by 3 . 
Mediation effect analysis was performed using criteria as suggested by Baron and Kenny (1986, p. 1176). These authors suggest "a variable may be called a mediator, to the extent that it accounts for the relation between the predictor and the criterion." They proposed that mediation is supported when the following four criteria are satisfied: (a) a significant correlation between the dependent and independent variables, (b) a significant correlation between the independent variables and the mediators, (c) the mediators should have a significant unique effect on the dependent variable when they are included alongside the independent variable in a multivariate test of these relationships, and (d) the effect of the independent variable on the dependent should be significantly attenuated or nullified when the mediators are included as independent predictors of the dependent variable. Pearson's correlation was used to examine the first and second criteria. First, correlation of the constraints dimensions were examined with intention (dependent variables) and then among the four constraints dimensions with attitudes, subjective norms, and PBC (mediators). The third criterion was examined by conducting a series of separate multivariate regression analyses, in which attitude, subjective norms, and PBC (mediators) and constraint dimensions (independent variables) that passed the first and second criteria were regressed on intention. The assessment of the fourth criterion involved two sets of regression analyses. In the first set of analysis, intention was regressed on each of the four constraint dimensions separately. In the second set, stepwise regression was conducted in which one mediator, for example attitudes, was entered in the first step and four constraints dimensions in the second step, in four separate regression analysis. The same procedure was repeated for examining the third and fourth criteria for subjective norms and PBC.

\section{Results}

\section{Profile of the Respondents}

The respondents were predominantly male (82\%) and white (98\%). The mean age of the respondents was 50 years, while the presence of young respondents (aged 20 or below) was less than 5\%. On average, the respondents have been hunting in Oregon for nearly 27 years, and most of them had been hunting for more than 29 years (median $=29$ ). Harvesting deer was the major motivation of big game hunting for the greatest proportion (45\%) of respondents, followed by time with family/friends (18\%) and solitude/escape from crowd or normal life. The harvesting success rate of deer hunters for the year 2008 was very low (38\%). The quality of hunting 
experience, measured on a 6-point scale $(1=$ worst to $6=$ excellent $)$ indicated that the hunters were somewhat dissatisfied with their current big game experience in Oregon (mean = 2.81). Results of the t-test analysis showed that the mean scores of the quality of experience of the hunters who successfully harvested one or more deer (mean $=3.58)$ were significantly higher than those who did not harvest any deer $($ mean $=2.43)$ at a confidence interval of $(t=7.624, p=.000)$. The hunters reported that low deer population, reduced access, too many hunters, and increase in predator population were the important reasons of lower harvesting success.

\section{TPB Components}

Factor analysis of the scale measuring the TPB variables indicated the existence of four distinct dimensions, precisely representing the four TPB components (i.e., attitudes, subjective norms, PBC, and intention) and explained nearly $78 \%$ of the total variance. The loadings of the items included in each component were close to .700 or higher (Table 2). The Cronbach's $\alpha$ for the subscales were also very high ( 0.953 for intention, 0.913 for attitudes, 0.899 for PBC, and .823 for subjective norms).

In general, the respondents possessed very positive attitudes toward participating in deer hunting (mean attitude index $=5.59$ ) in Oregon during the 2009 hunting season (Table 2). The perceived influence of significant others on their decision to participate in deer hunting was also very positive (mean subjective norms index $=5.81$ ). The hunters believed that they have higher levels of control over their ability to participate in deer hunting (mean PBC index $=5.80$ ). Most important, the hunters expressed a highly positive intention to participate in deer hunting in the 2009 hunting season in Oregon (mean intention index $=6.11$ ).

\section{Hunting Constraints}

The factor analysis, after removing the five items, produced four constraint dimensions (factors), which explained about 55\% of the variance. The reliability (Cronbach's $\alpha$ of the four constraint dimensions) was close to .70 or above (Table 3 ). These four constraint dimensions were somewhat consistent with previous constraints literature, representing the three types of constraints (intrapersonal, interpersonal, and structural) as suggested by Crawford and Godbey (1987). The first dimension was skill and confidence, consisting of six psychological (internal to the person) items representing intrapersonal constraints, for example, "lack of self-confidence" 
and "fear of sexual assault." The second dimension was partner and health. It consisted of three items representing a mix of interpersonal and intrapersonal constraints, such as "your physical health," "physical health of partner," and "don't have anyone to go with." The third and fourth dimensions represented two sub-dimensions of structural constraints, namely, site and management dimension and time, money, and distance dimension. The site and management dimension included six items, for example, "sites too crowded," "lack/difficulty to find deer," and "inadequate facilities," while the time, money, and distance dimension included five items, such as "lack of time," "lack of transportation," "sites far away," and "lack of money."

Among the four dimensions of hunting constraints, the site and management dimension $($ mean $=2.11)$ and partner and health dimension $($ mean $=1.90)$ were perceived to be more frequently realized by the respondents when participating in deer hunting in comparison to skill and confidence $($ mean $=1.29)$ and time, distance, and money $($ mean $=1.90)$ dimensions of the constraints. Crosstab analysis showed that the items "your health condition," "no one to go with," and "partner's health condition" constraints were more frequently reported by older people. 
Table 2: Means and factor loading of items on constraint dimensions and reliability of scales $(n=359)$

\begin{tabular}{|c|c|c|c|c|c|c|}
\hline \multicolumn{2}{|r|}{ TPB Components } & \multirow{2}{*}{ Mean } & \multirow{2}{*}{ Mode } & \multirow{2}{*}{$\mathrm{SD}$} & \multirow{2}{*}{$\begin{array}{l}\text { Factor } \\
\text { loading }\end{array}$} & \multirow{2}{*}{$\alpha$} \\
\hline PB Factors & Items & & & & & \\
\hline \multirow{4}{*}{ Intentions } & I intend to participate in deer hunting in OR in 09 & 6.25 & 7 & 1.5 & .867 & \multirow{3}{*}{.953} \\
\hline & I will try to participate in deer hunting in OR in 09 & 6.04 & 7 & 1.6 & .887 & \\
\hline & I am planning to go for deer hunting in OR in 09 & 6.04 & 7 & 1.6 & .879 & \\
\hline & INTENTION INDEX & 6.10 & & 1.5 & \multicolumn{2}{|c|}{$(28.3 \%)$} \\
\hline \multirow{7}{*}{ Attitudes } & $\begin{array}{l}\text { For me hunting deer would be: pleasant OR } \\
\text { unpleasant }\end{array}$ & 5.96 & 7 & 1.5 & .728 & \multirow{6}{*}{.913} \\
\hline & $\begin{array}{l}\text { For me hunting deer would be: boring OR } \\
\text { interesting }\end{array}$ & 5.59 & 7 & 1.8 & .890 & \\
\hline & $\begin{array}{l}\text { For me hunting deer would be: unenjoyable OR } \\
\text { enjoyable }\end{array}$ & 5.95 & 7 & 1.5 & .773 & \\
\hline & $\begin{array}{l}\text { For me hunting deer would be: socially harmful or } \\
\text { beneficial }\end{array}$ & 5.51 & 7 & 1.7 & .869 & \\
\hline & $\begin{array}{l}\text { For me hunting deer would be: health-wise harmful } \\
\text { or beneficial }\end{array}$ & 5.75 & 7 & 1.7 & .877 & \\
\hline & $\begin{array}{l}\text { For me hunting deer would be: economically } \\
\text { harmful or beneficial }\end{array}$ & 4.83 & 7 & 1.7 & .683 & \\
\hline & ATTITUDE INDEX & 5.59 & & 1.4 & $(22.3$ & \\
\hline \multirow{5}{*}{$\begin{array}{l}\text { Subjective- } \\
\text { norms }\end{array}$} & People important to me think I should hunt deer & 5.75 & 7 & 1.4 & .733 & \multirow{4}{*}{.823} \\
\hline & $\begin{array}{l}\text { People whose opinions I value think I should hunt } \\
\text { deer }\end{array}$ & 6.13 & 7 & 1.1 & .833 & \\
\hline & $\begin{array}{l}\text { People who are important to me will support my } \\
\text { deer hunting }\end{array}$ & 6.26 & 7 & 1.0 & .800 & \\
\hline & $\begin{array}{l}\text { People who are important to me will go deer } \\
\text { hunting }\end{array}$ & 5.13 & 7 & 1.6 & .730 & \\
\hline & SUBJECTIVE-NORMS INDEX & 5.81 & & 1.0 & $(16.4$ & \\
\hline \multirow{4}{*}{$\mathrm{PBC}$} & I am confident that I can go deer hunting in 2009 & 6.03 & 7 & 1.5 & 660 & \multirow[t]{4}{*}{.899} \\
\hline & If I want to go deer hunting in 2009 , I can go easily & 5.87 & 7 & 1.5 & .815 & \\
\hline & $\begin{array}{l}\text { Factors that influence my decision to go deer } \\
\text { hunting are in my full control }\end{array}$ & 5.50 & 7 & 1.7 & .889 & \\
\hline & PBC INDEX & 5.80 & & 1.4 & $(11.3$ & \\
\hline
\end{tabular}

Total variance explained $(78.2 \%)$

Notes:

1. Each statement was asked for the context of deer hunting in Oregon in 2009 hunting season

2. The figure inside parenthesis indicates amount of variance explained by respective unobserved variable.

3. 1 indicates extremely disagree with the statement, and 7 indicates extremely agree for all, except for attitude-related items in which 1 indicates extreme negative attitude and 7 indicates extremely positive attitude 
Table 3: Means and factor loading of items on constraint dimensions and reliability of scales $(n=359)$

\begin{tabular}{|c|c|c|c|c|c|c|}
\hline \multicolumn{2}{|r|}{ Constraints } & \multirow[b]{2}{*}{ Mean } & \multirow[b]{2}{*}{ Mode } & \multirow[b]{2}{*}{ S.D. } & \multirow{2}{*}{$\begin{array}{l}\text { Factor } \\
\text { loading }\end{array}$} & \multirow[b]{2}{*}{$\alpha$} \\
\hline $\begin{array}{l}\text { Constraints } \\
\text { Dimensions }\end{array}$ & Constraint Items & & & & & \\
\hline \multirow{7}{*}{$\begin{array}{l}\text { Skill \& } \\
\text { Confidence }\end{array}$} & Lack of training & 1.43 & 1 & 0.7 & .731 & \multirow{7}{*}{.719} \\
\hline & Lack of self-confidence & 1.24 & 1 & 0.6 & 691 & \\
\hline & Lack of skills & 1.37 & 1 & 0.6 & .684 & \\
\hline & Fear of sexual assault & 1.18 & 1 & 0.5 & .769 & \\
\hline & Fear of outdoors & 1.17 & 1 & 0.4 & .702 & \\
\hline & Fear of crime & 1.40 & 1 & 0.7 & .656 & \\
\hline & SKILL \& CONFIDENCE INDEX & 1.29 & & 0.4 & & \\
\hline \multirow{4}{*}{$\begin{array}{l}\text { Partner \& } \\
\text { Health }\end{array}$} & Your physical health & 2.06 & 1 & 1.2 & .810 & \multirow{4}{*}{.615} \\
\hline & $\begin{array}{l}\text { Physical health of someone you like to } \\
\text { hunt with }\end{array}$ & 2.03 & 1 & 1.0 & .792 & \\
\hline & Don't have anyone & 1.88 & 1 & 1.1 & .667 & \\
\hline & PARTNER \& HEALTH INDEX & 2.00 & & 0.7 & & \\
\hline \multirow{7}{*}{$\begin{array}{l}\text { Site \& } \\
\text { Management }\end{array}$} & Sites too crowded in or & 2.58 & 3 & 1.1 & .765 & \multirow{7}{*}{.776} \\
\hline & Inadequate facilities in or & 1.79 & 1 & 0.9 & .742 & \\
\hline & Lack of/difficulty to find deer & 2.58 & 3 & 1.2 & .708 & \\
\hline & Complex rules and regulation & 2.33 & 1 & 1.2 & .622 & \\
\hline & Lack of info & 1.64 & 1 & 0.8 & .580 & \\
\hline & Conflict with other uses/users & 1.78 & 1 & 0.9 & .537 & \\
\hline & SITE \& MANAGEMENT INDEX & 2.11 & & 0.7 & & \\
\hline \multirow{6}{*}{$\begin{array}{l}\text { Time, } \\
\text { Distance \& } \\
\text { Money }\end{array}$} & Lack of time & 2.35 & 1 & 1.2 & .705 & \multirow{6}{*}{.664} \\
\hline & Can't afford & 1.94 & 1 & 0.9 & 677 & \\
\hline & Sites are far away & 2.12 & 1 & 1.1 & .638 & \\
\hline & $\begin{array}{l}\text { No opportunity what you want to } \\
\text { perform }\end{array}$ & 1.75 & 1 & 0.8 & .533 & \\
\hline & Lack of transportation & 1.35 & 1 & 0.6 & .533 & \\
\hline & TIME, DISTANCE \& MONEY INDEX & 1.90 & & 0.6 & & \\
\hline \multirow{5}{*}{$\begin{array}{c}\text { Items } \\
\text { excluded } \\
\text { based on } \\
\text { commonality } \\
\text { criteria }\end{array}$} & Like to do other things for recreation & 2.16 & & & & \\
\hline & Don't like to do things in outdoor & 1.33 & & & & \\
\hline & Sites are closed & 2.26 & & & & \\
\hline & Feeling of unwelcome by ranger/staff & 1.58 & & & & \\
\hline & Racial conflicts among users & 1.19 & & & & \\
\hline
\end{tabular}

Note:

1. The score of 1 indicates never felt that constraint and 5 indicates always felt that constraint.

\section{Correlations between TPB Components and Constraints}

Pearson's correlation analysis indicated significant positive associations among the TPB variables (Table 4). Intention was strongly correlated to PBC $(r=.618)$ and moderately correlated to attitude and subjective norms ( $r=.362$ and .424 , respectively). On the other hand, 
significant negative correlations were revealed between intention and the four constraint dimensions. Intention showed strong negative correlation with skill and confidence dimensions of constraints ( $r=-.457)$; and moderate correlation with time, distance, and money constraint dimension $(r=-.372)$ and site and management constraint dimension $(r=-.314)$; and low correlation with partner and health constraint dimension $(r=-.153)$. The PBC exhibited significant moderate negative correlations with site and management $(r=-.434)$; skill and confidence ( $r=-.463)$; and time, distance, and cost dimension $(r=-.445)$ of constraints and weak but significant correlation with partner and health constraint dimension $(r=-.199)$. Attitude and subjective norms, however, showed weak but significant negative correlations with each constraint dimension $(r<-.300)$, except for the partner and health dimension, which showed insignificant correlation with subjective norms. Finally, weak to strong positive correlations were revealed among the constraint components.

Table 4: Correlations among TPB predictors and four constraint dimensions $(n=359)$

\begin{tabular}{lccccccc}
\hline & \multicolumn{7}{c}{ Pearson's correlation coefficients } \\
\cline { 2 - 7 } \multicolumn{1}{c}{$\begin{array}{c}\text { TPB predictors and } \\
\text { Constraints }\end{array}$} & $\begin{array}{c}\text { Sub. } \\
\text { norms }\end{array}$ & PBC & $\begin{array}{c}\text { Site \& } \\
\text { mgmt }\end{array}$ & $\begin{array}{c}\text { Health \& } \\
\text { partner }\end{array}$ & $\begin{array}{c}\text { Skill \& } \\
\text { confidence }\end{array}$ & $\begin{array}{c}\text { Time } \\
\text { dist. \& } \\
\text { money }\end{array}$ & Intention \\
\hline Attitude & $442^{* *}$ & $.343^{* *}$ & $-.238^{* *}$ & $-.226^{* *}$ & $-.280^{* *}$ & $-.253^{* *}$ & $.362^{* *}$ \\
Subjective norms & & $.454^{* *}$ & $-.206^{* *}$ & -.083 & $-.330^{* *}$ & $-.257^{* *}$ & $.424^{* *}$ \\
PBC & & & $-.434^{* *}$ & $-.199^{* *}$ & $-.463^{* *}$ & $-.445^{* *}$ & $.618^{* *}$ \\
Site \& mgmt. & & & $.227^{* *}$ & $.431^{* *}$ & $.487^{* *}$ & $-.314^{* *}$ \\
Partner \& health & & & & $.244^{* *}$ & $.272^{* *}$ & $-.153^{* *}$ \\
Skill \& confidence & & & & & $.479^{* *}$ & $-.457^{* *}$ \\
Time, distance \& money & & & & & & & \\
\hline
\end{tabular}

Notes:

1. ${ }^{*}$ Correlation is significant at the alpha level of 0.05 (2-tailed).

2. ${ }^{* *}$ Correlation is significant at the alpha level of 0.01 (2-tailed).

\section{Mediation Effects}

The correlation analysis (Table 4) revealed that intentions were significantly associated with all constraint dimensions, supporting the first mediation criterion of Baron and Kenny (1986). The second criterion was also fulfilled, as all mediators (i.e., attitudes, subjective norms, and $\mathrm{PBC}$ ) showed significant correlations with all four constraint dimensions (Table 4). The 
exception was subjective norms, which showed an insignificant correlation with partner and health dimensions. Following this, the mediation effect analysis of the subjective norms on partner and health dimension and intention relationship was excluded from further analysis. To test the third and fourth criteria, a series of regression analyses were performed separately for each of the three mediators (attitude, subjective norms, and PBC).

Mediation effects of attitudes: The results shown in the upper half of Table 5 indicate that attitudes satisfied the third criterion as well, as they contributed significantly to the prediction of intention when they were entered alongside the site and management $(\beta=0.304)$; partner and health $(\beta=0.344)$; skill and confidence $(\beta=0.253)$; and time, distance, and money $(\beta=0.286)$ in separate analyses. The lower half of Table 5 shows that all of the four constraint dimensions explained a unique variance on intention before including the attitudes in the model. The effects of all constraint dimensions, however, decreased after controlling for attitudes. Nonetheless, all effects were significant with the exception of the partner and health dimension, which failed to make a significant contribution after controlling for attitudes. These results indicated that attitudes mediated the influence of different constraints dimensions differently. Specifically, the effects of the partner and health dimension were fully mediated by attitudes, while the effects of the site and management; skill and confidence; and time, distance, and money were only partially mediated.

Mediation effects of subjective norms: Subjective norms satisfied the third criterion of mediation for the three constraint dimensions. Subjective norms contributed to the prediction of intention when entered alongside of site and management $(\beta=0.375)$; skill and confidence $(\beta=$ 0.307); and time, distance, and money $(\beta=0.652)$ in separate analyses (Table 6). Regarding the fourth criterion, the three constraint dimensions explained a unique variance on intention before including the subjective norms in the model in separate regressions. The effects of each constraint dimension decreased after controlling for the subjective norms; however, the effects were significant, indicating failure of meeting the fourth criterion of the mediation. This implies that subjective norms partially mediated the effects of the site and management; skill and confidence; time, distance, and money constraint dimensions on deer hunting intention, leaving out partner and health. 
Mediation effects of PBC: The PBC satisfied the third criterion, as it contributed significantly to predicting intention when it was entered alongside of site and management $(\beta=$ 0.594); partner and health $(\beta=0.612)$; skill and confidence $(\beta=0.518)$; and time, distance, and money $(\beta=0.565)$ in separate analyses (Table 7). For the fourth criterion, the results indicated that the four constraint dimensions explained a unique variance on intention before including the PBC in the model. The effects of the partner and health and site and management were nullified after controlling for the PBC. These findings implied that PBC fully mediated the effects of site and management and partner and health dimensions on hunting intention while partially mediating the effects of skill and confidence and distance and money constraint dimensions.

Table 5: Assessment of Third and Fourth criteria of mediation effect of attitudes on constraints-intentions relationship $(n=359)$

\begin{tabular}{|c|c|c|c|c|c|c|c|}
\hline \multicolumn{8}{|c|}{ Criteria 3: Effect of attitude (mediator) on intentions in presence of constraint dimensions } \\
\hline Dependent & \multicolumn{2}{|l|}{ Independent } & ${ }_{a d j} R^{2}$ & \multicolumn{2}{|c|}{$\begin{array}{l}\text { Effect of attitude } \\
(\beta)\end{array}$} & $T$ & $P$ \\
\hline \multirow{4}{*}{ Intentions } & \multicolumn{2}{|l|}{ Attitudes + site $\&$ management } & $.181^{* *}$ & $.304^{* *}$ & & 6.175 & .000 \\
\hline & \multicolumn{2}{|l|}{ Attitudes + partner $\&$ health } & $.131^{* *}$ & $.344^{* *}$ & & 6.812 & .000 \\
\hline & \multicolumn{2}{|l|}{ Attitudes + skill $\&$ confidence } & $.264^{* *}$ & $.253^{* *}$ & & 5.363 & .000 \\
\hline & \multicolumn{2}{|l|}{ Attitudes + time, distance \& money } & $.211^{* *}$ & $.286^{* *}$ & & 5.888 & .000 \\
\hline \multicolumn{8}{|c|}{ Criterion 4: Effect of constraint dimensions on intentions after controlling for mediators (attitude) } \\
\hline \multirow[t]{2}{*}{ Dependent } & \multirow[t]{2}{*}{ Constraints dimension } & \multicolumn{3}{|c|}{ Before including attitude } & \multicolumn{3}{|c|}{$\begin{array}{c}\text { After controlling for } \\
\text { attitude }\end{array}$} \\
\hline & & $\beta$ & $T$ & $P$ & $\beta$ & $T$ & $P$ \\
\hline \multirow{4}{*}{ Intentions } & Effect of site \& mgmt. & $-.314^{* *}$ & -6.248 & 0.000 & $-0.242^{* * *}$ & -4.908 & .000 \\
\hline & Effect of partner \& health & $-.153^{* *}$ & -2.933 & 0.004 & -0.076 & -1.497 & .135 \\
\hline & Effect of skill \& confidence & $-.457^{* *}$ & -9.701 & 0.000 & $-0.386^{* *}$ & -8.164 & .000 \\
\hline & Effect of time, dist. \& money & $-.372^{* *}$ & -7.757 & 0.000 & $-0.300^{* * *}$ & -6.181 & .000 \\
\hline
\end{tabular}

Notes:

1. "Significant at the alpha level of 0.05 (2-tailed).

2. ${ }^{* *}$ Significant at the alpha level of 0.01 (2-tailed). 
Table 6: Assessment of Third and Fourth criteria of mediation effect of subjective norms on constraintsintentions relationships $(n=359)$

Criteria 3: Effect of mediator (subjective norms) on intentions in presence of constraint dimensions

\begin{tabular}{llcccc}
\hline \multirow{2}{*}{ Dependent } & Independent & ${ }_{a d j} R^{2}$ & $\begin{array}{c}\text { Effect of Sub- } \\
\text { norms }(\beta)\end{array}$ & $T$ & $P$ \\
\hline \multirow{5}{*}{ Intentions } & Sub-norms + site \& management & $.229^{* *}$ & $.375^{* *}$ & 7.914 & .000 \\
& Sub-norms + partner \& health & \multicolumn{2}{c}{ Not included: $2^{\text {nd }}$ criteria not satisfied } \\
& Sub-norms + skill \& confidence & $.288^{* *}$ & $307^{* *}$ & 6.491 & .000 \\
& Sub-norms + time, distance \& money & $.250^{* *}$ & $.352^{* *}$ & 7.419 & .000 \\
\hline
\end{tabular}

Criterion 4: Effect of constraint dimensions on intentions after controlling for mediator (sub. norms)

\begin{tabular}{|c|c|c|c|c|c|c|c|}
\hline \multirow[t]{2}{*}{ Dependent } & \multirow[t]{2}{*}{ Constraints dimension } & \multicolumn{3}{|c|}{ Before including sub-norms } & \multicolumn{3}{|c|}{$\begin{array}{l}\text { After controlling for sub. } \\
\text { norms }\end{array}$} \\
\hline & & $\beta$ & $T$ & $P$ & $\beta$ & $T$ & $P$ \\
\hline \multirow{4}{*}{ Intentions } & Effect of site \& mgmt. & $-.314^{* *}$ & -6.248 & 0.000 & $-0.237^{* *}$ & -4.990 & 年 \\
\hline & Effect of partner \& health & \multicolumn{6}{|c|}{ Not included: $2^{\text {nd }}$ criteria not satisfied } \\
\hline & Effect of skill \& confidence & $-.457^{* *}$ & -9.701 & 0.000 & $-0.307^{* *}$ & -6.491 & 然 \\
\hline & Effect of time, dist. \& money & $-.372^{* *}$ & -7.757 & 0.000 & $-0.282^{* *}$ & -5.945 & .000 \\
\hline
\end{tabular}

Notes:

1. "Significant at the alpha level of .05

2. ${ }^{* *}$ Significant at the alpha level of .01

Table 7: Assessment of Third and Fourth criteria of mediation effect of PBC on constraints -intentions relationships $(n=359)$

\begin{tabular}{|c|c|c|c|c|c|c|c|}
\hline \multicolumn{8}{|c|}{ Criteria 3: Effect of mediator (PBC) on intentions in presence of constraint dimensions } \\
\hline Dependent & Independent & \multirow{2}{*}{\multicolumn{2}{|c|}{$\operatorname{adj}^{2} R^{2}$}} & \multicolumn{2}{|c|}{ Effect of PBC $(\beta)$} & $T$ & $P$ \\
\hline \multirow{4}{*}{ Intentions } & $\mathrm{PBC}+$ site $\&$ management & $.381^{* *}$ & & \multicolumn{2}{|c|}{$.594^{* *}$} & 12.874 & .000 \\
\hline & PBC + partner \& health & \multicolumn{2}{|c|}{$.380^{* *}$} & \multicolumn{2}{|l|}{$612^{* *}$} & 14.411 & 000 \\
\hline & $\mathrm{PBC}+$ skill \& confidence & \multirow{2}{*}{\multicolumn{2}{|c|}{$\begin{array}{l}.416 \\
.391^{* *}\end{array}$}} & \multicolumn{2}{|l|}{$.518^{* *}$} & 11.370 & .000 \\
\hline & PBC + time, distance \& money & & & \multicolumn{2}{|l|}{$.565^{* *}$} & 12.252 & .000 \\
\hline \multicolumn{8}{|c|}{ Criterion 4: Effect of constraint dimensions on intentions after controlling for mediators (PBC) } \\
\hline \multirow[t]{2}{*}{ Dependent } & \multirow[t]{2}{*}{ Constraints dimension } & \multicolumn{3}{|c|}{$\begin{array}{l}\text { Before controlling for } \\
\text { sub-norms }\end{array}$} & \multicolumn{3}{|c|}{$\begin{array}{l}\text { After controlling for sub- } \\
\text { norms }\end{array}$} \\
\hline & & $\beta$ & $T$ & $P$ & $\beta$ & $T$ & $P$ \\
\hline \multirow{4}{*}{ Intentions } & Effect of site \& mgmt. & $-.314^{* *}$ & -6.248 & 0.000 & -0.056 & -1.217 & .224 \\
\hline & Effect of partner \& health & $-.153^{* *}$ & -2.933 & 0.004 & -0.031 & -0.740 & .460 \\
\hline & Effect of skill \& confidence & $-.457^{* *}$ & -9.701 & 0.000 & $-0.217^{* *}$ & -4.770 & .000 \\
\hline & Effect of time, dist. \& money & $-.372^{* *}$ & -7.757 & 0.000 & $-0.121^{* *}$ & -2.618 & .000 \\
\hline
\end{tabular}

Notes:

1. "Significant at the alpha level of .05

2. "*ignificant at the alpha level of .01 


\section{Discussion}

The objective of the present study was to test the degree to which the elements of TPB act as mediators of the relationship between different constraint dimensions and deer hunting intention. Godbey et al. (2010) pointed out that the dimensionality of constraints is far more complex than it appears and questioned whether the three dimensions of constraints can be viewed as distinct categories, as suggested by Crawford and Godbey (1987). Accordingly, our first effort was to determine the constraint dimensions of hunting for further hypothesis testing. Our study revealed four constraint dimensions (skill and confidence; health and partner; site and management; and time, distance, and money). Similar constraint dimensions were reported by Alexandris et al. (2007) in their activity exercise study. Their intrapersonal constraints model included a psychological domain similar to the skill and confidence dimension of this study, while the interpersonal constraint dimension included lack of a partner, which is similar to partner and health in this study. Finally, the structural constraints were represented by two dimensions: the accessibility/financial dimension (similar to time, distance, and money in this study) and physical facilities (similar to site and management in this study).

The presence of more than two dimensions of constraints of structural nature also verified the existence of sub-dimensions within structural constraints, as reported by Jackson (1993). Crawford and Jackson (2005) suggested that time- and cost-related constraints rank among the most frequent and powerful constraints on leisure activities, while the site and facility dimension was not emphasized as much. In this context, it could be considered an important finding that site and facility constitutes a separate component of structural constraints, in addition to time and costs. The site and facility dimension of constraints was also reported by Alexandris et al. (2007) and was separate from time and costs.

One unique contribution of this research might be that the partner and health dimension of constraints represented an interaction between intrapersonal and interpersonal constraints. Generally, items such as "your health condition" would be regarded as intrapersonal, and items such as "partner's health condition" and "no one to go with" would be regarded as interpersonal constraints. We found these three items represented one dimension (partner and health). This could be explained on the basis of aging effects. Previous studies have shown that older people may face aging and health constraints more frequently and may face a difficulty in finding 
partners with which to participate in their desired activity (Burns \& Graefe, 2007; Jackson, 1993; Lee, Scott, \& Floyd, 2001). This finding further explains how intrapersonal constraints can influence interpersonal constraints and strengthens the view of possible interactions among intrapersonal, interpersonal, and structural constraints (Gilbert \& Hudson, 2000; Scott \& Munson, 1994). Furthermore, Godbey et al. (2010) suggested that for better understanding of the phenomenon, it is not sufficient to look into the constraints only; the underlying cause of the constraints must be looked into as well. In this case, it seems age may be more of a cause of the interpersonal constraints than of the constraint in itself.

The mediating effect analysis revealed some clear patterns. All of the TPB elements (attitudes, subjective norms, and PBC) mediated the effects of the four constraints dimensions on deer hunting intention, thus indirectly on deer hunting participation, in different ways. Some relationships were mediated partially, and some were mediated fully, while some did not mediate at all. We found that subjective norms did not mediate the relationship of the partner and health dimension with deer hunting intention. These patterns suggest that constraints influence deer hunting intention both directly and indirectly through attitudes, subjective norms, and PBC. This also provides limited support of the claims made by Ajzen (1988) that the effects of variables not included in the TPB are mediated by the elements of the TPB.

Our results showed that attitudes fully mediated the influence of the partner and health constraint dimension (interpersonal constraints) on deer hunting intention but partially mediated the impacts on the other three constraint dimensions. These dimensions are the skill and confidence dimension (intrapersonal); site and management dimension (structural); and the time, distance, and money dimension (structural). This implies that the interpersonal constraints affected intention only indirectly through attitudes, while intrapersonal and structural constraints affected deer hunting intention both directly and indirectly through attitudes.

The negative relationships of attitudes with all constraints dimensions suggested that people who perceived the highest level of constraints of different types hold less positive attitudes toward deer hunting. Alternatively, higher positive attitudes might be helpful in negotiating the effects of constraint dimensions on deer hunting intentions, thus to hunting participation. This result contradicts the findings of Alexandris et al. (2007), who concluded that 
attitudes fully mediated the influence of structural constraints (i.e., accessibility and facilities dimensions) and that interpersonal constraints (partner dimension) mediated the relationship only partially. These differences in the research findings may be a result of the differences in activity type. Alexandris et al. (2007) mentioned that health programs were more of a volitional type and that the services were much more organized for the participants. Conversely, hunting is less volitional and is an activity that demands more effort, time, resources, and skills. This finding provides additional evidence for the argument that individual psychological forces, such as attitudes, are less important if the activity desired is not under total volitional control, as suggested by Ajzen and Madden (1986).

In terms of the mediating effects of subjective norms, some clear patterns were revealed. Subjective norms partially mediated the effects of the structural constraints (site and management as well as time, distance, and money dimensions) and intrapersonal constraints (skill and confidence dimension) on deer hunting intention. As noted previously, subjective norms failed to mediate the effects of partner and health dimension (interpersonal constraints), perhaps because of the role of age-related constraints leading to lack of partner. These findings imply that, other than the partner and health dimensions, the structural and intrapersonal constraints affected deer hunting intention directly and also indirectly through the subjective norms. Alexandris et al. (2007) did not find any role of subjective norms in this regard. This finding supports the notion that participation in health and exercise is more of an internal psychological need than a social need, hence less influenced by external forces such as social and structural constraints, especially when the activity is easily available and under volitional control.

PBC was revealed as the strongest mediator, fully mediating the effects of the partner and health dimension (interpersonal constraints) and site and management dimension (one category of structural constraint). PBC also partially mediated the effects of the skill and confidence dimension (intrapersonal constraints) and the time, distance, and money dimension. These results support previous studies suggesting that perceived behavioral control is the most powerful predictor of intention and behavior within the TPB (Armitage \& Conner, 1999, 2001; Conner \& Armitage, 1998). This finding implies practitioners could potentially target PBC and try to enhance the confidence (PBC) of hunters so they can overcome the effects of constraints on intentions. 
The relatively weaker mediating roles of attitude and subjective norms and stronger roles of PBC provide evidence to support the proposition of Ajzen and Madden (1986) and Kimiecik (1992). These findings suggested the strength of internal (psychological) and external constraints (interpersonal and structural) are determined by PBC. This means, in the context of deer hunting, that PBC could play a more important role in mitigating the effects of constraints on intentions than on attitude and subjective norms. This finding also suggests that deer hunting is not under total volitional control, which may explain why PBC has been more effective in reducing the relationship of constraints on intentions. In essence, volitional control is decreased as adequate resources (e.g., time, money, skills, and cooperation of other people) and perceived opportunities are decreased. If resources are made available and hunters' skills and confidence are developed, the role of attitude and subjective norms may then become more important.

\section{Management Implications}

The results of this study are relevant and may be useful to resource managers and other practitioners in many ways. State game management budgets are often heavily funded by hunting license fees and state grants derived from federal excise taxes on shooting and hunting arms and ammunition. As the number of hunting licenses drop and hunters cease purchasing hunting gear, it can be surmised these sources of revenue will be reduced (Duda, Jones, \& Criscione, 2010; U.S. Fish and Wildlife Service [USFWS], 2006). It may also result in a decline in the hunting industry and negatively impact industry jobs. Furthermore, hunters help to manage healthy populations of game by keeping populations in check and reducing other deer-management problems (e.g., Lyme disease control, roadside accidents, crop damage), which are a vested interest of many state agencies.

Using the study site to illustrate an example of this issue, the number of hunting licenses sold in Oregon has decreased by nearly one third (29\%) between 1980 and 2008. During the same time, the population of Oregon has increased to from 2.6 million to 3.8 million. Accordingly, this disparity between population growth and hunting has effectively halved the hunting participation rate (from $15 \%$ of the population to $7 \%$ ) during this time frame. This situation begs for urgent action by resource managers, including developing public-private partnerships that can be used to create awareness within the hunting community and supporting 
industry. Opportunities must be created, or in other words, capacity needs to be created that will create opportunities to hunt and cause an increase in hunting participation.

Resource managers may also want to focus on creating opportunities for others and on recruiting efforts causing non-hunters to begin hunting. Target groups may be the families of current hunters - particularly the children, grandchildren, and spouses of hunters - as the tradition of hunting is often passed down from generation to generation. Previous research has shown that parents and family are the most important agents of introduction to hunting (Responsive Management, 2008), and family involvement also has a strong positive association with length of time involved with hunting (Enck, Decker, \& Brown, 2000). Hunting promotional programs could potentially focus on the benefits of quality family time spent in nature. In the long term, policy makers may want to focus recruiting efforts on young hunters, women, and minorities, as the proportion of hunters in these social groups is very low. Recent surveys have shown that, although only $20 \%$ of U.S. hunters are female, there has been a sharp increase in hunting participation by women in recent years (USFWS, 2006). Because women make up about half of the total U.S. population, this may be an opportunity for state resource managers. This is particularly promising given the increasing cultural changes and greater societal acceptance of women hunters. Similar efforts should also be focused on recruiting minorities, in particular the U.S. Hispanic population, the most rapidly growing racial/ethnic minority group.

This study suggests hunters faced many constraints (site, management, partner, health, time, distance, and money). If these constraints are not mitigated, future recruitment may be negatively affected. We suggest the elements of TPB (attitude, subjective norms, and PBC) reduced the negative effect of constraints on hunting intentions, which is itself a reliable predictor of behavior. This finding conveys very important meaning for the practitioners.

The finding that our survey population consists of relatively older, highly experienced hunters suggests that skill and confidence constraints may be of little importance to resource managers and already well established. However, responsible entities should ensure the constraints identified in this study are addressed in developing new recruitment efforts. The development of skills training programs may increase hunter confidence and possible fears related to crime and safety. 
Resource managers could possibly address many issues within the site and management constraint by implementing traditional social carrying capacity solutions. These management actions may include managing game populations and extending hunting opportunities. This could be done through increasing public-private partnerships that may allow for access to private hunting areas.

A recent report (Responsive Management, 2008) suggests many interested youths could not participate because of age restrictions. Exposing these interested youths to hunting education programs may result in a sustained level of interest that may be otherwise lost over time.

Likewise, lottery systems also have the potential to restrict people from hunting. Policy makers may want to review existing policies related to these concerns in the hope that additional new hunters could be attracted. Another consideration may be to simplify hunting rules and better communicate management priorities and hunting-related rules and regulations, as these seemed to be the most important items within the site and management constraint.

There's not much managers can do to reduce the time, distance, and money constraints; however, the distance component (i.e., hunting sites are far away) of this constraint dimension might be addressed by resource planners. Studies have shown that two thirds of hunters traveled more than 60 miles for hunting, and 42\% travel more than 120 miles (Montgomery, 2010). In such situations, managers could identify new hunting sites in different areas. If needed, a private landowner could be taken into confidence for this purpose, once again highlighting the need for greater public-private partnerships.

The stronger role of PBC in mediating different dimensions of constraints implies that practitioners should target perceived behavior control to reduce hunting constraint effects on people's intentions to participate in deer hunting. Alexandris et al. (2007) suggested consultation, education, psychological support, design, and delivery of appropriate programs are among the strategies that should be applied, all of which could enhance the influence of the PBC in minimizing the negative impacts of constraints on intentions. Gigliotti (2004) described that consumptive hunters' sole focus is on successful harvesting. According to Gigliotti, if resource managers have an intimate knowledge of the hunter group, they can plan to satisfy their needs 
and quality of experience. The actions required for achieving such a goal will be similar to the one already discussed in preceding sentences in the context of constraint management.

\section{Future Research}

The successful mediation effect of the TPB elements in influencing the constraintsintentions relationship might be an encouraging source of inspiration for researchers desiring to extend the theory of planned behavior by adding constraint dimensions to the TPB. Such an effort may be helpful for better understanding the intention and behaviors for different recreation activities including hunting.

From the constraints research point of view, until now only the negotiation role of motivations has been examined for mitigating the effects of constraints (Hubbard \& Mannell, 2001) on leisure participation. The findings of this research indicate that higher positive attitudes, higher positive subjective norms, and higher PBC help to mediate the effects of constraint dimensions on deer hunting intentions. This is similar to the preferences of constraints theory, as both are the immediate predictor of participation. Some scholars (Mannell \& Kleiber, 1997; Vallerrand \& Losier, 1999; Wigfield \& Eccles, 2000) have suggested that social and psychological mediators, including attitudes, values, and beliefs, serve as a force for intrinsic and extrinsic motivations whose influence on constraint negotiation has already been established. Therefore, these findings suggest to researchers that the psychological predictors of the TPB (attitudes, subjective norms, and PBC) may be useful variables to focus on as constraint negotiators in future studies and to expand our knowledge regarding why people participate in leisure and recreation activities despite the presence of constraints. 


\section{References}

Ajzen, I. (1985). From intentions to actions: A theory of planned behavior. In J. Kuhl \& J. Beckmann (Eds.), Action control: From cognition to behavior (pp. 11-39). Heidelberg, NY: Springer.

Ajzen, I. (1988). Attitudes, personality and behavior. Chicago, IL: Dorsey Press.

Ajzen, I. (1991). The theory of planned behavior. Organizational Behavior and Human Decision Processes, 50, 179-211.

Ajzen, I. (2002). Constructing a TPB questionnaire: Conceptual and methodological considerations. Revised in 2006. Retrieved from http://socgeo.ruhosting.nl/html/files/spatbeh/tpb.measurement.pdf

Ajzen, I., \& Driver, B. (1991). Prediction of leisure participation from behavioral, normative and control beliefs: An application of theory of planned behavior. Leisure Sciences, 13, 185204.

Ajzen, I., \& Driver, B. (1992). Application of theory of planned behavior to leisure choice. Journal of Leisure Research, 24(3), 207-224.

Ajzen, I., \& Fishbein, M. (1980). Understanding attitudes and predicting social behavior. Englewood Cliffs, NJ: Prentice-Hall.

Ajzen, I., \& Madden, T. (1986). Prediction of goal-directed behavior: Attitudes, intentions, and perceived behavior control. Journal of Experimental Psychology, 22, 453-474.

Alexandris, K., Barkoukis, V., \& Tsormpatzoudis, C. (2007). Does theory of planned behavior elements mediate the relationship between perceived constraints and intention to participate in physical activities? A study among older individuals. European Review of Aging and Physical Activity, 4, 39-48.

Alexandris, K., Barkoukis, V., Tsormpatzoudis, H., \& Grouios, G. (2003). A study of perceived constraints on a community-based physical activity program for the elderly in Greece. Journal of Aging and Physical Activity, 11, 305-318.

Alexandris, K., \& Stodolska, M. (2004). The influence of perceived constraints on the attitudes towards recreational sport participation. Leisure Sociology, 27, 197-217. 
Alexandris, K., Tsormpatzoudis, H., \& Grouios, G. (2002). Perceived constraints on recreational participation: Investigating their relationship with intrinsic motivation, extrinsic motivation and amotivation. Journal of Leisure Research, 34, 233-252.

Armitage, C., \& Conner, M. (1999). The theory of planned behaviour: Assessment of predictive validity and "perceived control." British Journal of Social Psychology, 38, 35-54.

Armitage, C., \& Conner, M. (2001). Efficacy of the theory of planned behaviour: A metaanalytic review. British Journal of Social Psychology, 40, 471-499.

Armstrong, J. S., \& Overton, T. S. (1977). Estimating nonresponse bias in mail surveys. Journal of Marketing Research, 14, 396-402.

Baron, M., \& Kenny, A. (1986). The moderator-mediator variable distinction in socialpsychological research: Conceptual, strategies and statistical considerations. Journal of Personality and Social Psychology, 51, 1173-1182.

Burns, R. C., \& Graefe, A. R. (2007). Constraints to outdoor recreation: Exploring the effects of disabilities on perceptions and participation. Journal of Leisure Research, 39(1), 156181.

Carroll, B., \& Alexandris, K. (1997). Perception of constraints and strength of motivation: Their relation to recreational sport participation. Journal of Leisure Research, 29(3), 279-299.

Conner, M., \& Armitage, C. (1998). Extending the theory of planned behavior: A review and avenues for further research. Journal of Applied Social Psychology, 28, 1429-1464.

Crawford, D., \& Godbey, G. (1987). Reconceptualizing barriers to family leisure. Leisure Sciences, 9, 119-127.

Crawford, D., \& Jackson, E. (2005). Leisure constraints theory: Dimensions, directions, and dilemmas. In E. L. Jackson (Ed.), Constraints to leisure (pp. 153-167). State College, PA: Venture.

Crawford, D., Jackson, E., \& Godbey, G. (1991). A hierarchical model of leisure constraints. Leisure Sciences, 13, 309-320. 
Dawson, K. A., Gyurcsik, N. C., Culos-Reed, S. N., \& Brawley, L. R. (2001). Perceived control: A construct that bridges theories of motivated behavior. In G. C. Roberts (Ed.), Advances in motivation in sport and exercise (pp. 321-356). Champaign, IL: Human Kinetics.

Dillman, D. A. (2000). Mail and internet surveys: The tailored design method. New York, NY: John Wiley \& Sons, Inc.

Downs, D. S., Graham, G. M., \& Yang, S. P. (2006). Youth exercise intention and past exercise behavior: Examining the moderating influences of sex and meeting exercise recommendations. Research Quarterly for Exercise \& Sport, 77, 91-99.

Downs, D. S., \& Hausenblas, H. A. (2005a). Applying the theories of reasoned action and planned behavior to exercise: A meta-analytic update. Journal of Physical Activity and Health, 2, 76-97.

Downs, D. S., \& Hausenblas, H. A. (2005b). Elicitation studies and the theory of planned behavior: A systematic review of exercise beliefs. Psychology of Sport and Exercise, 6, $1-31$.

Duda, M., Jones, M., \& Criscione, A. (2010). Sportsman's voice: Hunting and fishing in America. State College, PA: Venture.

Eccles, J., Adler, T., Futterman, R., Goff, S., Kaczala, C., Meece, J., \& Midgley, C. (1983). Expectancies, values and academic behaviors. In J. T. Spence (Ed.), Achievement and achievement motivation (pp. 75-146). San Fransico, CA: W. H. Freeman.

Enck, J., Decker, D., \& Brown, T. (2000). Status of hunter recruitment and retention in the United States. Wildlife Society Bulletin, 28(4), 817-824.

Gigliotti, L. (2004). 2004 Black Hills deer hunter survey. Pierre, SD: Game, Fish, \& Parks. Gilbert, D., \& Hudson, S. (2000). Tourism demand constraints: A skiing participation. Annals of Tourism Research, 27, 906-925.

Godbey, G., Crawford, D., \& Shen, X. (2010). Assessing hierarchical leisure constraints theory after two decades. Journal of Leisure Research, 42(1), 111-134.

Godin, G., \& Kok, G. (1996). The theory of planned behavior: A review of its applications in health-related behaviors. American Journal of Health Promotion, 11, 87-98. 
Hrubes, D., Ajzen, I., \& Daigle. J. (2001). Predicting hunting intentions and behavior: An application of the theory of planned behavior. Leisure Sciences, 23, 165-178.

Hubbard, J., \& Mannell, R. (2001). Testing competing models of the leisure constraints and negotiation process in a corporate employee recreation setting. Leisure Sciences, 23, 145163.

Jackson, E. L. (1993). Recognizing patterns of leisure constraints: Results from alternative analysis. Journal of Leisure Research, 25, 127-149.

Jackson, E. L. (2000). Will research on leisure constraints still be relevant in the twenty first century? Journal of Leisure Research, 32(1), 62-68.

Jackson, E. L., Crawford, D. W., \& Godbey, G. (1993). Negotiation of leisure constraints. Leisure Sciences, 15, 1-11.

Jackson, E. L., \& Rucks, V. C. (1995). Reasons for ceasing participation and barriers to participation: Further examination of constrained leisure as an internally homogeneous concept. Leisure Sciences, 15, 217-230.

Jackson, E., \& Scott, D. (1999). Constraints to leisure. In E. Jackson \& T. Burton (Eds.), Leisure studies: Prospects for the twenty-first century (pp. 299-321). State College, PA: Venture.

Kimiecik, J. (1992). Predicting vigorous physical activity of corporate employees: Comparing the theories of reasoned action and planned behavior. Journal of Sport and Exercise Psychology, 14, 192-206.

Koca, C., Henderson, K., Asci, F., \& Bulgu, N. (2009). Constraints to leisure-time physical activity and negotiation strategies in Turkish women. Journal of Leisure Research,41(2), $225-251$.

Kraemer, H., Stice, E., Kazdin, A., Offord, D., \& Kupfer, D. (2001). How do risk factors work together? Mediators, moderators, and independent, overlapping, and proxy risk factors. American Journal of Psychiatry, 158, 848-856.

Lee, J., Scott, D., \& Floyd, M. (2001). Structural inequalities in outdoor recreation participation: A multiple hierarchy stratification perspective. Journal of Leisure Research, 33(1), 427449. 
Livenwood, J., \& Stodolska, M. (2004). The effects of discrimination and constraints negotiation on leisure behavior of American Muslims in the post-September 11 America. Journal of Leisure Research, 36(2), 183-208.

Mackinnon, D., Fairchild, A., \& Fritz, M. (2007). Mediation analysis. Annual Review of Psychology, 58, 593-614.

Mannell, R., \& Kleiber, D. (1997). A social psychology of leisure. State College, PA: Venture.

Montgomery, R. (2010, July 1). The impact of access, cost, demographics, and individual constraints on hunting frequency and future participation. Academy of Marketing Studies Journal. Retrieved from http://www.faqs.org/periodicals/201007/2196887261.html\#ixzz17jU9RNNM

Preacher, K., \& Hayes, A. (2004). SPSS and SAS procedures for estimating indirect effects in simple mediation models. Behavior Research Methods, Instruments, \&Computers, 36(4), 717-731.

Responsive Management (2008). North Dakota hunting survey. Harrisonburg, VA: Responsive Management National Office.

Robins, J., \& Greenland, S. (1992). Identifiability and exchangeability for direct and indirect effects. Epidemiology, 3, 143-155.

Rossi, A. N., \& Armstrong, J. B. (1999). Theory of reasoned action vs. theory of planned behavior: Testing the suitability and sufficiency of a popular behavior model using hunting intentions. Human Dimensions of Wildlife, 4, 40-46.

Scott, D., \& Jackson, E. L. (1996). Factors that limit and strategies that might encourage people's use of public parks. Journal of Park and Recreation Administration, 14(1), 1-11.

Scott, D., \& Munson, W. (1994). Perceived constraints to park usage among individuals with low incomes. Journal of Park and Recreation Administration, 12, 79-96.

Shinew, K., Floyd, M., \& Parry, D. (2004). Understanding the relationship between race and leisure activities and constraints: Exploring an alternative framework. Leisure Science, 26, 181-199. 
Smith, A., \& Biddle, S. (1999). Attitude and exercise adherence: Test of the theories of reasoned action and planned behavior. Journal of Sport Science, 17, 269-281.

Son, J., Kerstetter, D., \& Mowen, A. (2008). Do age and gender matter in the constraint negotiation of physically active leisure? Journal of Leisure Research, 40(2), 267-289.

Vallerand, R., \& Losier, G. (1999). An integrative analysis of intrinsic and extrinsic motivation in sport. Journal of Applied Sport Psychology, 11, 142-169.

Walker, G., Jackson, E., \& Deng, J. (2007). Culture and leisure constraints: A comparison of Canadian and mainland Chinese. Journal of Leisure Research, 39(4), 567-590.

Wigfield, A., \& Eccles, J. (2000). Expectancy-value theory of achievement motivation. Contemporary Educational Psychology, 25, 68-81.

Woods, A., \& Kerr, G. (2010). Recreational game hunting: Motivations, satisfactions and participation. Land Environment and People Research Report No. 18. Canterbury, New Zealand: Lincoln University.

U.S. Fish and Wildlife Service. (2006). 2006 national survey of fishing, hunting, and wildlifeassociated recreation. Washington, DC: U.S. Department of the Interior, Fish and Wildlife Service, and U.S. Department of Commerce, U.S. Census Bureau. 


\title{
CHAPTER 4: Article 3
}

An Assessment of the Effectiveness of the Original and Constraint Integrated Theory of Planned

Behavior Models in Predicting Deer Hunting Participation

Suresh K. Shrestha

Robert C. Burns

\begin{abstract}
The paper addresses two research questions. First, can the theory of planned behavior (TPB) successfully predict deer hunting behavior? Second, can the integration of constraints dimensions in the TPB model improve the prediction of deer hunting intention and behavior? The data were collected from a two-staged mail back surveys of the hunters from Oregon in 2009 and 2010. The response rates were $20 \%$ and $67 \%$ in the first and second survey, respectively. Model assessments were performed using structural equation modeling (SEM). The results showed that the original TPB model successfully predicted $51 \%$ variance in the intentions and $21 \%$ variance in the reported participation in deer hunting. Among the six constraints integrated TPB models, fear integrated, time, money and distance integrated and total constraint integrated model showed good fit with the data, and explained $2 \%$ to $4 \%$ more variance in reported hunting participation. Both original and extended models showed that attitude and subjective norms had no significant role in the model while PBC was a significant factor for predicting deer hunting participation (directly as well as indirectly) through intentions. Evidence was found regarding the constraint negotiation roles of the TPB predictors on deer hunting participation. Recommendations are made to use more comprehensive measures of attitudes, subjective norms and PBC as well as specific measures of constraints for better understanding of the entire phenomenon. Practitioners are advised to develop programs for enhancing PBC and reducing internal and external constraints through skill development and providing more satisfying hunting opportunities by enhancing quality and quality of game population.
\end{abstract}

Keywords: Theory of Planned Behavior, Deer Hunting Intentions and Behavior, Constraint Integrated TPB model. 


\section{Research Inspiration}

According to the theory of planned behavior (TPB) (Ajzen, 1991) the ultimate predictor of participation of an individual in a given activity is his/her intention to participate in that activity. The TPB model further proposes that intention depends on attitudes, subjective norms and perceived behavioral control (PBC) of the person towards that behavior. When the behavior is non-volitional in nature (i.e., not under a person's conscious control), the PBC might also directly influence the behavior. The usefulness of the theory in describing various human behaviors, including leisure and recreation activity participation, has been empirically verified by numerous studies (Ajzen \& Driver, 1992 \& 1991; Kimiecik, 1992; Mummery \& Wankel, 1999; Hrubes, Ajzen \& Daigle 2001; Eves, Hoppe, \& McLaren, 2003; Hausenblas, et al., 2008; Shrestha, Burns, Pierskalla \& Selin, 2012). Some studies also used TPB for explaining general hunting intentions and/or behavior (Hrubes, Ajzen \& Daigle, 2001; Rossi \& Armstrong, 1999). Ajzen (1991) suggested that the model is more effective for describing specific activity at specific time and place. Shrestha et al. (2012a) used the model to predict a specific hunting activity (i.e., deer hunting) but they used it only for describing hunting intentions, not the behavior. Therefore, the first objective of this study was to assess the effectiveness of the TPB in explaining deer hunting behavior.

The findings of Parr (1996) and Hemingway and Parr (2000) reflected that recreation practitioners had their own theories about their work (personal theories) and the language of practitioners did not necessarily fit with the researchers' explanation of behavior as described in public theories as they do not provide specific actions to an specific issue. By understanding practitioners' personal theories (what they believe about leisure and leisure services practice), researchers and practitioners can begin to understand, question, and pose alternatives to these beliefs, and actions resulting from these beliefs (Henderson, Presley \& Bialeschki, 2004; Henderson, 2010). The TPB model consists mostly of psychological variables, such as attitudes, subjective norms, PBC and intentions, which do not provide a clear direction to recreation managers for addressing a field problem.

Another framework, the constraints approach to leisure research, recognizes that participation in a leisure activity depends on presence or absence of constraints. According to Jackson (1991) the goal of leisure constraints research is to "investigate and understand the 
factors that are assumed by researchers and perceived by individuals to inhibit or prohibit participation and enjoyment in leisure. The constraints approach provides straightforward information to planners and managers about which factors constrain participation. Accordingly, managers can work on reducing the effect of the identified constraints. Many scholars supported the view that constraints approach is useful for practitioner for decision making. For example, according to White and Bustam, (2010) it is important for scientists and natural resource managers to gain an awareness and understanding of situations and factors that can act as a barrier or constraint to recreation. The field of constraints research offers such an understanding. Walker and Virden (2005) suggested that the field of leisure constraints research can provide beneficial information not only to recreation researchers, but also to protected area managers to assist them in decision-making. Jackson (1998) suggested that leisure constraints research results can be directly applied in recreation management strategies; while Boothby, Tungatt, and Townsend (1981) emphasized constraint research's role to improve the quality of participation. Constraints research although has been of limited success in providing an explanation for recreation participation because people participated in recreation activities even in the presence of constraints (Son et al., 2008; Burns \& Graefe, 2007; Walker, Jackson \& Deng, 2007; Carroll \& Alexandris, 1997; Scott \& Jackson, 1996; Hubbard \& Mannell, 2001). The negotiation component was later added to the constraints process for addressing the nonparticipation issue (Jackson, Crawford \& Godbey, 1993).

Considering the efficiency of the TPB in understanding why people participate in an activity and prospect of the leisure constraint research to the practitioners, we hypothesize it would be a productive exercise to extend the TPB model by integrating the constraints dimensions. We found sufficient theoretical and empirical backings for testing this theory. For example, Ajzen (1991) described the model as open to further elaboration if further important proximal determinants are identified: "The theory of planned behavior is, in principle, open to the inclusion of additional predictors if it can be shown that they capture a significant proportion of the variance in intention or behavior after the theory's current variables have been taken into account (p. 199). He further contended that the effects of any variable not included in the TPB model are mediated by its predictors. Additionally, several constraint-TPB studies suggested that the TPB predictors have significant negative correlations with constraints dimensions (Alexandris, Barkoukis, Tsormpatsoudis \& Grouios, 2003; Alexandris \& Stodolska, 
2004) and the TPB predictors partially or fully mediate the effects of constraints on behavioral intensions (e.g., Shrestha, Burns, Deng, Confer, Graefe \& Covelli, 2012; Alexandris, Barkoukis \& Tsormpatsoudis, 2007; Alexandris \& Stodolska, 2004; Alexandris, Barkoukis, Tsormpatsoudis \& Grouios, 2003). If this is true, the inclusion of constraints in the TPB model should help enhancing the predictive capability and practicability of the TPB. Despite these indications no research has made an attempt to extend the TPB by combining constraints. Thus, the second objective of this paper was to assess the efficiency of the constraint integrated TPB model in predicting deer hunting intention and behavior in comparison to the original TPB.

\section{Literature Review}

The theory of planned behavior (Ajzen, 1991) suggests that a person's participation in a behavior can be predicted by the intentions of the person to engage in that behavior. Behavioral intention itself depends on (a) the individual's attitudes toward the behavior (internal evaluation of the behavior), (b) the influence of subjective norms (perceived social norms) towards the behavior, and (c) the PBC (intrinsic evaluation of the perceived level of control on the behavior). Ajzen described attitudes as the affective and instrumental evaluations of performing a behavior by an individual, based on his/her behavioral beliefs concerning the consequences of engaging in the behavior. Subjective norms were described as the perceived social pressure on the individual to perform or not to perform a particular behavior. The PBC was described as an individual's perceptions about her/his capability of successfully engaging in the behavior (Ajzen, 1985). The $\mathrm{PBC}$ is represented by the perceptions of whether the behavior can be performed both in terms of self-efficacy (ease or difficult) and controllability (perceived extent of control - a little or a lot) taking into account the individual's perception of skills, resources, and opportunities needed to perform a behavior (Ajzen, 1991). The PBC component was specifically added to the model to describe non-volitional control over certain behavior (Ajzen, 1985 \& 1988; Ajzen \& Madden, 1986). The PBC is also described to have a direct effect on behavior if the behavior in question is of non-volitional nature.

During the last two decades, the TPB model has been successfully used for describing a variety of behaviors including outdoor recreation participation (e.g., Ajzen \& Driver 1992 \& 1991; Kimiecik, 1992; Rossi, \& Armstrong, 1999; Mummery \& Wankel, 1999; Hrubes, Ajzen \& Daigle 2001; Eves, Hoppe, \& McLaren, 2003; Hausenblas, et al., 2008; Shrestha et al., 2012a). 
Meta-analytic reviews conducted by Godin and Kok (1996), Conner and Armitage (1998), Armitage and Conner (1999 \& 2001) and Downs and Hausenblas (2005a \& 2005b) across health, leisure and recreation behaviors found that in most of the studies the TPB model predicted a relatively sufficient amount of variation in behavioral intentions and participation. According to these reviews, the amount of variation explained by TPB in intention ranged between $39 \%$ and 55\% and the amount of variation explained in reported or observed participation ranged between $27 \%$ and $51 \%$. These reviews also confirmed that intention was a strong and reliable predictor of recreation activity participation while attitudes, subjective norms and PBC were positively related to the intention. Among the three predictors, PBC was a consistent and strong predictor of both behavioral intentions and participation, especially for those activities that were less under volitional control. The role of the attitudes and subjective norms depended on the type of behavior and strength of measure of normative components.

Three studies applied TPB model to explain hunting behavior, i.e., Shrestha et al. (2012a), Hrubes, Ajzen, and Daigle (2001) and Rossi and Armstrong (1999). The study conducted by Hrubes, Ajzen, and Daigle (2001) found that attitudes, subjective norms and PBC contributed $93 \%$ of the variance in explaining behavioral intention of hunting, while intention alone described $62 \%$ of the variation in hunting participation. The other two studies only examined the model's capacity to explain hunting intentions. Rossi and Armstrong (1999) found TPB explained only 38\% variance in the hunting intention. The studies of both Hrubes et al. and Rossi et al. were for general hunting behavior, rather than a specific big game species such as deer. According to Ajzen (1991) TPB is more effective for describing specific behavior at specific time and place. Following this, the study of Shrestha et al. was more focused on explaining specific hunting intention (deer hunting) during specific hunting season. Their study was able to describe $49 \%$ variations in the deer hunting intentions. It would be also relevant to mention that Ajzen (1988) contended that the effect of non-TPB variables on intention was likely to be mediated by the variables included in the TPB. However, none of the studies, including the three referenced here, has attempted to extend the model by including constraint dimension.

In leisure studies, research has focused on constraints for several decades, with some studies in outdoor recreation dating back to the mid 1900's (Jackson \& Burton, 1999). Theories and frameworks have emerged with aspirations of defining constraints and the effect on leisure 
behavior. For example, leisure constraints have been defined as "the factors that are assumed by researchers and perceived by individuals to inhibit or prohibit participation and enjoyment in leisure" (Jackson, 2000, p. 62). According to Jackson and Scott (1999), the term "constraints" includes not only the physical and external-to-the-individual constraints such as facility problems, but also includes social constraints such as the lack of partners, and psychological constraints such as confidence, fear, and perceived skills. Crawford and Godbey (1987) categorized leisure constraints into intrapersonal, interpersonal, and structural constraints. Intrapersonal constraints are considered to be "internal" to an individual and are mainly related to the psychological states and attributes, such as lack of skills and perceived health problems. Interpersonal constraints are related to social states and attributes such as an individual's inability to find partners to participate with. Structural constraints are "external-to-an individual" such as lack of resources, lack of facilities, and financial limitations. According to Crawford, Jackson and Godbey (1991) these constraints are encountered hierarchically. They viewed that the intrapersonal (psychological) and interpersonal (social) constraints have a direct influence on an individual's preference for a specific activity. Some studies however showed that people participated in leisure even in the presence of constraints (Son et al., 2008; Burns \& Graefe, 2007; Walker, Jackson \& Deng, 2007; Hubbard \& Mannell, 2001; Carroll \& Alexandris, 1997; Scott \& Jackson, 1996). In order to describe participation in leisure even in the presence of constraints, Jackson, Crawford and Godbey (1993) proposed that people try to negotiate constraints for participation in a leisure activity. According to this proposition, the presence of constraints does not always lead to non-participation. Rather the final outcomes (participation, non-participation, modified participation), to a large degree depend upon the negotiation of these constraints with the development of appropriate strategies. The review of constraint research by Godbey, Crawford and Shen (2010) and Jackson (2000), found that several studies supported negotiation of leisure constraints and many individuals were participating in leisure activities (modified participation) even in the presence of constraints (Son et al., 2008; Burns \& Graefe, 2007; Walker, Jackson \& Deng, 2007; Hubbard \& Mannell, 2001; Carroll \& Alexandris, 1997; Scott \& Jackson, 1996). Like the TPB, the constraints approach to research also recognizes that leisure behaviors are not always under the degree of volitional control (Jackson \& Scott, 1999; Smith \& Biddle, 1999). 
Shrestha, et al. (2012b) found there are some similarities between the three constructs of TPB and three types of constraints. For example, the attitudes concept appears to be similar to the intrapersonal constraints in the sense that both are the factors that are internal to the person. The subjective norms seem comparable to the interpersonal constraints in the sense that both factors exhibit a person's social interaction. The PBC seems similar to the intrapersonal constraints in the sense that they represent factors related to the availability of different kind of resources and skills. The potential conceptual relationships among these variables have been suggested by many scholars (Walker, Jackson \& Deng, 2007; Hubbard \& Mannell, 2001; Wigfield \& Eccles (2000); Vallerrand \& Loisier (1999). For example, Mannel and Kleiber (1997) suggested that like intrapersonal and interpersonal constraints, the attitudes, subjective norms and PBC could describe the formation of leisure preference. Wigfield and Eccles (2000) and Eccles, et al. (1983) suggested that choice, preference and performance can be explained by beliefs (e.g., attitudes, sub-norms and PBC). Walker, Jackson and Deng (2007) expressed concern that isolating intrapersonal constraints from other psycological factors such as attitude, subjective norms and PBC. Shrestha et al. (2012b) pointed out that if the above suggestions are true, leisure constraints, especially intrapersonal constraints, should be a construct similar to attitudes, subjective norms and PBC and help to explain intention.

Many constraint negotiation studies (Koca, Henderson, Asci, \& Bulgu, 2009; Walker, Jackson \& Deng, 2007; Livenwood \& Stodoloska, 2004; Alexandris, Tsormpatsoudis \& Grouios, 2002; Hubbard \& Mannell, 2001; Caroll \& Alexandris, 1997) have indicated the influence of motivation on negotiation of perceived constraints. According to Vallerrand and Loisier (1999) social factors and psychological mediators, including attitudes, values and beliefs, enforce intrinsic and extrinsic motivations which influences constraint negotiation. Hubbard and Mannell (2001) and Jackson and Rucks (1995) also suggested that personal control factor, a construct similar to the PBC, may play a role in constraints negotiation. These literatures suggest that the predictors of the TPB my have some role in constriant negotiation through motivations. Several scholars (Hubbard \& Mannell, 2001; Walker, Jackson \& Deng, 2007) expressed a need for investigating the relationships between constraints and variables related to the attitudinal models describing participation. A study conducted by Dawson, Gyurcsik, Culos-Reed and Brawley (2001) found the power of PBC in the TPB is related to the perceived availability of resources (e.g., time, money, skills, \& cooperation of other people) to an individual, the existence or 
absence of perceived constraints, and perceived ability to overcome those constraints. This result supported Ajzen and Driver's (1991) the view that the perceptions of presence and strength of internal and external constraints decrease the intensity of the PBC. Alexandris, Barkoukis, Tsormpatsoudis and Grouios (2003) found a negative impact of constraints on intention, while Alexandris and Stodolska (2004) found negative relationships between the attitudinal variables included in the TPB and perceived leisure constraints. More recently, Alexandris, Barkoukis and Tsormpatsoudis (2007) and Shrestha et al. (2012b) found that the predicators of the TPB mediated the relationships of different constraints dimensions with behavioral intention, and that PBC has a strong mediation effect on these relationships. The literature suggests that though there have been some efforts to expand the TPB by integrating non-TPB factors such as past behavior (Hausenblas et al., 2008; Cheng, Lam, \& Hsu, 2005), role identity (Kouthouris \& ASpontis, 2008), and social support (Rhodes, Jones, \& Courneya, 2002), with mixed success, there have been no attempt made to expand the TPB by integrating constraints, despite the established relationships of constraints with TPB predictors literature.

\section{Methods}

\section{Mail Back Survey}

The data were collected using a two-stage mail back survey of Oregon hunters following Dillman's (2000) Tailored Design Method. The first mail back survey was conducted in JulySeptember, 2009. This survey asked respondents' intentions regarding participating in deer hunting in the 2009 hunting season, and the frequency of perceived constraints associated with hunting. A total of 2000 hunters who had purchased big game hunting license for the year 2008 were randomly selected from information provided by the Oregon Department of Fish and Wildlife (ODFW). Pre-survey cards were mailed before mailing the survey instrument. Postsurvey cards were mailed to the non-respondents requesting them to respond twice; the first time without and second time with a replacement instrument. We received 360 completed surveys (RR 20\%) after deleting 190 incorrect addresses. Dillman (2000) suggested incentives and an additional contact with the non-respondents via certified mail or its alternative. These steps might have had improved the response rate, however, it was not feasible in this case. First, because the hunting season had already started in Oregon, the hunting intention questions were 
made irrelevant, as some of the respondents might have already begun hunting. Second, providing incentives for completing and returning surveys was not permitted.

The second mail back survey was conducted in January 2010 with 360 hunters who completed the first survey in 2009. The purpose of second survey was to ask whether they participated in deer hunting in 2009 in Oregon. The response rate for the second survey was $67 \%$. The analysis was conducted with 242 responses as they consisted of both intention and participation responses.

\section{Measurement and Scales}

Multiple item constructs suggested by Ajzen and Driver (1992) were used for measuring TPB constructs. Attitude was measured with six items, subjective norms with four items, and $\mathrm{PBC}$ and intentions each with three items. These items were rephrased to represent participation in deer hunting in Oregon. Each of the constructs was measured using a 7-point semantic differential scale ranging from 1 (strong disagreement/negative feeling) to 7 (strong agreement/positive feeling). Hunting intentions represented respondents' conscious plan or decision to participate in deer hunting in Oregon during the 2009 hunting season. Attitudes toward hunting reflected a person's evaluation of the benefits of participation in deer hunting in Oregon in 2009. Subjective-norms represented the respondents' perception about what other people important to the person thought about his/her participation in deer hunting in Oregon during the 2009 hunting season. The PBC characterized a person's perceived level of confidence to participate in deer hunting in Oregon in 2009 hunting season, taking account of all nonvolitional forces, including resources and skills. Participation in hunting was conceptualized as "reported participation in deer hunting in Oregon in 2009 hunting season" and was measured by a binary scale with "yes" or "no" response options.

Perceived constraints to hunting were measured by asking about 25 constraints for participation in hunting in Oregon. The constraint items were derived from Shinew, Floyd and Parry (2004) and Burns and Graefe (2007) and were rephrased for hunting. A 5-point scale developed by Shinew et al. (2004), ranging from 1 (never/not at all) to 5 (always/a lot) was used to measure the hunting constraints. 
We compared our sample to the hunting population for selected indicator variables as a method of understanding if non-response bias existed. The results showed little difference in the male and female ratio and mean age of hunters between the sample and the population. For example, the mean age of the population was 52 years and sample mean was 51 years, while the male-female ratio was 84:14 in the population and 83:17. In addition, an extrapolation approach suggested by Armstrong and Overton (1977), and Israel (2011) was used. For this process, among the participants of 2009 survey, we compared the profiles of the hunters who responded before the second follow up survey $(n=236)$ with the hunters who responded after second follow up survey $(n=124)$. There were no significant differences between the groups in these respects. Finally, we also found that our sample's deer harvesting success rate (35\%) was within the forecasted deer harvesting success rate range of 26-37\% for the years 1992 to 2003 (ODFW, 2011). These results suggested there were little or no differences between respondents and nonrespondents.

\section{Data Analysis}

IBM SPSS, Version 21 was used for descriptive and inferential analysis of the data. The descriptive analysis included respondents' profiles, hunting motivations and satisfaction, harvest rate, and items of TPB model and constraints. Principal component analysis (PCA) method of factor analysis (varimax rotation) was implied to identify constraints dimensions. Following Fabrigar, Maccallum, Wegener, and Strahan (1999), besides eigenvalues, communality score criterion was used to eliminate odd and unwanted variables during the PCA. According to Costello and Osborne (2005), items with low communality value (.5 or lower) could be dropped or a new similar item should be added. According to Moore and Benbasat (1991), removing a specific variable would not negatively impact the domain. Accordingly, we removed items having communality scores of .4 or below. The reliability of the constraints dimensions and TPB construct measurement scales were examined by calculating Cronbach's $\alpha$ lpha. Pearson's correlation coefficients were used to examine correlations among various dependent and independent variables of the model.

Structural equation modeling (SEM) was used to assess the fit of the data with the original and extended TPB models. The SEM was performed in Analysis of Moment of Structures (AMOS). The measurement model (observed-latent variables relationships) was 
assessed using confirmatory factor analysis (CFA). The structural model assessment was performed by calculating path coefficients (regression weights) using maximum likelihood estimates (MLE). The fit of the measurement model and structural model was assessed using Chi-square fit index (CMIN). However, because of the high sensitivity of the Chi-square to sample size (Garson, 2011), five other popular goodness of fit measures were applied (Arbuckle 2006; Jaccard \& Wan 1996; Kline 1998). These measures included relative chi-square (CMIN/DF ratio), baseline comparisons like Comparative Fit Index (CFI), Normed Fit Index (NFI), and the Standardized Root Mean Square Residuals (SRMR) and Root Mean Square Error of Approximation (RMSEA). Models were compared by assessing chi-square fit index, CMIN/DF ratio), Akaike information criterion (AIC) and Browne-Cudeck criteria (BCC). The models having lower values for these measures were regarded as comparatively better fitted model.

\section{Results}

\section{Profile of the Respondents}

Nearly all of the respondents were white (97\%) and male (83\%) The mean age of the respondents was 52 years, while the presence of young respondents (20 years or below) was just $2.5 \%$. A majority of the respondents were very experienced hunters (mean number of years of hunting in Oregon 28.1, and median 30 years). The presence of beginners was just 2.3\%. The motivation of deer hunting was "meat/trophy/hide" for about half of the respondents (45\%), followed by "solitude/relaxation/open space" and "enjoy nature" (24.2\%) and "time with family and friends" (17.5\%). Deer harvesting success rate was relatively lower in 2009 (32.3\%) than in $2008(36.2 \%)$. The quality of hunting experience, measured on a 6-point scale $(1=$ worst to $6=$ perfect) indicated that it was below average in both $2008($ mean $=2.8)$ and $2009($ mean $=2.9)$. The hunters reported that low deer population, reduced access, too many hunters, and increase in predator population were the important reasons of lower harvesting success in 2008.

\section{TPB Components}

The reliability test (Cronbach's $\alpha$ ) of the TPB constructs indicated that removal of item "people important to me will go deer hunting" from the measures of subjective norms would increase scale reliability significantly, hence this item was removed. The reliability test scores $(\alpha$ 
coefficients) in Table 1 confirmed that the items and scales used for measuring intentions (.943), attitudes (.909), subjective norms (.822) and PBC (.892) were reliable. Table 1 also shows that the respondents, in general, possessed very positive attitudes toward participating in deer hunting (overall mean $=5.59, \mathrm{SD}=1.42$ ) in Oregon during the 2009 hunting season (Table 1). The perceived influence of significant others (subjective norms) on their decision to participate in deer hunting was also very positive (overall mean $=5.84, \mathrm{SD}=1.06$ ). The hunters believed that they have higher levels of control (PBC) over their ability to participate in deer hunting (overall mean $=5.91, \mathrm{SD}=1.49)$. Most important, the hunters expressed a highly positive intention to participate in deer hunting in the 2009 hunting season (overall mean $=6.23, \mathrm{SD}=1.33$ ). Consistent with their intentions, a majority of the respondents $(92 \%)$ reported that they participated in deer hunting in 2009. A small proportion of respondents (8\%) could not participate in hunting in 2009, despite their intentions to participate. According to the respondents, the most common reasons for not participating in 2008 hunting season were cost of participation, difficulties in drawing a tag, increased tag cost, personal and partners poor health, and loss of equipment. Likewise, lack of transport, too many hunters, and increase in the predator population were the important reasons of lower harvesting success. 
Table 1: Mean attitudes, subjective norms, PBC and intentions to participate in deer hunting in 2009 in Oregon and reliability of the items used to measure the TPB constructs $(n=242)$

\begin{tabular}{llcc}
\hline TPB constructs & Items used for measuring TPB constructs & Mean (s.d) & $\alpha$ \\
\hline $\begin{array}{l}\text { Intention } \\
\text { (oveall mean }\end{array}$ & I intend to participate in deer hunting & $6.36(1.33)$ & .943 \\
$6.23)$ & I will try to participate in deer hunting & $6.18(1.44)$ & \\
\hline & I am planning to participate in deer hunting & $6.17(1.45)$ & \\
Attitude & Hunting deer will be: Unpleasant-Pleasant & $5.94(1.52)$ & \\
$\begin{array}{l}\text { (overall mean } \\
5.59)\end{array}$ & Hunting deer will be: Boring-Interesting & $5.58(1.85)$ & \\
& Hunting deer will be: Unenjoyable-Enjoyable & $5.96(1.58)$ & .909 \\
& Hunting deer will be: Harmful-Useful (socially) & $5.54(1.79)$ & \\
\hline $\begin{array}{l}\text { Subjective } \\
\text { Norms } \\
\text { (overall mean }\end{array}$ & Hunting deer will be: Harmful-Useful (healthwise) & $5.75(1.71)$ & .884 \\
$5.84)$ & Hunting deer will be: Harmful-Useful (financially) & $4.81(1.79)$ & \\
\hline $\begin{array}{l}\text { PBC } \\
\text { (overall mean }\end{array}$ & People important to me think I should hunt deer & $5.81(1.42)$ & $6.15(1.10)$ \\
5.91, s.d 1.49) & If I want to go deer hunting, I can go easily. & $6.29(1.00)$ \\
& Factors that influence my decision to go deer hunting, & $5.64(1.57)$ & \\
\hline
\end{tabular}

\section{Notes:}

1. Mode was 7 for all items

2. Rephrasing included addition of ".... in Oregon in 2009 hunting season" to all items

\section{Hunting Constraints}

The PCA, after removal of six items having communalities values less than 0.4 , produced five unique constraints dimensions which explained $58 \%$ of the variance (Table 2). The five constraint dimensions were (a) FEAR (b) skill and confidence (SAC), (c) health and partner (HAP), (d) site and facility management (SFM), and (e) time, money and distance (TMD). Loading of items in their respective dimensions was high ( $b$-value close to .5 or higher). The Cronbach's $\alpha$ for each of the five constraint dimensions was close to .70 (Table 2) which asserted the reliability of the scales. These five constraint dimensions were somewhat consistent with previous constraints literature, representing the three types of constraints (intrapersonal, interpersonal, and structural) as suggested by Crawford and Godbey (1987). The FEAR dimension consisted of three psychological (internal to the person) items representing intrapersonal constraints such as "fear of sexual assault" and "fear of outdoors." Four 
intrapersonal items related to lack of skill and confidence, including "lack of skill," "lack of selfconfidence," and "lack of training facilities" were loaded in SAC dimension. The HAP dimension consisted of three items representing a mix of interpersonal and intrapersonal constraints, including “your physical health," "physical health of partner," and "don't have anyone to go with." The remaining two dimensions represented two sub-dimensions of structural constraints (i.e., SFM dimension \& TMD dimension). The SFM dimension included four items related to site management, including "sites too crowded," "lack/difficulty to find deer," and "inadequate facilities," while the TMD dimension included personal structural constraints items, of "lack of time," "lack of transportation," "sites far away," and "lack of money." Similar constraints dimensions were reported by Shrestha et al. (2012b) and Alexandris (2007).

Table 2: Mean for constraint items, factor loading of items on constraints dimensions and reliability of items measuring the constructs $(n=242)$

\begin{tabular}{|c|c|c|c|c|}
\hline $\begin{array}{l}\text { Constraint } \\
\text { Dimensions }\end{array}$ & $\begin{array}{l}\text { How often you feel these constraints for } \\
\text { participation in hunting? }\end{array}$ & $\begin{array}{l}\text { Mean } \\
(\mathrm{SD})\end{array}$ & $\begin{array}{l}\text { Factor } \\
\text { Loading }\end{array}$ & $\begin{array}{l}\text { Cronbach' } \\
\text { s alpha }(\alpha)\end{array}$ \\
\hline \multirow{3}{*}{$\begin{array}{l}\text { Fear } \\
\text { (overall mean } 1.24)\end{array}$} & Fear of sexual assault & $1.18(.54)$ & .822 & \multirow{3}{*}{672} \\
\hline & Fear of outdoors & $1.18(.45)$ & .713 & \\
\hline & Fear of crime & $1.38(.73)$ & 698 & \\
\hline \multirow{4}{*}{$\begin{array}{l}\text { Skill \& Confidence } \\
\text { (overall mean 1.35) }\end{array}$} & Lack of self-confidence & $1.25(.58)$ & .724 & \multirow{4}{*}{.712} \\
\hline & Lack of skills & $1.39(.64)$ & .657 & \\
\hline & Lack of training facilities & $1.47(.76)$ & .642 & \\
\hline & Don't like to do things in outdoor & $1.29(.80)$ & .576 & \\
\hline \multirow{3}{*}{$\begin{array}{l}\text { Health \& Partner } \\
\text { (overall mean 2.08) }\end{array}$} & Health of someone you hunt with & $2.10(1.06)$ & .818 & \multirow{3}{*}{.675} \\
\hline & Lack partner/No one to go with & $2.02(1.09)$ & .733 & \\
\hline & Your physical health & $2.12(1.24)$ & 699 & \\
\hline \multirow{4}{*}{$\begin{array}{l}\text { Site \& Facility } \\
\text { Management } \\
\text { (overall mean 2.18) }\end{array}$} & Inadequate facilities & $1.83(.94)$ & .776 & \multirow{4}{*}{.752} \\
\hline & Sites are too crowded & $2.60(1.10)$ & .742 & \\
\hline & Difficulty of finding animal/deer & $2.62(1.22)$ & .715 & \\
\hline & Lack of information & $1.66(.85)$ & .651 & \\
\hline \multirow{5}{*}{$\begin{array}{l}\text { Time, Money \& } \\
\text { Distance } \\
\text { (overall mean 1.92) }\end{array}$} & Lack of time & $2.30(1.16)$ & .770 & \multirow{5}{*}{699} \\
\hline & Can't afford & $1.99(.96)$ & .635 & \\
\hline & Sites are far away & $2.18(1.10)$ & .557 & \\
\hline & No opportunity when want to perform & $1.75(.84)$ & .453 & \\
\hline & Lack of transportation & $1.37(.70)$ & .412 & \\
\hline \multirow{6}{*}{$\begin{array}{l}\text { Items excluded from } \\
\text { PCA based on } \\
\text { commonality criteria }\end{array}$} & Sites are closed & $2.21(1.19)$ & & \\
\hline & Like to do other things for recreation & $2.14(1.08)$ & & \\
\hline & Conflict with other users & $1.89(1.06)$ & & \\
\hline & Feeling of unwelcome by staff & $1.55(.81)$ & & \\
\hline & Racial conflict among users & $1.18(.43)$ & & \\
\hline & Complex rules and regulations & $2.29(1.18)$ & & \\
\hline
\end{tabular}


Among the five constraints dimensions, the SFM (overall mean = 2.18) and HAP (overall mean $=2.08$ ) were perceived to be more frequently realized by the respondents in comparison to FEAR, and SAC and TMD dimensions. Crosstab analysis showed that the items "your health condition," "no one to go with," and "partner's health condition" constraints were more frequently reported by older people.

Before conducting the model assessment, we examined the correlations of overall means of constraint dimensions with overall means of TPB elements (Table 3). As expected, each of the five constraint dimensions and TOTAL constraint index (overall mean of 19 constraint items) showed a significant negative correlation with the TPB variables, with the exception of the correlation between FEAR dimensions and hunting participation. The constraint dimensions exhibited relatively higher correlations with the PBC and intentions than with the attitude and subjective norms.

Table 3: Correlation of overall means of constraint dimensions with overall means of TPB components $(n$ $=242$ )

\begin{tabular}{lllllll}
\hline & FEAR & HAP & SAC & SFM & TMD & TOTAL \\
\hline Attitude & $-.222^{* *}$ & $-.261^{* *}$ & $-.145^{* *}$ & $-.288^{* *}$ & $-.246^{* *}$ & $-.353^{* *}$ \\
\hline Sub. Norms & $-.314^{* *}$ & $-.195^{* *}$ & $-.345^{* *}$ & $-.227^{* *}$ & $-.290^{* *}$ & $-.387^{* *}$ \\
\hline PBC & $-.300^{* *}$ & $-.229^{* *}$ & $-.424^{* *}$ & $-.420^{* *}$ & $-.435^{* *}$ & $-.541^{* *}$ \\
\hline Intension & $-.427^{* *}$ & $-.206^{* *}$ & $-.437^{* *}$ & $-.351^{* *}$ & $-.406^{* *}$ & $-.521^{* *}$ \\
\hline Hunted deer & -.062 & $-.143^{*}$ & $-.231^{* *}$ & -.104 & -.125 & $-.195^{* *}$ \\
\hline
\end{tabular}

Notes:

1. ${ }^{*}$ Correlation significant at $\alpha$ level of 0.05

2. ${ }^{* *}$ Correlation significant at the alpha level of 0.01

\section{Assessment of Original TPB Model}

The SEM analysis of original TPB model showed that the measurement model was valid. Figure 1 displays that the Beta values of latent variables (i.e., attitudes, subjective norms, PBC \& intentions) with their respective observed variables (i.e., items measured) are very high (close to .80 or higher except for between attitude and item ATT6). 


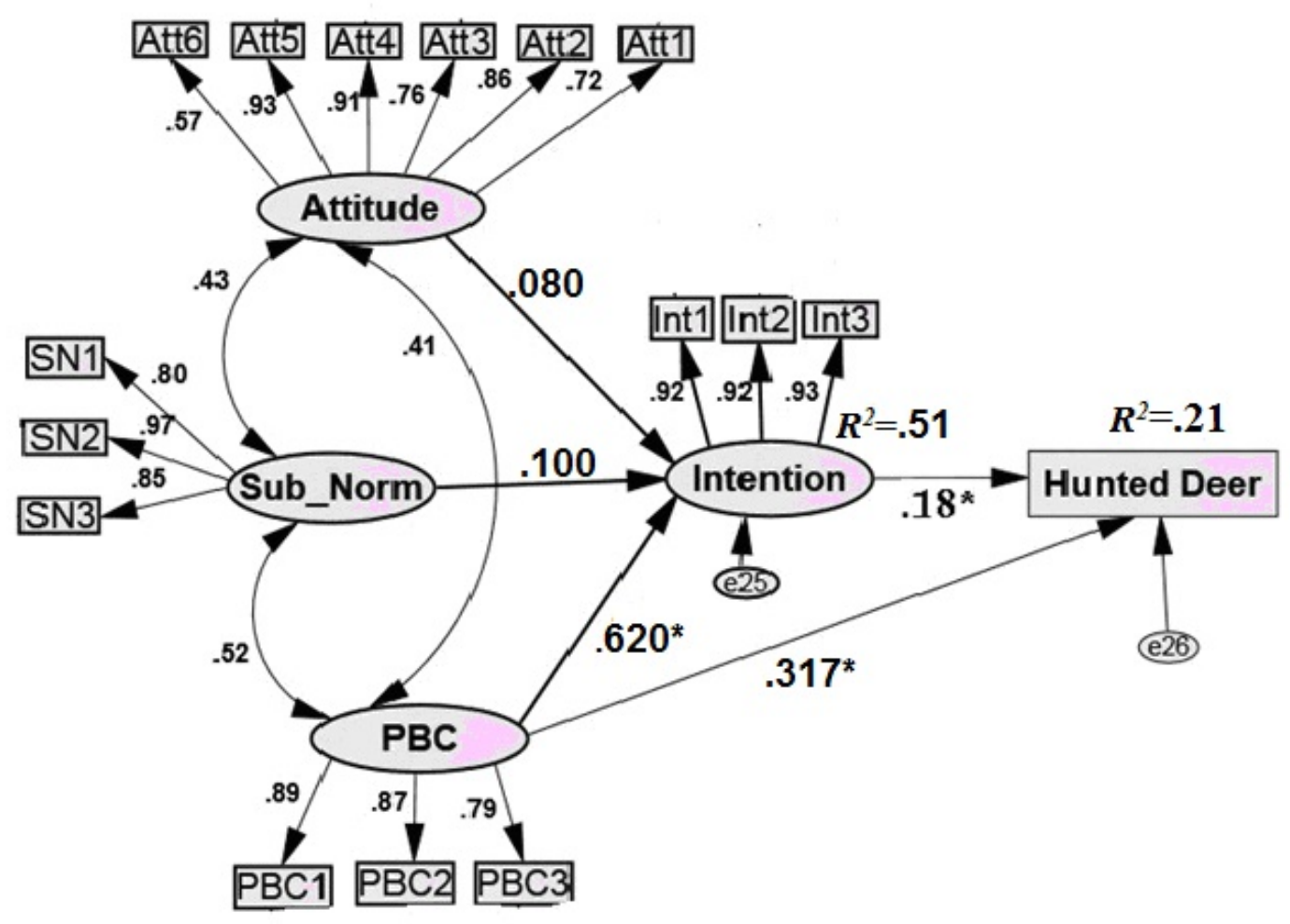

Figure 1: Original TPB model showing relationships among latent variables and their respective measurement variables $(n=242)$

The structural model statistics in Table 4 showed that chi-square value is significant $\left(\mathcal{Z}^{2}\right.$ $=338.234, p<.01, n=242, \mathrm{DF}=97)$ and RMSEA (.102) is high. These two statistics indicated that the deer hunting data does not fit well with the TPB model. However, the four other model fit indexes $\left(\chi^{2} / \mathrm{DF}=3.487, \mathrm{CFI}=.923, \mathrm{NFI}=.905, \mathrm{SRMR}=.502\right)$ indicated that the deer hunting participation data fit well with the original TPB model. This suggests that our first research question that TPB model can successfully explain deer hunting participation is accepted. Figure 1 and Table 4 also displayed that the TBP model explained 51\% variations in the deer hunting intentions $\left(R^{2}=.515\right)$ and $21 \%$ variation in reported deer hunting participation $\left(R^{2}=.212\right)$. It further illustrated that attitude and subjective norms did not have a significant effect on intention, while PBC played most important roles in describing intentions. The result exhibited that although both intentions $(\beta=.177)$ and $\operatorname{PBC}(\beta=.317)$ significantly affected reported participation in deer hunting, the strength of effect of PBC was almost double that of intentions. This finding demonstrated that, unlike general hunting, (Hrubes et al., 2001; Rossi \& Armstrong 1999), deer hunting is more of non volitional nature (Shrestha et al., 2012a). 
Table 4: Model assessment statistics for original and constraint integrated TPB models $(n=242)$

\begin{tabular}{|c|c|c|c|c|c|c|c|c|c|c|c|}
\hline \multirow[b]{2}{*}{ Models } & \multicolumn{2}{|c|}{ Variance Explained } & \multicolumn{9}{|c|}{ Model Fit Indexes } \\
\hline & $R^{2}$ Intention & $\begin{array}{l}R^{2} \\
\text { Behavior }\end{array}$ & $X^{2}$ & $\mathrm{DF}$ & $\chi^{2} / \mathrm{DF}$ & SRMR & CFI & TLI & RMSEA & AIC & $\mathrm{BCC}$ \\
\hline Original TPB & .515 & .212 & $338.234^{* *}$ & 97 & 3.487 & .502 & .923 & .905 & .102 & 448.234 & 552.303 \\
\hline FEAR Integrated & .650 & .252 & $460.236^{* *}$ & 143 & 3.218 & .070 & .905 & .908 & .096 & 592.234 & 718.216 \\
\hline HAP Integrated & .469 & .203 & $486.716^{* *}$ & 143 & 3.404 & .1066 & .896 & .875 & .100 & 580.716 & 744.696 \\
\hline SAC Integrated & .544 & .215 & $474.968^{* *}$ & 161 & 2.950 & .078 & .907 & .890 & .090 & 572.968 & 743.926 \\
\hline SFM Integrated & .441 & .210 & $495.026^{* *}$ & 161 & 3.075 & .1233 & .903 & .885 & .093 & 593.026 & 763.984 \\
\hline TMD Integrated & .487 & .224 & $499.351^{* *}$ & 180 & 2.774 & .0892 & .906 & .909 & .078 & 601.351 & 779.286 \\
\hline $\begin{array}{l}\text { TOTAL Const. } \\
\text { Integrated }\end{array}$ & .569 & .240 & $496.798^{* *}$ & 180 & 2.760 & .0700 & .910 & .909 & .072 & 598.798 & 776.734 \\
\hline
\end{tabular}

Notes:

1. ${ }^{* *}$ Significant at the alpha level of 0.01

2. *Significant at the alpha level of 0.05 


\section{Assessment of Constraint Integrated Models}

TPB predictors partially or fully mediate the effect of different constraint dimensions on intentions (Alexandris, et al., 2007; Shrestha et al., 2012b). Likewise, leisure constraints model suggests that presence of constraints affect an individual's participation in a behavior. Our analysis also showed significant negative correlations between constraints and reported deer hunting participation (Table 3). Thus, we assumed a direct effect of constraints on participation, in addition to indirect effects through attitude, subjective norms and PBC. Accordingly, we developed six constraint integrated models, in each of which a constraints dimension was placed at the proximal end of the model where the relationship of constraint dimension with intention and behavior was mediated by the attitudes, subjective norms and PBC, directly and indirectly (Figure 2). These six models were: (a) fear integrated model (FIM), (b) health and partner integrated model (HAPIM), (c) skill and confidence integrated model (SACIM), (d) site and facility management integrated model (SFMIM), (e) time, money and distance integrated model (TMDIM), and (f) total constraints integrated model (TCIM). 


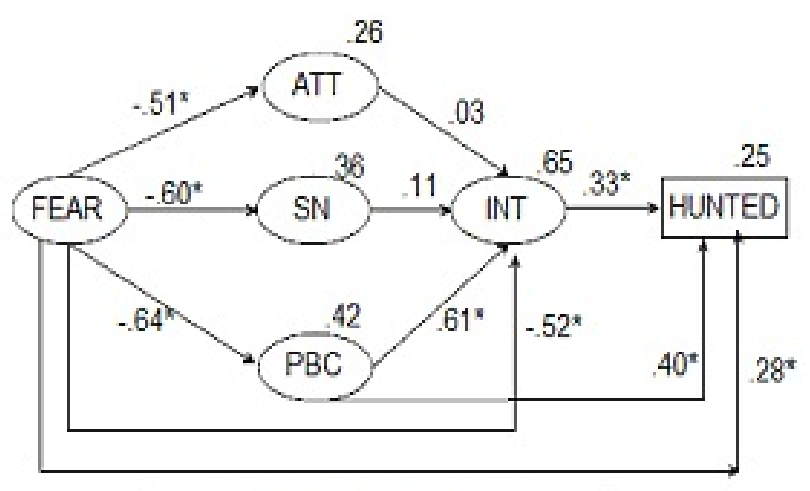

Figure 2A: FEAR Integrated

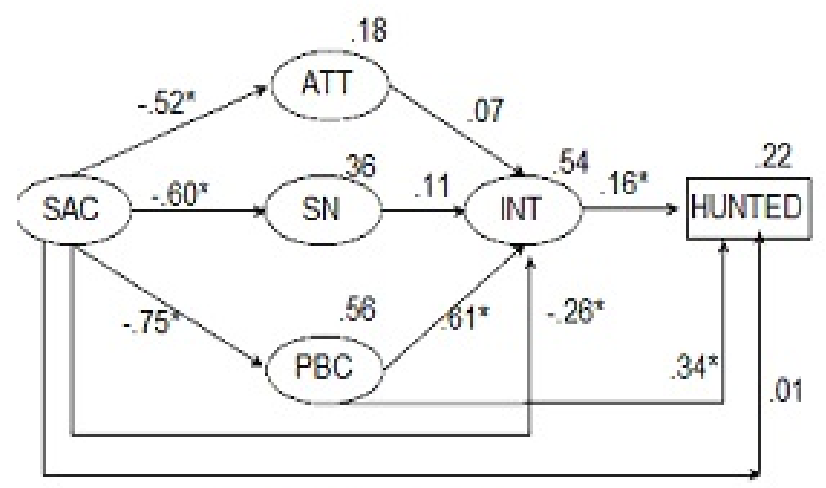

Figure 2C: SAC integrated

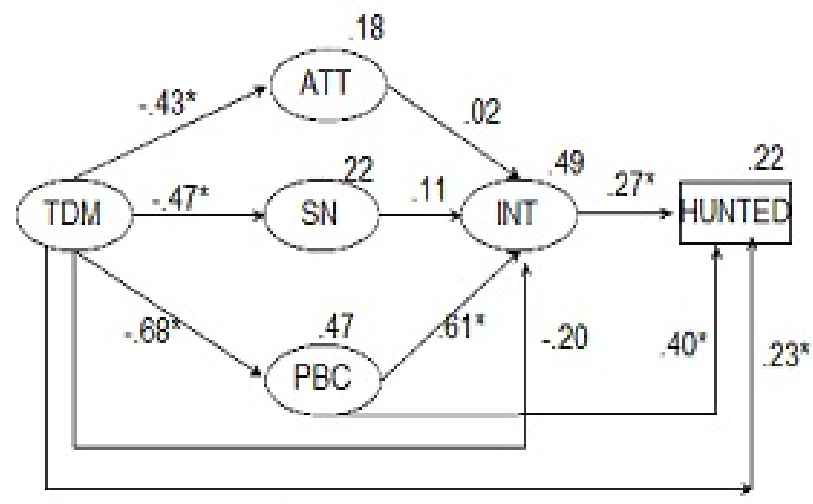

Figure 2E: TDM Constraints Integrated

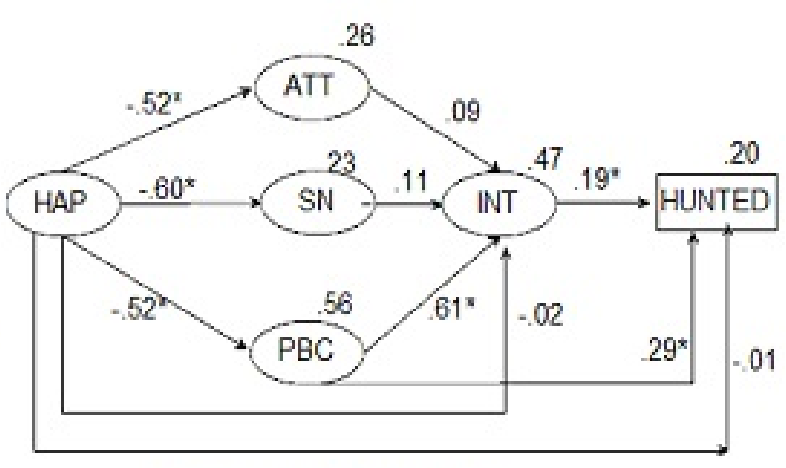

Figure 2B: HAP Integrated

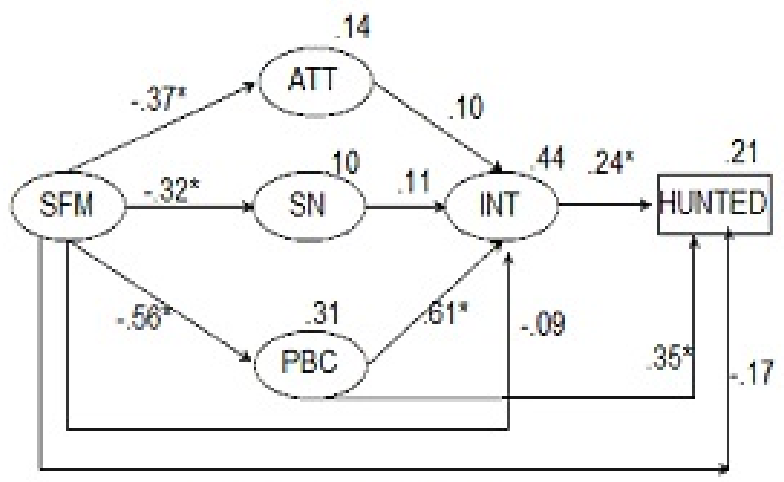

Figure 2D: SFM Integrated

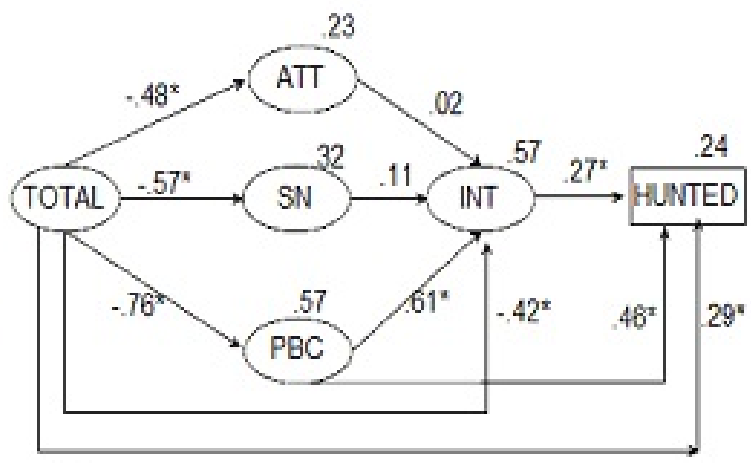

Figure 2F: TOTAL Constraint Dimension Integrated

Figure 2: Constraint integrated TPB models showing relationships among model variables $(n=242)$

Measurement modeling (factor analysis) showed in all extended models that the Beta value of observed variables (item) to their respective latent variables (attitudes, subjective norms, $\mathrm{PBC}$, intentions \& constraint dimensions) was .6 or above and significant. This reflected that the 
items and scales used for measuring their respective latent variables were valid. Structural modeling showed mix results. Similar to the original TPB model, the chi-square value was significant for all six extended models (Table 4), suggesting rejection of all extended models. Examination of other five indexes in Table 4, however, suggested that at least three of the six constraints integrated models (FIM, TMDIM \& TCIM) were not rejected. These models were not rejected because out of five additional model fit statistics, four indicated that the data fit well with these models. For example, for the FIM, the $\chi^{2} / \mathrm{DF}$ was 3.218 and the CFI, NFI, and SRMR were 9.05, .900, and .070 , respectively. Similarly, for the TMDIM, the $\chi^{2} / \mathrm{DF}$, CFI, NFI, and RMSEA were $2.774, .906, .901$ and .075 and for TCIM they were $2.760, .910, .909$, and .072 . The poorly fitted models were HAPIM, SACIM and SFMIM. The HAPIM was rejected by all fit indices, except for the $\chi^{2} / \mathrm{DF}$ ratio, while SACIM and SFMIM were rejected by three indexes. These findings suggested that the fear integrated, time, money and distance integrated and total constraint integrated TPB were accepted, indicating they successfully describe deer hunting intentions and behavior (models accepted). The remaining three extended models were rejected, as they did not successfully explained hunting intentions and behavior.

Figure 2 shows the relationships (standardized Beta) among the dependent and independent variables in all six extended models. It shows that, like the original TPB model, attitude and subjective norms failed to show significant contribution in describing intentions, while PBC significantly contributed to explain intentions as well as behavior. It also reveals that each constraint dimensions has significant negative impact on attitude, subjective norms, PBC and intentions. Examination of Beta coefficients in the rejected models shows an insignificant effect of constraints on reported deer hunting participation, despite the fact that the correlations analysis in Table 3 showed a significant correlation between them. This result indicated that the TPB predictors fully mediated the effect of HAP, SAC and SFM constraints on behavior. Conversely, the effects of constraints in the three accepted models reveal FEAR, TMD and TOTAL constraints have a significant positive relationship with deer hunting behavior, suggesting that effects of these constraints dimensions are partially mediated by the TPB predictors.

Examination of $R^{2}$ values in Figure 2 and Table 4 for the three accepted constraint integrated models shows that the FIM can explain $65 \%$ variance in intentions $\left(R^{2}=.650\right)$ and $25 \%$ variance in hunting behavior $\left(R^{2}=.252\right)$. Likewise, the TMDIM can explain $49 \%$ variance in 
intentions $\left(R^{2}=.487\right)$ and $22 \%$ variance in behavior $\left(R^{2}=.224\right)$ while TCIM explained $57 \%$ variations in intentions $\left(R^{2}=.569\right)$ and $24 \%$ variance in behavior $\left(R^{2}=.240\right)$.

The outcomes of multiple model comparison of original TPB model with three accepted constraint integrated models were mixed. In terms of model fit, in contrast to our assumption, the TPB model fit best among all alternative models. Thet $\chi^{2}$ value, as well as AIC and BIC values, are lowest for original TPB model, although the CMIN/DF ratio was higher for it. Also from parsimonious criterion, the original TPB was most simple model among all. The results however provided support to our assumption that some constraint integrated models, such as, FIM, TMDIM and TCIM, can successfully explain hunting behavior. On the other hand, in terms of amount of variance explained, the FIM explained about $15 \%$ more variation in intentions $(65 \%$ against $51 \%$ by the TPB model) and about $4 \%$ more variation in behavior ( $25 \%$ compared to $21 \%$ by the TPB). In a similar way, the TCIM also predicted $3 \%$ more variance in behavior in comparison to the original TPB model.

\section{Discussion}

The two main goals of this paper were to assess whether the original TPB model could successfully predict deer hunting participation and examine whether inclusion of constraints could improve the TPB model's capability in terms of model fit and power of predicting hunting participation. The fit of the data in the original model confirmed that the TPB model can be used in predicting deer hunting intentions and participation. Our results showed that the TPB model explained $51 \%\left(R^{2}=.515\right)$ variance in the hunting intentions and $21 \%\left(R^{2}=.212\right)$ variation in the reported participation in deer hunting. These findings are comparable to many earlier research works in terms of similarities and differences. For example, our results were consistent to the findings of Armitage and Conner's $(1999,2001)$ meta-analytic review of the TPB research in exercise and outdoor recreation domain, which showed that the TPB model explained $22 \%$ to $50 \%$ variations in behavioral intentions and $27 \%$ of variance in behavior when the behavior measures were self-reported. Downs et al. (2006) also reported that attitude, subjective norms and PBC predicted $55 \%$ of the variance in intentions. They reported that intentions and PBC explained $51 \%$ variance when dependent variable was past exercise behavior which is higher than our findings. We can argue that had they used actual behavior or reported behavior instead of past behavior, their results might have been different. 
No study has yet used TPB for predicting participation in deer hunting, although some studies used it for predicting general hunting intentions and participation. Rossi and Armstrong's (1999) work in an Alabama hunters' study showed that attitude, subjective norms, and PBC could describe $38 \%$ of the variance in hunting intentions. Hrubes et al. (2001), in a Vermont general hunter's survey, however found that the TPB model explained 86\% variance in general hunting intentions, which is exceptionally higher in compare to other studies. Hrubes et al. did not provided any explanation regarding what could have resulted in such a large amount of variance being explained. Sherstha et al. (2012a) found that TPB model could explain $49 \%$ variations in their Oregon hunters study. They explored possible reasons for such a huge differences in the amount of variance explained between their and Hrubes et al.'s findings. One of the reasons they suggested was based on "specificity" criteria of measuring TPB constructs including the behavior. They suggested that higher amount of variance explained in the Hrubes et al.'s study might be due to lack of focus on a specific hunting activity in terms of species, place and time. According to Ajzen (1991), TPB is more efficient for describing intentions and behaviors for specific activities. In the case of Hrubes et al., the lack of specificity might have provided the hunters the freedom to consider participation in hunting many game species during expressing their attitudes, subjective norms, PBC and intentions. This, in turn, might have led them expressing more positive attitudes, subjective norms, PBC, and hunting intentions based on the species they intend to hunt at any place and time; which might have inflated the amount of variance explained.

Rossi and Armstrong (1999) reported that all three predictors of the TPB significantly affected hunting intentions. Our study found that only PBC had significant effect on deer hunting intentions and the role of attitude and subjective norms was less important. These findings reflected that deer hunting is a more of a non-volitional activity which is not always under one's conscious control. This indicated that only positive personal and social motivations are not enough for participating in deer hunting. In reality, it requires over coming many limitations ranging from personal skill, availability of time and physical and financial resources. This verifies Ajzen's argument that as the intensity of PBC increases the roles of intrapersonal (attitude) and interpersonal personal (subjective norms) forces decrease. According to Ajzen (1991, p. 188) "The relative importance of attitude, subjective norm, and $P B C$ in the prediction of intention is expected to vary across behaviors and situations ..." He claimed that in situations where attitudes are strong, or where normative influences are powerful, PBC may be less predictive of 
intentions and vice versa. This means the magnitude of the PBC-intention relationship is dependent on the type of behavior and context. Sherstha et al. (2012a), who found results similar to ours, provided an additional explanation for it based on the expectancy-value model (Fishbein \& Ajzen, 1975). As suggested by Fishbein and Ajzen (1995), Daigle, Hrubes, and Ajzen (2002) reported that the hunter participated in preferred activities because they believed that preferred activities are expected to produce more desired outcomes than the less desired activities. Daigle et al. went on to suggest that preference was associated with more favorable attitudes, subjective norms, and perceptions of control. Shrestha et al. (2012a) reported that Oregon hunters were aware that not all of their behavioral beliefs, such as successful harvesting of deer for meat, could be met by participating in deer hunting. This is why, despite positive attitude and subjective norms, the hunters might have had possessed different levels of intentions. Hini, Gendall, and Kearns (1995) suggested that such relationships might be associated with the amount and quality of opportunity to perform the behaviors. People may have strong positive attitudes and beliefs, but, knowing that there are limited and less quality opportunities available in a specific place for a specific activity, an individual's intentions might not be truly reflected by his/her attitudes and beliefs.

The second objective of the study was to extend the TPB model by integrating constraint dimensions and compare its efficiency in describing hunting behavior with the original model. Our expectation was that the constraint integrated models will be more efficient than the original TPB model in terms of model fit and amount of variance described in participation. The outcomes of the study were, however, mixed. The results of multiple model comparisons indicated that the original TPB model fit better with hunting participation data; however three of the constraint dimension integrated models (i.e., FIM, TMDIM \& TCIM) also showed good fit with the data and two which explained about $4 \%$ more variance in the reported hunting participation, which is considered a good increase in social science.

Before discussing the efficiency of the models we would like to shed some light on important findings of the constraint integrated models. As mentioned before, three of our extended models (HAPIM, SACIM \& SFMIM) were rejected. The possible reasons of rejection of the HAPIM, SACIM and SFMIM models might be complete mediation of the effect of HAP, SAC and SFM constraint dimensions by the TPB predictors. In other words, the hunters were 
fully aware of these constraints dimensions and they had strong beliefs that they could overcome these constraints while they were reporting their attitudes, subjective norms and PBC.

Examination of Beta values for these rejected models also verifies this assumption. For example, despite the significant negative relationships of constraints with hunting participation, their effects on participation became insignificant in these models. Shrestha et al. (2012b) and Alexandris et al. (2007) have already empirically verified such mediation effects of TPB variables on the relationships between constraint dimensions and intentions.

In the similar fashion, the good fit extended models indicated that the effects of FEAR, TDM and TOTAL constraint dimensions were partially mediated by the TPB predictors. It is also noteworthy that despite the negative correlation of these constraints with hunting participation, due to the mediating effects of TPB predictors, these constraints dimensions showed significant positive effects on participation. This finding clearly implied that TPB variables not only partially mediated the effects of FEAR, TDM and TOTAL constraints on participation but also helped to reduce the effects of these constraints dimensions on participation. It is for this reason that the Beta values in these models showed a significant positive relationship between constraint dimension and hunting participation, although these constraint dimensions had significant negative correlation with the participation (Table 3). These findings suggested that the TPB predictors, specially the PBC helped to negotiate the effect of constraints as proposed by Jackson, Crawford and Godbey (1993). It provided an excellent explanation of why people participate in a recreation activity despite the presence of constraints. In other words, individuals encountering constraints still may take part in a given recreation activity if they have positive attitudes, positive subjective norms and positive PBC (confidence of taking part) and positive intentions toward that activity.

The possible theoretical explanation for such effects of TPB variables on constraint negotiation has been already suggested by some scholars. For example, Mannell and Kleiber (1997) suggested that the attitudes, subjective norms, and PBC could affect the formation of leisure preference (ultimate predictor of behavior), which depends on intra- and interpersonal constraints. Wigfield and Eccles (2000) and Eccles et al. (1983) suggested that choice, preference, and performance of individuals can be explained by their beliefs (e.g., attitudes, subjective norms, $\&$ PBC). 
Regarding the stronger role of the PBC in constraint negotiation, we may find its clarification in the definition of PBC. According to Ajzen (1991, p. 183) “... the PBC concept refers to people's perception of the ease or difficulty of performing the behavior of interest." Ajzen suggested that PBC, which included both internal control factors (e.g., information, personal deficiencies, skills, abilities, \& emotions) and external control factors (e.g., opportunities, dependence on others, \& barriers), is likely to facilitate the performance of the behavior. On the other hand, leisure constraints literature defines constraints as the factors or conditions that are assumed by the researchers and perceived or experienced by the individuals to limit/inhibit the formation of leisure preferences or prohibit participation (Jackson, 2000). Contrary to this, leisure facilitators are the factors or conditions that are assumed by the researchers and perceived or experienced by the individuals to enable/promote the formation of leisure preferences and encourage/enhance participation (Raymore, 2002).. According to Ajzen (1991), PBC is assumed to have a positive relationship with intentions and participation. In other words, it should function as a facilitator to preferences and participation. Furthermore, the negative correlation of constraints with PBC (Sherstha 2012b, and Alexandris 2007) also indicated that PBC acts as an opposite force (like a facilitator) to the constraints. Jackson (1991) proposed that constraints do not always lead to non-participation; they can also lead to modified participation due to constraint negotiation strategies. Shrestha et al. (2012b) and (Alexandris, 2007) found indications that PBC and other TPP predicators might help in constraint negotiation. Their findings, however, are yet to be tested by constraint research. If their findings are true, the effects of constraints might have been reduced by $\mathrm{PBC}$, and possibly by intentions also, on participation.

Concerning the efficiency of the extended model in terms of amount of variance explained, two of the extended models were more effective in explaining the overall variance in reported hunting participation, while one was equal to the TPB. There may be several possible explanations for not finding a large difference in the amount of variation explained. Our methodological limitation might be one of them. For example, specificity is one of the most important criteria in measuring the TPB constructs. Ajzen $(1991,2002)$ suggested that for accurate prediction of behavior, the measures of intention and PBC must be compatible with the behavior and context. That is, all TPB constructs including intentions must be assessed in relation to the behavior of interest and the specified context (place and time). These measures must be the 
same as that in which the behavior is to occur. They also suggested that for accurate behavioral prediction, intentions and $\mathrm{PBC}$ must remain stable over time and space because intervening events may produce changes in intentions or in $\mathrm{PBC}$, with the effect that the original measures of these variables no longer permit accurate prediction of behavior. He did not however discuss these requirements if one tries to expand the theory by integrating new variable(s). We may argue that like intentions and other TPB constructs if new variables are to be integrated in the TPB, they should also need to be compatible with the specificity criteria, especially if the new variables represented constraint dimensions. This becomes important because type and intensity of the leisure constraints also changes with the type of activity and contexts. Mannell and Zuzanck's (1991) study concluded: "Support was found for the contention that factors perceived to inhibit participation are variable and temporary in their influence. In fact, there was clear evidence that the respondents "switched constraints' across behavioral contexts" (p. 348). In our study we maintained the specificity criteria for measuring TPB components but the measures for constraints were very general. We asked the perceived intensity of various constraints they might face during hunting. Had we inquired about the intensity of the perceived constraints to participating in deer hunting, might have allowed for more accurate prediction of the behavior in our extended models. This in turn might have also improved the data fit issue for the rejected models.

\section{Implications}

This paper is first to assess the capability of the TPB in predicting deer hunting behavior, and made the first effort to extend TPB by integrating constraint dimensions. Therefore, the findings of this paper have a number of theoretical and managerial implications.

From the theoretical point of view, the findings demonstrated that the theory of planned behavior could be used to predict deer hunting intentions and participation with substantial amount of variance in intentions and behavior. In other words, it offers a method that can help to understand why people participate in specific hunting activities like deer hunting. The emergence of PBC as a sole significant predictor (after interaction with attitude and subjective norms) demonstrated that unlike the volitional nature of participation in general hunting, deer hunting may not be completely volitional. The research has been also helpful in confirming the complexity in constraint dimensions in terms of number of categories, sub-dimensions within 
intrapersonal and structural constraints and interactions between elements of different constraint categories.

We have also demonstrated that three constraint integrated models, FIM, TMDIM and TCIM can successfully explain a behavior and two of these models were more efficient in explaining deer hunting participation. Thus, these two better fitted models can be a useful tool for the researchers for understanding participation from the researchers' and resource manager's point of view. However if our purpose is developing pure theoretical understanding of participation, then TPB model itself can serve the purpose as it is not only most parsimonious model, but is capable of explaining a good amount of variance.

We found that three constraint integrated models (FIM, TMDIM, \& ICIM) successfully predicted participation, while the three other models (HAPIM, SACIM \& SFMIM) were rejected. Two of the valid models also explained more variance in hunting participation, however the differences in the amount of variance explained was between 2-5\% more than the original TPB model. This finding may indicate that the TPB predictors, mainly the PBC, also embraced an individual's anticipation of the constraints. This may be especially true for HAP, SAC and SFM. Similarly, it may be an individual's ability to overcome anticipated constraints that causes the HAPIM, SACIM and SFMIM models to be less effective. In the present study, instead of asking constraints for specific hunting activity at specific time, as suggested by Ajzen (2002), we used general frequency of perceived constraints for general hunting without mentioning time and species hunted. Likewise, we used a direct measure of attitudes, subjective norms and PBC. Future research may consider using more comprehensive measures as suggested by Ajzen (2002). Such measures should involve products of behavioral beliefs and outcomes evaluation for measuring attitudes, product of normative beliefs and motivation to comply for measuring subjective norms, and product of control beliefs and control belief strength as a measure of PBC. Likewise, constraints should be also measured for specific hunting activity at a specific time and place. Using these measures might provide further insights into the capability of the constraint integrated models as well as exploring the more specific roles of attitudes and subjective norms in original and extended models. 
The study demonstrated how the TPB constructs directly and indirectly mediates the effects of constraints on behavior. Perhaps this study was first to establish the constraint negotiation role of the TPB predictors, specially the PBC. These findings provide new insights that expand our understanding of why hunters participated in the deer hunting despite encountering various constraints. Researchers might be interested in consolidating these finding by replicating similar studies in different behaviors and in different contexts. We also found some evidence of mediating roles of intentions in determining the relationships between constraints dimensions and behavior. Accordingly, along the attitude, subjective norms, and PBC, intentions might be another new variable whose role cold be explored in future constraint negotiation research.

From the managerial point of view also, there are several implications of the study. The descriptive findings might be encouraging to resource managers because the hunters expressed very high positive intentions to participate in deer hunting in next hunting season, indicating possible growth of this activity in the future. The study also demonstrated that the PBC played the most important role in describing hunting intentions and participation. These findings suggest that the managers should recognize the potential hunters' positive intentions and focus on initiating new programs and strategies that may enhance the PBC of hunters. Gigliotti (2004) suggested that resource managers who have an intimate knowledge of the hunter group can plan to satisfy their needs and quality of experience. In the present case, the hunters' main motivation was "meat/trophy" and their level of satisfaction was relatively low due to poor harvesting success. According to Gigliotti such hunters belong to the "meat/trophy hunter group." In such a scenario, managers may plan for improving the quality of experience by developing programs and strategies for increasing harvesting success. In order to achieve these goals managers may want to focus on addressing internal resources issues (e.g., skill development) and external resources (e.g., enhancing game population through habitat improvement \& predator control, \& extending hunting opportunities by opening up new areas both in public \& private lands). These initiatives could help to keep hunters who have positive intentions to participate motivated to hunt in future seasons. This is particularly relevant because limitations related to the hunting site and/or constraints are not under volitional control of the hunters. It is the resource managers who have control of these external resources, although most agencies suffer from long standing budgetary constraints. The stronger role of PBC in mediating different dimensions of constraints also implies 
that practitioners should target enhancing the PBC, which may reduce the impact of constraint effects on people's intentions to participate in deer hunting. Alexandris, Barkoukis \& Tsormpatsoudis (2007) suggested consultation, education, psychological support, design, and delivery of appropriate programs are among the strategies that should be applied to reduce the influence of perceived behavioral control. In this case the appropriate programs will be similar to the ones that we have already discussed above.

One of our goals of the study was to extend the TPB model to a more useful model for the practitioners by integrating constraint dimensions into it. The finding showed that at least two extended models (i.e., FIM \& TCIM) showed greater potential than the original TPB model in terms of amount of prediction of participation. The acceptance of fear integrated models might be conveying a message to the managers that enhancing the power of attitudes, subjective norms and PBC would nullify the negative effect of fear related constraints. Minimizing peoples' fear and developing more positive attitudes, subjective norms, and PBC may requires actions like training programs for developing skills, providing adequate security to the hunters, and creating awareness among to participate with friends and families.

It also may be important to examine the extended model (TCIM) to understand the different constraints related to the hunting to enhance peoples' attitude, subjective norms and PBC. Although resource managers cannot do much to reduce personal constraints such as time and money, they can at least gain an understanding that may be useful for identifying and opening new hunting areas close to the hunters' residences.

Finally, we recommend more research with constraint integrated models involving comprehensive measures of the TPB constructs and more specific measures of constraint items involving different species at different times and places. This insight would expand our knowledge regarding the effectiveness of constraint integrated models. 


\section{References}

Ajzen, I. (1985). From intentions to actions: A theory of planned behavior. In J. K.uhl \& J. Beckmann (Eds.), Action Control: From Cognition to Behavior (pp. 11-39). Heidelberg, NY: Springer.

Ajzen, I. (1988). Attitudes, Personality and Behavior. Chicago, IL: Dorsey Press.

Ajzen, I. (1991). The theory of planned behavior. Organizational Behavior and Human Decision Processes, 50, 179-211.

Ajzen, I. (2002). Constructing a TPB questionnaire: Conceptual and Methodological Considerations. Revised in 2006. Retrieved from http://socgeo.ruhosting.nl/html/files/spatbeh/tpb.measurement.pDF.

Ajzen, I., \& Driver, B. (1991). Prediction of leisure participation from behavioral, normative and control beliefs: An application of theory of planned behavior. Leisure Sciences, 13, 185204.

Ajzen, I., \& Driver, B. L. (1992). Application of theory of planned behavior to leisure choice. Journal of Leisure Research, 24(3), 207-224.

Ajzen, I., \& Madden, T. (1986). Prediction of goal-directed behavior: attitudes, intentions, and perceived behavior control. Journal of Experimental Psychology, 22, 453-474.

Alexandris, K., Barkoukis, V., Tsorbatzoudis, H., \& Grouios, G. (2003). A study of perceived constraints on a community-based physical activity program for the elderly in Greece. Journal Aging and Physical Activity, 11, 305-318.

Alexandris, K. Barkoukis, V., \& Tsormpatzoudis, C. (2007). Does theory of planned behavior elements mediate the relationship between perceived constraints and intention to participate in physical activities? A study among older individuals. European Review of Aging and Physical Activity, 4, 39-48.

Alexandris K., Tsorbatzoudis, H., \& Grouios, G. (2002). Perceived constraints on recreational participation: investigating their relationship with intrinsic motivation, extrinsic motivation and amotivation. Journal of Leisure Research, 34, 233-252.

Alexandris, K., \& Stodolska, M. (2004). The influence of perceived constraints on the attitudes towards recreational sport participation. Leisure Sociology, 27, 197-217.

Arbuckle, J. (2006). Amos 7.0 User's Guide. Amos Development Corporation, PA: Spring House. 
Armitage, C. J., \& Conner, M. (2001). Efficacy of the theory of planned behaviour: A metaanalytic review. British Journal of Social Psychology, 40, 471-499.

Armitage, C. J., \& Conner, M. (1999). "The theory of planned behaviour: Assessment of predictive validity and ""perceived control." British Journal of Social Psychology, 38, 3554.

Armstrong, J. S., \& Overton, T. S. (1977). Estimating nonresponse bias in mail surveys. Journal of Marketing Research, 14, 396-402.

Baron, M., \& Kenny, A. (1986). The moderator-mediator variable distinction in socialpsychological research: conceptual, strategies and statistical considerations. Journal of Pers Social Psychology. 51, 1173-1182.

Boothby, J., Tungatt,M.F. \& Townsend, A.R. (1981). Ceasing participation in sports activity: Reported reasons and their implications. Journal of Leisure Research, 13, 1-14.

Burns, R. C., \& Graefe, A. R. (2007). Constraints to outdoor recreation: Exploring the effects of disabilities on perceptions and participation. Journal of Leisure Research, 39(1), 156-181.

Carroll, B., \& Alexandris, K. (1997). Perception of constraints and strength of motivation: their relation to recreational sport participation. Journal of Leisure Research, 29, 279-299.

Cheng, S., Lam, T., \& Hsu, C.H.C. (2005) Testing the sufficiency of the theory of planned behavior: a case of customer dissatisfaction responses in restaurants. Hospitality Management, 24, 475-492.

Conner, M., \& Armitage, C. J. (1998). Extending the theory of planned behavior: A review and avenues for further research. Journal of Applied Social Psychology, 28, 1429-1464.

Costello, A.B. \& Osborne, J.W. (2005). Best practices in exploratory factor analysis: Four recommendations for getting the most from your analysis. Practical Assessment, Research Evaluation, 10(7), 1-9. Retrieved from http://pareonline.net/pdf/v10n7.pdf, Feb 13, 2013.

Crawford, D., Jackson, E., \& Godbey, G. (1991). A hierarchical model of leisure constraints. Leisure Sciences, 13, 309-320.

Crawford, D., Jackson, E., \& Godbey, G. (1991). A hierarchical model of leisure constraints. Leisure Sciences, 13, 309-320.

Crawford, D., \& Godbey, G. (1987). Reconceptualizing barriers to family leisure. Leisure Sciences, 9, 119-127. 
Daigle, J. J., Hrubes, D., \& Ajzen, I. (2002). A Comparative Study of Beliefs, Attitudes, and Values Among Hunters, Wildlife Viewers, and Other Outdoor Recreationists. Human Dimensions of Wildlife, 7(1), 1-19. Retrieved from http://www.tandfonline.com/doi/abs/10.1080/108712002753574756, January 4, 2013

Dawson, K. A., Gyurcsik, N. C., Culos-Reed, S. N., \& Brawley, L. R. (2001). Perceived control: A construct that bridges theories of motivated behavior. In G. C. Roberts (Ed.), Advances in motivation in sport and exercise (pp. 321-356). Champaign, IL: Human Kinetics.

Dillman, D. A. (2000). Mail and Internet Surveys: The Tailored Design Method. New York, NY: John Wiley \& Sons, Inc.

Downs, D. S., Graham, G. M., Yang, S., Bargainnier, S., \& Vasil, J. (2006). Youth exercise intention and past exercise behavior: Examining the moderating influences of sex and meeting exercise recommendations. Research Quarterly for Exercise \& Sport, 77, 91-99.

Downs, D. S., \& Hausenblas, H. A. (2005a). Applying the theories of reasoned action and planned behavior to exercise: A meta-analytic update. Journal of Physical Activity and Health, 2, 7697.

Downs, D. S., \& Hausenblas, H. A. (2005b). Elicitation studies and the theory of planned behavior: A systematic review of exercise beliefs. Psychology of Sport and Exercise, 6, 131.

Eccles, J. S., Adler, T.F., Futterman, R., Goff, S.B., Kaczala, C.M., Meece, J.L., \& Midgley, C. (1983). Expectancies, values and academic behaviors. In J.T. Spence (Ed.), Achievement and Achievement Motivation (pp. 75-146). San Fransico, CA: W.H. Freeman.

Eves, F., Hoppe, R., \& McLaren, L. (2003). Prediction of Specific Types of Physical Activity Using the Theory of Planned Behavior. Journal of Applied Biobehavioral Research, 8(2), $77-95$.

Fabrigar, L. R.,Wegener,D. T., MacCallum, R. C.,\&Strahan, E. J. (1999). Evaluating the use of exploratory factor analysis in psychological research. Psychological Methods, 4, 272-299.

Fishbein, M., \& Ajzen, I. (1975). Belief, attitude, intention and behavior: an Introduction to theory and research. Reading, MA: Addison-Wesley.

Gilbert, D., \& Hudson, S. (2000). Tourism demand constraints: A skiing participation. Annals of Tourism Research, 27, 906-925. 
Godbey, G., Crawford, D.W., \& Shen, X.S. (2010). Assessing hierarchical leisure constraints theory after two decades. Journal of Leisure Research, 42(1).

Godin, G., \& Kok, G. (1996). The theory of planned behavior: A review of its applications in health-related behaviors. American Journal of Health Promotion, 11, 87-98.

Hausenblas, H., Downs, D.S., Giacobbi, P., Tuccitto, D., \& Cook, J. (2008). A multilevel examination of exercise intention and behavior during pregnancy. Social Science \& Medicine, 66, 2555-2561.

Hini, D., Gendall, P., and Kearns, Z. (1995). The link between environmental attitudes and behaviour. Marketing Bulletin, 6, 22-31.

Hrubes, D., Ajzen, I., \& Daigle. J. (2001). Predicting hunting intentions and behavior: An application of the theory of planned behavior. Leisure Sciences, 23, 165-178.

Hubbard, J., \& Mannell, R. (2001). Testing competing models of the leisure constraints and negotiation process in a corporate employee recreation setting. Leisure Sciences, 23, 145 163.

Hemingway, J. L., \& Parr, M. G. (2000). Leisure research and leisure practice: Three perspectives on constructing the research-practice relation. Leisure Sciences, 22, 139-162.

Henderson, K.A. (2010). Leisure Studies in the 21st Century: The Sky is Falling? Leisure Sciences, 32, 391-400.

Henderson, K.A., Presley, J. \& Bialeschki, M. D. (2004). Theory in Recreation and Leisure Research: Reflections from the Editors, Leisure Sciences: An Interdisciplinary Journal, 26(4), 411-425.

Israel, G.D. (2011). Sampling issues: Nonresponse. PEOD9. Gainesville, FL: Agricultural Education and Communication Department, University of Florida. Retrieved from http://edis.ifas.ufl.edu/pd008.

Jaccard, J., \& Wan, C. K. (1996). LISREL approaches to interaction effects in multiple regression. Thousand Oaks, CA: Sage Publications.

Jackson, E. L. (2000). Will research on leisure constraints still be relevant in the Twenty-First Century? Journal of Leisure Research, 32, 62-68.

Jackson, E. L. (1993). Recognizing patterns of leisure constraints: results from alternative analysis. Journal of Leisure Research, 25, 127-149. 
Jackson, E.L. (1988). Leisure constraints: A survey of past research. Leisure Sciences, 10, 203215.

Jackson, E.L. (1991). Leisure constraints/constrained leisure: Special issue introduction. Journal of Leisure Research, 23(4), 279-285.

Jackson, E. L., Crawford, D.W., \& Godbey, G. (1993). Negotiation of leisure constraints. Leisure Sciences, 15, 1-11.

Jackson, E., \& Scott, D. (1999). Constraints to leisure. In Jackson E, Burton T (Eds.), Leisure studies: prospects for the Twenty First Century (pp. 299-321). State College, PA: Venture.

Jackson, E. L., \& Rucks, V. C. (1995). Reasons for ceasing participation and barriers to participation: Further examination of constrained leisure as an internally homogeneous concept. Leisure Sciences, 15, 217-230.

Kimiecik, J. (1992). Predicting vigorous physical activity of corporate employees: comparing the theories of reasoned action and planned behavior. Journal of Sport and Exercise Psychology, 14, 192-206.

Kline, R. B. (1998). Principles and practices of structural equation modeling. New York, NY: Guilford Press.

Koca, C., Henderson, K. A., Asci, F. H., \& Bulgu, N. (2009), Constraints to leisure-time physical activity and negotiation strategies in Turkish women. Journal of Leisure Research, 41(2), $225-251$.

Kouthouris, C.H. \& Spontis, A. (2008). Outdoor Recreation Participation: An Application of the Theory of Planned Behavior. The Sport Journal, 11(2). Retrieved from http://www.thesportjournal.org/article/outdoor-recreation-participation-application-theoryplanned-behavior.

Lee, J. H., Scott, D., \& Floyd, M. F. (2001). Structural inequalities in outdoor recreation participation: a multiple hierarchy stratification perspective. Journal of Leisure Research, $33,427-449$.

Livenwood J., \& Stodoloska M. (2004). The effects of discrimination and constraints negotiation on leisure behavior of American Muslims in the Post-September 11 America. Journal of Leisure Research, 36, 183-208.

Mannell, R., \& Kleiber, D. (1997). A social psychology of leisure. State College, PA: Venture, 336-341. 
Mannell, R. C, \& Zuzanek, J. (1991). The nature and variability of constraints in daily life: The case of the physically active leisure of older adults. Leisure Sciences, 13, 337-351.

Moore, G. C.,\& Benbasat, I. (1991). Development of an Instrument to Measure the Perception of Adopting and Information Technology Innovation. Information Systems Research, 2(3), 192-222.

Mummery, W., \& Wankel, L. (1999). Training adherence in adolescent competitive swimmers: an application of the theory of planned behavior. Journal of Sport \& Exercise Psychology, 21(4), 313-328.

Parr, M. (1996). The relation between leisure theory and recreation practice. Leisure Sciences, 18, 315-332.

Raymore, L.A. (2002). Facilitators to Leisure. Journal of Leisure Research, 34(1) 37-51.

Rhodes, R., Jones, L.W. \& Courneya, K.S. (2002). Extending the theory of planned behavior in the exercise domain: a comparison of social support and subjective norm: Research Note-Psychology. Research Quarterly for Exercise and Sport, (June 01, 2002). Retrieved from http://www.highbeam.com/doc/1G1-88183340.html.

Rossi, A. N., \& Armstrong, J. B. (1999), Theory of reasoned action vs. theory of planned behavior: testing the suitability and sufficiency of a popular behavior model using hunting intentions. Human Dimensions of Wildlife, 4, 40-46.

Scott, D., \& Munson, W. (1994). Perceived constraints to park usage among individuals with low incomes. Journal of Park and Recreation Administration, 12, 79-96.

Scott, D., \& Jackson, E. (1996). Factors that limit and strategies that might encourage people's use of public parks. Journal of Park and Recreation Administration, 14 (1), 1-11.

Shinew, K. J., Floyd, M. F., \& Parry, D. (2004). Understanding the relationship between race and leisure activities and constraints: Exploring an alternative framework. Leisure Science, 26, 181-199.

Shrestha, S., Burns, R., Pierskalla, C., \& Selin, S. (2012a). Predicting deer hunting intentions using the theory of planned behavior: A survey of Oregon big game hunters. Human Dimensions of Wildlife, 17, 129-140. 
Shrestha, S., Burns, R., Deng, J. \& Confer, J., Graefe, A., Covelli, E. (2012b). The Role of Elements of Theory of Planned Behavior in Mediating the Effects of Constraints on Intentions: A Study of Oregon Big Game Hunters. Journal of Park and Recreation Administration, 30(2), 41-62.

Smith, A., \& Biddle, S. (1999). Attitudes and exercise adherence: test of the theories of reasoned action and planned behavior. Journal of Sport Science, 17, 269-281.

Son J. S., Kerstetter, D. L., \& Mowen, A. J. (2008). Do age and gender matter in the constraint negotiation of physically active leisure? Journal of Leisure Research, 40(2), 267-289.

Vallerand, R. J., \& Losier, G. F. (1999). An integrative analysis of intrinsic and extrinsic motivation in sport. Journal of Applied Sport Psychology, 11, 142-69.

Walker, G.J., \& Virden, R.J. (2005). Constraints on outdoor recreation. In E. L. Jackson (Ed.), Constraintsto Leisure (pp. 201-219). State College, PA.: Venture Publishing.

Walker, G. J., Jackson, E. L., \& Deng, J. (2007). Culture and Leisure Constraints: A Comparison of Canadian and Mainland Chinese. Journal of Leisure Research, 39(4), 567-590.

White, H.R. \& Bustam, T.D. (2010). Using leisure constraints research to inform outdoor recreation research and natural resource management decisions. Parkbreak Perspective. Hancock, MI: George Wright Society, Retrieved from http://www.georgewright.org/pbp005_white.pdf, January 15, 2013.

Wigfield, A., \& Eccles, J. S. (2000). Expectancy-Value Theory of achievement motivation. Contemporary Educational Psychology, 25, 68-81. 


\section{ANNEX 1 \\ PRE-SURVEY POST CARDS}

\section{BIG GAME HUNTING STUDY!!!}

In a few days from now you will receive in the mail a request to fill out a brief questionnaire for an important research project being conducted by the West Virginia University. This study is important because it will help adaptive recreation agencies to understand the behaviors of the hunters and existing pattern of big game hunting in Oregon.

Thank you for your time and consideration. It's only with the generous help of concerned hunters like you that our research can be successful.

Sincerely, 


\section{ANNEX 2 \\ OREGON BIG GAME HUNTERS' SURVEY}

Dear Oregon Big Game Hunter: We are conducting a survey of Oregon hunters to better understand the motivations, constraints, needs and perceptions of Oregon hunters. This survey focuses on your previous deer hunting experiences in Oregon, and your intentions to hunt deer in Oregon in the future.

We will provide the results of the survey, in anonymous report format, to ODFW and US Forest Service resource managers. Your input is extremely valuable, and your information will remain confidential. Please complete the form as soon as possible and mail back to us in the stamped/addressed envelope provided in your survey packet.

\section{SECTION 1: DEER HUNTING PARTICIPATION IN 2008}

1. Did you participate in DEER HUNTING in OR during the $\underline{2008}$ deer hunting season?

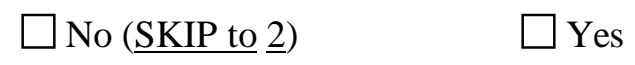

1a. If yes, how many days in 2008: = days

2. Including 2008, how many years have you been hunting deer in OR? Number of years:

3. Did you hunt deer in OR in the following years?

\begin{tabular}{|c|c|c|c|}
\hline 2007 & $\square$ No & $\square$ Yes & if yes, how many days in 2007 : \\
\hline 2006 & $\square$ No & $\square$ Yes & if yes, how many days in 2006 : \\
\hline 2005 & $\square$ No & $\square$ Yes & if yes, how many days in 2005 : \\
\hline 2004 & $\square$ No & $\square$ Yes & if yes, how many days in 2004 : \\
\hline
\end{tabular}

4. Did you harvest any deer during the $\underline{2008}$ deer hunting season in OR? $\quad \square$ No (KIP to 5) $\quad \square \quad$ Yes (GO to $4 \mathrm{a}$ )

If yes: a. Number of bucks harvested ___ $\quad$ b. Number of does harvested

5. Considering everything, how would you rate the quality of your $\underline{2008}$ deer hunting season in OR?

$\square$ Poor $\square$ Fair $\square$ Good $\square$ Very good $\square$ Excellent $\square$ Perfect

6. If you have hunted deer in OR before 2008, how would you rate your present quality of experience in comparison to previous experience(s)?
Worse
Same
Better 
7. From the list below, please rank the THREE most important purposes for deer hunting in OR? (Please check 1 for the $1^{\text {st }}$ important purpose, 2 for $2^{\text {nd }}$ and 3 for the $3^{\text {rd }}$ ).

Harvest deer (for meat/trophy/controlling the number)

Solitude/escape from crowd/normal life

Enjoy nature/open space

Time with family/friends

$\square$ Exercise/health

$\square$ Education/knowledge/research

$\square$ Test limit/improve skills

$\square$ Experience the challenge of hunt

Competition

Any other (please specify):

8. If you checked "harvest deer" in Question 7 (above), how important are each of the below listed reasons for deer harvesting. Please circle one number for each reason.

\begin{tabular}{|l|c|c|c|c|}
\hline \multicolumn{1}{|c|}{ Important reasons to harvest deer } & Not at all & Slightly & Moderately & Extremely \\
\hline Bringing deer meat home for me to eat & 1 & 2 & 3 & 4 \\
\hline Bringing deer meat home for my family to eat & 1 & 2 & 3 & 4 \\
\hline Harvesting only a trophy deer & 1 & 2 & 3 & 4 \\
\hline Controlling the number of deer in the herd & 1 & 2 & 3 & 4 \\
\hline Controlling male to female deer ratio in the herd & 1 & 2 & 3 & 4 \\
\hline Helping to control the spread of diseases/CWD & 1 & 2 & 3 & 4 \\
\hline
\end{tabular}

8. What one type of deer hunting do you do most often in OR? Please check one.

$\square$ Gun (ex: rifle, shotgun) $\square$ Bow/Archery $\square$ Muzzle loader $\square$ Never hunted deer in OR

\section{SECTION 2: DEER HUNTING INTENTIONS, ATTITUDES, SUBEJCTIVE NORMS AND PBC}

9. What is your level of agreement with the following statements about your intentions to hunt DEER in OR in 2009 ?

\begin{tabular}{|l|l|l|l|l|l|l|l|l|}
\hline Intentions to go deer hunting & \multicolumn{5}{|c|}{ Strongly disagree $\leftarrow$------ $\rightarrow$ Strongly agree } \\
\hline I intend to participate in deer hunting in OR in 2009 & 1 & 2 & 3 & 4 & 5 & 6 & 7 \\
\hline I will try to participate in deer hunting in OR in 2009 & 1 & 2 & 3 & 4 & 5 & 6 & 7 \\
\hline I am planning to go for deer hunting in OR in 2009 & 1 & 2 & 3 & 4 & 5 & 6 & 7 \\
\hline
\end{tabular}


10. For you, deer hunting in OR in 2009 would be: (Please circle one number for each item listed below)

\begin{tabular}{|l|c|c|c|c|c|c|c|l|}
\hline Extremely unpleasant & 1 & 2 & 3 & 4 & 5 & 6 & 7 & Extremely pleasant \\
\hline Extremely boring & 1 & 2 & 3 & 4 & 5 & 6 & 7 & Extremely interesting \\
\hline Extremely unenjoyable & 1 & 2 & 3 & 4 & 5 & 6 & 7 & Extremely enjoyable \\
\hline $\begin{array}{l}\text { Extremely harmful } \\
\text { (socially) }\end{array}$ & 1 & 2 & 3 & 4 & 5 & 6 & 7 & $\begin{array}{l}\text { Extremely beneficial } \\
\text { (socially) }\end{array}$ \\
\hline $\begin{array}{l}\text { Extremely harmful } \\
\text { (health-wise) }\end{array}$ & 1 & 2 & 3 & 4 & 5 & 6 & 7 & $\begin{array}{l}\text { Extremely beneficial } \\
\text { (health-wise) }\end{array}$ \\
\hline $\begin{array}{l}\text { Extremely harmful } \\
\text { (economically) }\end{array}$ & 1 & 2 & 3 & 4 & 5 & 6 & 7 & $\begin{array}{l}\text { Extremely beneficial } \\
\text { (economically) }\end{array}$ \\
\hline
\end{tabular}

11. What is your level of agreement with the following statements regarding DEER hunting in OR in 2009 ?

\begin{tabular}{|l|c|c|c|c|c|c|c|}
\hline \multicolumn{1}{|c|}{ Statements } & \multicolumn{7}{|c|}{ Strongly disagree $\leftarrow$-------- $\rightarrow$ Strongly agree } \\
\hline $\begin{array}{l}\text { Most people who are important to me think that I } \\
\text { should go deer hunting in OR in 2009 }\end{array}$ & 1 & 2 & 3 & 4 & 5 & 6 & 7 \\
\hline $\begin{array}{l}\text { Most people whose opinions I value would } \\
\text { approve of my deer hunting in OR in 2009 }\end{array}$ & 1 & 2 & 3 & 4 & 5 & 6 & 7 \\
\hline $\begin{array}{l}\text { Most people who are important to me will support } \\
\text { my deer hunting in OR in 2009 }\end{array}$ & 1 & 2 & 3 & 4 & 5 & 6 & 7 \\
\hline $\begin{array}{l}\text { Most people who are important to me will go deer } \\
\text { hunting in OR in 2009 }\end{array}$ & 1 & 2 & 3 & 4 & 5 & 6 & 7 \\
\hline $\begin{array}{l}\text { I am confident that I can go deer hunting in OR in } \\
\text { 2009 }\end{array}$ & 1 & 2 & 3 & 4 & 5 & 6 & 7 \\
\hline $\begin{array}{l}\text { If I want to for deer hunting in OR in 2009, I can } \\
\text { go easily. }\end{array}$ & 1 & 2 & 3 & 4 & 5 & 6 & 7 \\
\hline $\begin{array}{l}\text { The factors that influence my decision to go deer } \\
\text { hunting in OR in 2009 are under my control }\end{array}$ & 1 & 2 & 3 & 4 & 5 & 6 & 7 \\
\hline
\end{tabular}

\section{SECTION 3: HUNTING CONSTRAINTS AND DEMOGREAPICS}

12. Please look at the list below and describe the extent to which these items constrain your participation in DEER/ELK/BEAR HUNTING in OR during 2009.

\begin{tabular}{|l|c|c|c|c|c|}
\hline \multicolumn{1}{|c|}{ Constraint items } & \multicolumn{5}{c|}{ Level of Perceived Constraints } \\
\hline & Not at all & Very little & Some & Quite a bit & A lot \\
\hline Physical health & 1 & 2 & 3 & 4 & 5 \\
\hline Health of someone you like to hunt with & 1 & 2 & 3 & 4 & 5 \\
\hline Don't have anyone to go with & 1 & 2 & 3 & 4 & 5 \\
\hline Lack of time & 1 & 2 & 3 & 4 & 5 \\
\hline Like to do other things for recreation & 1 & 2 & 3 & 4 & 5 \\
\hline
\end{tabular}




\begin{tabular}{|l|l|l|l|l|l|}
\hline Don't like to do things in outdoors & 1 & 2 & 3 & 4 & 5 \\
\hline Sites are closed when want & 1 & 2 & 3 & 4 & 5 \\
\hline $\begin{array}{l}\text { Have no opportunity what you want to } \\
\text { perform }\end{array}$ & 1 & 2 & 3 & 4 & 5 \\
\hline Sites are far away & 1 & 2 & 3 & 4 & 5 \\
\hline Fear of crime & 1 & 2 & 3 & 4 & 5 \\
\hline Fear of outdoors & 1 & 2 & 3 & 4 & 5 \\
\hline Complex rules and regulation & 1 & 2 & 3 & 4 & 5 \\
\hline Sites in OR are too crowded & 1 & 2 & 3 & 4 & 5 \\
\hline Inadequate facilities in OR & 1 & 2 & 3 & 4 & 5 \\
\hline Lack of information & 1 & 2 & 3 & 4 & 5 \\
\hline Can't afford & 1 & 2 & 3 & 4 & 5 \\
\hline Lack of transportation & 1 & 2 & 3 & 4 & 5 \\
\hline Lack of skill & 1 & 2 & 3 & 4 & 5 \\
\hline Lack of training facilities & 1 & 2 & 3 & 4 & 5 \\
\hline Conflict with other uses & 1 & 2 & 3 & 4 & 5 \\
\hline Feeling of unwelcome by rangers/staff & 1 & 2 & 3 & 4 & 5 \\
\hline Racial conflicts among users & 1 & 2 & 3 & 4 & 5 \\
\hline Fear of sexual assault & 1 & 2 & 3 & 4 & 5 \\
\hline Lack of self-confidence & 1 & 2 & 3 & 4 & 5 \\
\hline Lack of game./difficulty to find game & 1 & 2 & 3 & 4 & 5 \\
\hline
\end{tabular}

31. AGE: __ years $32 . \underline{\text { SEX}}: \square$ Male $\square$ Female

33. RACE/ETHNICITY: $\square$ White (Caucasian) $\square$ Hispanic (White) $\quad \square$ Hispanic

$\square$ African-American $\square$ Asian-American
$\square$ Native-American \& Pacific Islander $\square$ Other (specify)

34: We would like to ask you about your 2009 hunting experience at the end of the season. Will you be willing to participate in a five-question e-mail or phone survey in January, 2010?

$\square$ No $\quad \square \quad$ Yes If yes, please provide your email address (Please PRINT) or telephone number

THANK YOU FOR COMPLETING THE SURVEY.

YOUR INPUT IS VERY IMPORTANT.

Please return the completed survey at your earliest convenience in the enclosed pre-stamped envelope. 


\section{ANNEX 3 \\ FOLLOW-UP SURVEY}

\section{Participation in Deer Hunting in 2009}

1. Did you participate in deer hunting in Oregon during the 2009 hunting season?

$\begin{array}{ll}\text { No } & \text { (Please go to Q. 2) } \\ \text { Yes } & \text { (Please go to Q. 3) }\end{array}$

2. If NO, what were your three primary reasons of not participation in big game hunting in 2009 hunting season?

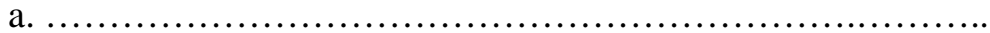

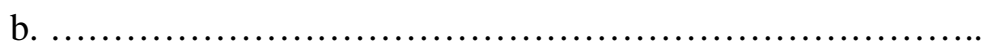

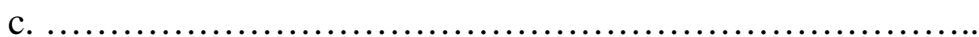

(Your survey is complete. Please mail it back in the address above in the enclosed post paid envelope) Thank you for your time.

3. Did you harvest any deer?

$\square$ Yes (Please go to Q. 4) $\square$ No (Please go to Q. 5)

4. If yes, how many deer did you harvest in the 2009 hunting season?

Number of deer harvested:

5. Overall, how would you rate the quality of your 2009 hunting experiences in Oregon?
Poor $\square$ Fair $\square$ Good
$\square$ Very good $\square$ Excellent
Perfect

Thank you very much for your participation. 